\title{
III. MEDIZIN(STRAF)RECHT IN FINNLAND
}



13.

\title{
Rechtfertigungs- und Entschuldigungsprobleme im Bereich medizinischer Tätigkeit / Problems of Justification and Excuse in the Field of Medicine: A Finnish View
}

\begin{abstract}
Summary
The paper first gives a general examination of the distinction between justification and excuse, as well as of the role of criminal law in the regulation of medical activity. It focuses on the policy aspects, with particular attention being paid to the current legislative initiatives in Finland for the development of mechanisms for the legal protection of patients.

The author considers the reasons for the increase in medical law regulation. He notes that this tendency is connected with the increased emphasis in public debate on human rights principles, legal safeguards as well as the rights of the consumer (in this case also the client / patient). This, in turn, is connected with the increase in general well-being and information. The development of bio-medicine has led to new problems in human rights.
\end{abstract}

The paper further presents in depth the 1982 proposal for an act on the rights of patients. The purpose of uniform regulation of the care and treatment of patients is to clarify those principles (for example, the right of the patient to information as well as his right of self-determination) and, at the same time, to strengthen their importance and ensure that they are applied in a uniform manner. If enacted, such medical law regulation would lead to a decrease in the penal law problems connected with justification and excuse.

There have been very few criminal trials in Finland focusing on medical procedure. In practice, erroneous or faulty medical procedures undertaken by a physician or other medical personnel generally considered from the point of view of disciplinary or tort liability. In June 1986, the Finnish Parliament adopted a unique system of no-fault compensation for personal injuries suffered by a patient or a human subject of biomedical research. This system is based on mandatory insurance for the benefit of all patients and test subjects, and the tort liability is entirely independent of the guilt of the medical personnel. The obligation to insure applies to those offering health care services, in most cases local or government authorities.

$* * *$

Es erscheint mir angebracht, vor der Behandlung des eigentlichen Themas zunächst auf die Einteilung in Rechtfertigung- und Entschuldigungsgründe im allgemeinen sowie auf die Rolle des Strafrechts bei der Regelung der medizinischen Tätigkeit im besonderen 
einzugehen. Ich habe hierbei besonders die rechtliche Situation Finnlands vor Augen, möchte aber auch einige vergleichende Gesichtspunkte zu den Rechtsordnungen der übrigen nordischen Länder und der Bundesrepublik Deutschland vorbringen.

Der Schwerpunkt meiner gesamten Abhandlung wird auf rechtspolitischen Aspekten liegen. Im Zusammenhang mit der eigentlichen Behandlung des Themas werde ich den Inhalt und die Bedeutung besonders jener die rechtliche Stellung des Patienten betreffenden legislativen Pläne erläutern, die in Finnland zur Zeit aktuell sind.

\section{Rechtfertigung und Schuldausschluss in der finnischen Strafrechtsdoktrin}

Die finnische Doktrin basiert traditionell in erster Linie auf der deutschen Strafrechtswissenschaft, wenn auch in den letzten Jahrzehnten der Einfluß des Strafrechts und des strafrechtlichen Schriftums der übrigen nordischen Länder zunehmend stärker geworden ist.

Gegenwärtig herrscht in Finnland allgemeine Unzufriedenheit mit dem Stand der Strafrechtsdogmatik, die immer noch zu sehr auf den ursprünglich in den vierziger Jahren von Brynolf Honkasalo verfaßten Lehrbüchern beruht. ${ }^{1}$ Über die Richtung einer Änderung und über mögliche Alternativen herrscht indes weitgehend Unklarheit. Auf jeden Fall existiert ein gewisser Druck hin zu einer kritischen Neubewertung der strafrechtlichen Systematik und des strafrechtlichen Begriffsapparats. Besonders groß ist der Bedarf nach Lehr- und Handbüchern, in denen die Grundfragen der Straftatlehre in moderner Weise behandelt werden. So findet dieses deutsch-skandinavische Kolloquium aus finnischer Sicht zu einem denkbar günstigen Zeitpunkt statt, zumal in unserem Land zur Zeit eine Gesamtreform des Strafrechts betrieben wird.

Das in Finnland geltende Strafgesetz wurde im Jahr 1889 erlassen. Während seines 90jährigen Bestehens hat es natürlich eine Reihe von Änderungen erfahren, aber hinsichtlich der Grundstruktur der Straftat und des Strafrechtssystems sind so gut wie keine bedeutsamen Novellierungen vorgenommen worden. In das im Geist der klassischen Strafrechtsschule entstandene Strafgesetz wurden nur sehr wenige allgemeine Lehren enthaltende Rechtsvorschriften aufgenommen.

Der Umstand, daß zentrale Begriffe der Deliktslehre nicht definiert worden sind, hat es ermöglicht, daß sich verschiedene Auffassungsweisen von der

1 Siehe auch Honkasalo, Das finnische Strafrecht, in: Mezger / Schönke / Jescheck (Hrsg.), Das ausländische Strafrecht der Gegenwart II, 1957. 
Grundstruktur der Straftat herausgebildet haben. ${ }^{2}$ Die finnische Doktrin wurde von den auf dem klassischen und neoklassischen Verbrechensbegriff aufbauenden Lehrkonstruktionen stark beeinflußt, wie sie im deutschen Schrifttum repräsentiert waren. In den letzten Jahrzehnten hat auch der finale Verbrechensbegriff in der finnischen strafrechtlichen Literatur seinen Niederschlag gefunden. Die moderne deutsche Diskussion ist den finnischen Juristen vor allem durch das Strafrechts-Lehrbuch von Hans-Heinrich Jescheck vertraut geworden.

Ein Problem der finnischen Strafrechtswissenschaft ist bis in die letzten Jahre die geringe Zahl der Forscher gewesen, die sich für die Strafrechtsdogmatik und deren Entwicklung interessierten. So ist zum Beispiel die sehr differenzierte deutsche Diskussion über die Rechtfertigungs- und Entschuldigungsgründe nicht in ausreichendem Maße in Finnland aufgenommen worden. Auf der anderen Seite muß man auch eingestehen, daß in Finnland eine solch fein durchstrukturierte Systembildung, wie sie dem deutschen Schrifttum eigen ist, vom praktischen Standpunkt als weniger wesentlich angesehen worden ist.

Die nordische Strafrechtsdoktrin ist sowohl hinsichtlich des Rechtswidrigkeitsals auch hinschlich des Schuldbegriffs sehr heterogen. Einige skandinavische Forscher haben die Ansicht vertreten, daß bei der Erörterung der Voraussetzungen der strafrechtlichen Verantwortlichkeit die Begriffe „Rechtswidrigkeit“ und „Rechtfertigungsgründe“ nicht notwendig seien. Dementsprechend haben viele zur Verwendbarkeit der Begriffe „Schuld“ und „Entschuldigungsgründe“ bei der Einschränkung der Verantwortlichkeit eine kritische oder ablehnende Haltung eingenommen.

Mit dieser Kritik hat man meiner Einschätzung nach indes nicht darauf abgezielt, diejenige Differenzierung der materiellen Grundbestandteile des Verbrechensbegriffs, gemäß der das Unwerturteil der Rechtsordnung einerseits über die Tat (das Unrecht), andererseits über den Täter (die Schuld) ausgesprochen wird, in Frage zu stellen. Es geht außer um terminologische Meinungsverschiedenheiten auch um die Unstimmigkeiten darüber, wie der genauere Inhalt der genannten Grundbestandteile und eine etwaige Unterteilung in Unterbegriffe zu verstehen ist.

Im Kapitel 3 des finnischen Strafgesetzes sind die Gründe geregelt, die die Strafbarkeit ausschließen oder vermindern. In der Doktrin sind diese Gründe in objektive und subjektive unterteilt worden. Als objektive, die Strafbarkeit ausschließende oder mildernde Gründe, d .h. als Rechtfertigungsgründe, gelten

2 Vgl. zum Folgenden vor allem Utriainen, Syyllisyys muuttuvana käsitteenä (English summary: Guilt as a changing concept), 1984. 
die Notwehr (Kapitel $3 \S \S 6,7,8$ und 9) und der Notstand (Kapitel $3 \S 10$ ). Als subjektive, die Strafbarkeit beeinflussenden Gründe, die in dem besagten Kapitel des Strafgesetzes genannt werden und die in der Literatur als Entschuldigungsgründe bezeichnet werden, gelten der Notwehrexzess und der Notstand in dem Fall, daß eine rechtswidrige Tat vorliegt, bei der wegen der Existenz subjektiver Gründe von einer Strafe abgesehen oder eine mildere Strafe verhängt wird.

Bedingt durch die deutsche Vorbildwirkung haben auch die normative Schuldauffassung und der Begriff der Zumutbarkeit in der finnischen Strafrechtswissenschaft breite Aufnahme gefunden. Das Verständnis der Schuld in erster Linie als Vorwerfbarkeit brachte Honkasalo dazu, es als allgemeinen Grundsatz des positiven Rechts anzusehen, daß wegen des Fehlens des Schuldvorwurfs keine Person in einem Fall bestraft werden soll, in dem aufgrund der allgemeinen Lebenserfahrung in der betreffenden Lage von keinem Durchschnittsmenschen eine zu rechtmäßigem Handeln führende Motivierung erwartet werden konnte. Dieser Standpunkt, die Unzumutbarkeit normgemäßen Verhaltens als allgemeinen übergesetzlichen Entschuldigungsgrund anzuerkennen, hat indes Kritik auf sich gezogen, und in der Gerichtspraxis hat man in den von Honkasalo gemeinten Fällen nicht den Weg beschritten, daß man, ohne sich auf das Gesetz zu berufen, von einer Bestrafung abgesehen hätte. Eine Erweiterung des Bereichs der allgemeinen Entschuldigungsgründe erfolgte erst durch die in den 60er und 70er Jahren vorgenommenen Änderungen im Sanktionensystem, als Vorschriften über das Absehen von Strafe und Strafverfolgung bei geringfügigen Straftaten erlassen und die Gerichte das Recht erhielten, in gewissen Fällen der Unbilligkeit das Minimum des anzuwendenden Strafrahmens zu unterschreiten.

In einem Bericht des Komitees, das mit der Ausarbeitung der Gesamtreform des Strafrechts beauftragt war, aus dem Jahre 1977 wird vorgeschlagen, gemäß der in der schwedischen Doktrin verwendeten Terminologie Rechtsvorschriften über den sog. Haftungsausschluß zu erlassen. Das folgende Zitat aus dem Bericht des Komitees möge den Gedankengang beleuchten:

Die Gruppierung der Haftungsausschließungsgründe beruht zu einem großen Teil auf Ermessen. Die die Haftungsausschließungsgründe betreffenden Vorschriften sind oft nach dem Aspekt in zwei Gruppen unterteilt worden, ob der jeweilige Haftungsausschließungsgrund mit der äußeren Seite des Verhaltens oder mit der inneren Einstellung des Täters zusammenhängt. Demgemäß hat man von Rechtfertigungsgründen und Entschuldigungsgründen gesprochen. In typischen Fällen wenn auch nicht unbedingt in allen Einzelfällen - verweist der Rechtfertigungsgrund auf die Erwünschtheit oder die Akzeptierbarkeit der Tat vom Standpunkt der Gesellschaft, während der Entschuldigungsgrund darauf verweist, daß das Verhal- 
ten vom Standpunkt der Gesellschaft zwar nicht als wünschenswert, aber doch als verständlich angesehen wird. ${ }^{3}$

Aus dem Zitat geht hervor, daß man die Differenzierung in Rechtfertigungsund Entschuldigungsgründe bewahren möchte, auch wenn zum Beispiel in den Vorschlägen des Strafrechtskomitees betreffend den Notstand die Grenze zwischen ihnen nicht deutlich gezogen wurde. Demgemäß dürfte man an den derzeitigen Rechtsauffassungen festhalten: Eine tatbestandsmäßige Handlung wird als rechtswidrig angesehen, falls nicht irgendein Rechtfertigungsgrund geltend gemacht werden kann. Entsprechend ist man der Ansicht, daß ein Entschuldigungsgrund den Schuldvorwurf entfallen läßt. Zwar wird in der Doktrin nicht völlig klar, ob ein Entschuldigungsgrund ausschließlich einen Schuldminderungsgrund darstellt oder ob er als kombinierter Unrechts- und Schuldminderungsgrund angesehen werden kann. In $\S 9$ im Kapitel 3 des Strafgesetzes, der den Notwehrexzess zum Thema hat, spricht man nach der 1983 vorgenommenen Gesetzesänderung von „besonderen, die Vorwerfbarkeit der Tat vermindernden Gründen“. Die Unterscheidung der Rechtfertigungsund Entschuldigungsgründe von anderen Bestandteilen des Delikts ist jedoch besonders problematisch bei Fahrlässigkeits- und Unterlassungsdelikten, und diese bilden ja gerade im Bereich der medizinischen Tätigkeit in der Praxis häufig auftretende Deliktformen.

\section{Rechtspolitische Tendenzen}

Der die medizinische Tätigkeit regelnde Rechtsbereich - das Medizinrecht oder Arztrecht - hat in Finnland erst in den letzten Jahren größere Aufmerksamkeit auf sich gezogen. Ein zentraler Punkt hierbei ist die Entwicklung von Rechtssicherheitssystemen für den Bereich der Gesundheitsfürsorge und Krankenpflege gewesen.

Von den skandinavischen Ländern hat besonders Schweden mehrere auf die Verbesserung der rechtlichen Stellung des Patienten abzielende legislative Maßnahmen oder andere juristische Regelungen verwirklicht. Im Jahre 1980 wurde in Schweden das Gesetz über die Überwachung des Gesundheits- und Krankenpflegepersonals erlassen. In diesem Gesetz finden sich unter anderem Bestimmungen über die allgemeinen Pflichten des Personals, über die Disziplinarhaftung und die Einschränkung bzw. den Widerruf des Berufsausübungsrechts. Nach einem Abkommen zwischen den Krankenanstalten und den Versicherungsgesellscharten ist in Schweden im Jahre 1975 ein Patientenversicherungssystem in Kraft getreten. Die Entschädigungsgründe nach diesem

3 Rikosoikeuskomitean mietintö, Komiteamietintö 1976:72 (1977), S. 102. 
System sind milder als die allgemeinen Haftungsregeln des Schadensersatzrechts. Zum Erhalt eines Schadensersatzes ist es nicht notwendig, daß man dem Pflegepersonal einen Fehler oder eine Unterlassung (d.h. ein vorwerfbares Verhalten) nachweisen kann, sondern maßgeblich ist, ob der Patient einen in den Bedingungen des Abkommens definierten Personenschaden erlitten hat.

Ähnliche Reformpläne sind auch in Finnland betrieben worden. Die Fragen der Rechtssicherheit im Bereich der Gesundheitsfürsorge und Krankenpflege sind von einer vom Sozial- und Gesundheitsministerium eingesetzten Kommission (die von 1980 bis 1982 unter meinem Vorsitz tätig war) umfassend analysiert worden. ${ }^{4}$ Diese Kommission schlug die Einführung eines gesetzlichen Entschädigungssystems für Patientenschäden vor. Nach schwedischem Vorbild würden die Personen, die einen Personenschaden im Bereich medizinischer Tätigkeit erlitten haben, direkt aus einer für sie bestehenden Versicherung entschädigt. Für die Kosten dieser obligatorischen Versicherung kämen meistens die für die Aufrechterhaltung der öffentlichen Gesundheitsfürsorge und Krankenpflege zuständigen kommunalen und staatlichen Organe auf. ${ }^{5}$

Die Kommission schlug ferner den Erlaß eines Gesetzes über die Rechte des Patienten vor. Durch einheitliche Regelung der Grundsätze für die Betreuung und Behandlung des Patienten sollten diese Prinzipien deutlicher herausgearbeitet und verstärkt werden (siehe Anlage).

Die erläuterten Reformpläne wie auch die Angaben darüber, welcher Art die Formen der rechtlichen Verantwortung sind, die in der medizinischen Tätigkeit üblich sind, sind Indizien dafür, daß die Bedeutung des Strafrechts auf diesem Sektor im Vergleich zu anderer rechtlicher Regelung relativ gering ist. Im ärztlichen Bereich scheint das Strafrecht wirklich nur die ultima ratio des Rechtsgüterschutzes zu sein. Albin Eser hat jedoch völlig zu Recht die auch in diesem Bereich bedeutsame Leit- und Verstärkungsfunktion des Strafrechts betont. $^{6}$

Die Frage, wie notwendig gerade das Strafrecht für die genannten Funktionen sei, ist wohl berechtigt. Könnten nicht dieselben Ziele mittels andersartiger medizinrechtlicher Regelungen erreicht werden? Ein kennzeichnender Trend, der in Finnland wie auch in den übrigen nordischen Ländern zu beobachten ist, ist der, daß eine solche andersartige Regelung ständig zunimmt. Die medizini-

4 Siehe die Berichte der Kommission: Terveydenhuollon oikeussuojatoimikunnan mietinto I-II, Komiteanmietintö 1982: 29, 1982:65.

5 Der Reichstag hat die Gesetzesvorlage (Nr. 54/1986) zur Einführung des genannten Patientenversicherungssystems im Juni 1986 beschlossen.

6 Eser, Medizin und Strafrecht, ZStW 97 (1985), S. 1 ff., 44 ff. 
sche Tätigkeit ist ein Gebiet, auf dem man seit jeher gesetzgeberische Maßnahmen und rechtliche Regelungen ganz allgemein so weit wie möglich vermeiden wollte. Seit alters her ist man der Ansicht, daß für die medizinische Tätigkeit neben den Erfordernissen der ärztlichen Praxis die medizinischen und medizinethischen Grundsätze ausreichen würden. Unter diesen Bedingungen ist es interessant, die Begründungen für eine zunehmende rechtliche Regelung der medizinischen Tätigkeit zu analysieren. Ich meine, daß eine solche Analyse den Leitgedanken der Rechtfertigung tatbestandsmäßigen Handelns des Arztes und des übrigen Pflegepersonals beleuchten dürfte.

\section{Gesetzliche Regelungen im Bereich medizinischer Tätigkeit}

Wenn man irgendeinen ärztlichen Eingriff im Lichte von Rechtsprinzipien sehr allgemeinen Charakters zu beurteilen hat, so gestaltet sich die Rechtslage leicht diffus. Dies wiederum begrenzt die Möglichkeit, solche Eingriffe zu unternehmen, und kann die Forderung nach Reform der einschlägigen Regelung nach sich ziehen. Vor dem Sondergesetz des Jahres 1935 bestimmte sich die Zulässigkeit der Sterilisation danach, inwieweit dieser Eingriff, der rechtlich die Tatbestandsmerkmale der Körperverletzung erfüllt, gewohnheitsrechtlich als rechtmäßig angesehen werden konnte. Vor dem Gesetz über den Schwangerschaftsabbruch aus dem Jahre 1950 war die Zulässigkeit dieser Maßnahme - d.h. die Rechtfertigung oder Entschuldbarkeit der Abtreibung der Leibesfrucht - auf der Grundlage der Vorschrift über den Notstand des Strafgesetzes zu beurteilen. (In dem 1970 erlassenen Gesetz über den Schwangerschaftsabbruch wurden die Indikationen für diesen Eingriff weiter gelockert.) Desgleichen begrenzten strafrechtliche Vorschriften Manipulationen an der Leiche, so zum Beispiel die Entnahme von Gewebeteilen von einem Toten, bis hierüber ein Sondergesetz erlassen wurde (das Gesetz über die Gewebstransplantation von 1957).

Von den genannten Gesetzen besitzt wohl nur das letztgenannte einen direkten Zusammenhang zur Entwicklung der Medizin; die übrigen sind vielmehr Widerspiegelungen der Entwicklung, die sich in den Moralauffassungen und dem gesellschaftlichen Leben vollzogen hat. Aus den Begründungen des Gewebstransplantationsgesetzes spricht die Sorge um die Entwicklung und volle Nutzbarmachung der Gewebstransplantationschirurgie. Wegen des Fehlens der notwendigen Bestimmungen war es unmöglich gewesen, Gewebe zu bekommen. Auf die von der Weiterentwicklung der Medizin erzeugten Änderungsbedürfnisse wird auch in den Vorarbeiten zu dem 1985 novellierten Gesetz über Organ- und Gewebstransplantation hingewiesen: Die Medizin hat 
auch andere Möglichkeiten der Herstellung und Verwendung von Gewebeteilen als die Übertragung von Gewebe von einem Toten zur Verwendung für einen unbedingt notwendigen Heileingriff an einer kranken Person eröffnet. Es sollte keine Gewebstransplantation allein deswegen unversucht bleiben, weil sich die für die Transplantation zuständigen Ärzte über die rechtlichen Folgen dieser Maßnahme im Unklaren sind. Aus diesem Grund wurden in dem neuen Gesetz die Voraussetzungen für die Verpflanzung von Gewebeteilen oder Organen sowohl eines Toten als auch einer lebenden Person definiert. Hinsichtlich der Begründungen des Gesetzes sei noch angemerkt, daß man die Novellierung des Gewebstransplantationsgesetzes nicht nur mit der rapiden Entwicklung der Medizin motivierte, sondern auch durch die Feststellung, daß sich die ethischen Auffassungen gewandelt hätten.

Bei der Erörterung der Frage, wie die Schadenshaftung bei Patientenschädigungen im Bereich der Gesundheitsfürsorge oder Krankenpflege zu regeln sei, hat man unter anderem-die rasche Entwicklung der medizinischen Technik und die Anwendung von neuen Untersuchungs- und Behandlungsmethoden als relevante Sachverhalte angesehen. In dieser Situation funktioniert das herkömmliche Haftungssystem, wonach die Schadensersatzberechtigung davon abhängt, ob man dem behandelnden Personal ein vorwerfbares Verhalten nachweisen kann, nicht besonders gut. Dieser Mißstand wird in dem oben genannten Bericht der Kommission für Rechtssicherheit in der Gesundheitsfürsorge und Krankenpflege von 1982 als ein Gesichtspunkt genannt, der für ein besonderes Patientenversicherungssystem spreche.

Die Zunahme medizinrechtlicher Regelungen scheint damit zusammenzuhängen, daß die Menschenrechte und die Rechtssicherheit ebenso wie die Rechte des Verbrauchers und damit auch die des Kunden / Patienten in der öffentlichen Diskussion stärker als früher hervorgehoben werden. Dies wiederum hängt mit dem Wachstum des allgemeinen Wohlstandes und des Bildungsniveaus zusammen.

Die wissenschaftlich-technische und biomedizinische Entwicklung wird als Ursache dafür angesehen, daß neue, unter anderem auch mit dem Problembereich Gesundheil zusammenhängende Menschenrechtsprobleme entstanden sind. Für ihre zentrale Stellung spricht auch der Umstand, daß von der UNO und der WHO Analysen darüber in Auftrag gegeben worden sind, welche Anforderungen die Errungenschaften auf den Gebieten Biologie, Medizin und Biochemie an den Schutz der Persönlichkeit des Individuums sowie an seine physische und intellektuelle Unverletzlichkeit stellen. Man war der Ansicht, daß der wissenschaftliche Fortschritt neben seinen positiven Auswirkungen auch gewisse Verletzungen der Menschenwürde und des Persönlichkeitsschut- 
zes fördern könne. Diese Grundsätze könnten etwa in den Bereichen künstliche Befruchtung, Genmanipulation und Intensivbehandlung von Todkranken in bisher unbekannter Weise verletzt werden.

Eine interessante Beobachtung ist, daß man vor einigen Jahrzehnten aus Gründen der Rechtssicherheit detaillierte Rechtsvorschriften nur für solche Bereiche der medizinischen Tätigkeit verlangte, bei denen die Frage der Rechte und Pflichten des Individuums sowie starke Interessenkonflikte zentral sind (z.B. beim Gesetz über Geisteskranke oder bei den Gesetzen über ansteckende Krankheiten), während man in der letzten Zeit immer mehr die Präzisierung der rechtlichen Stellung des Patienten und des Pflegepersonals ganz allgemein gefordert hat. Besonders hervorgehoben wurde die Stärkung der Rechte des Patienten durch Rechtsvorschriften.

Diese Forderungen scheinen mit den Entwicklungen im Gesundheitswesen zusammenzuhängen, weil gerade in den Krankenhäusern die Arbeitsteilung weit fortgeschritten ist, zugleich aber eine Organisation geschaffen wurde, die den Bedürfnissen des Patienten nach Information nur sehr schlecht nachkommt. Eine im Auftrag der oben erwähnten Kommission für die Rechtssicherheit in der Gesundheitsfürsorge und Krankenpflege im Jahre 1982 durchgeführte Umfrage unter Patienten hatte zum Ergebnis, daß beinahe zwei Drittel der Befragten nicht oder nur sehr lückenhaft wußten, was sie tun könnten, wenn sie meinten, sie würden eine schlechte Betreuung und Behandlung erhalten.

Einige konkrete Beispiele sollen im folgenden die Probleme erhellen, die wegen der sich an vielen Stellen zeigenden Unklarheit der derzeitigen Rechtslage auftreten. Die Beispiele betreffen das Selbstbestimmungsrecht des Patienten allgemein (IV), einige Situationen der Pflichtenkollision (V) und die Regelung der sog. terminalen Behandlung von Todkranken (VI).

\section{Das Selbstbestimmungsrecht des Patienten}

Der Grundsatz des Selbstbestimmungsrechts des Patienten ist in den siebziger Jahren unter anderem in mehreren Stellungnahmen des Ombudsmannes des Reichstags und des Zentralamts für Gesundheitswesen bestätigt worden. Von besonderer Bedeutung ist diesbezüglich ein Beschluß, den der Ombudsmann des Reichstags aufgrund einer Klage getroffen hat. In diesem Beschluß drückt er unter anderem aus, daß die finnische Rechtsordnung auf der Anerkennung der körperlichen Unversehrtheit und des Selbstbestimmungsrechts einer Person aufbaut. Die Gesetzgebung enthält keine allgemeine Legitimation zur Einschränkung des Selbstbestimmungsrechts einer Person, nur der Eingriff in 
deren körperliche Unversehrtheit kann objektiv beurteilt als den Interessen der Person entsprechend angesehen werden. ${ }^{7}$ Das Selbstbestimmungsrecht des Patienten hervorhebende Stellungnahmen sind unter anderem in den folgenden Richtlinien des Zentralamtes für Gesundheitswesen enthalten: über klinische Pharmazeutika-Untersuchungen, über die Stellung von Lehrpatienten sowie über die Ausübung von Forschungs- und Entwicklungstätigkeit in Gesundheitszentralen und Krankenpflegeanstalten. ${ }^{\mathbf{P}}$

Zur Untermauerung des Selbstbestimmungsrechts des Patienten ist bei uns selten auf die Vertragskonstruktion verwiesen worden. Dies ist auch angesichts dessen verständlich, daß man der Ansicht gewesen ist, das Verhältnis zwischen dem Patienten und dem ihn behandelnden Arzt sei in erster Linie nur in der Privatpraxis-Situation ein Vertragsverhältnis. Als eine Entwicklungserscheinung der Gesundheitsfürsorge und Krankenpflege hat man gerade auch angesehen, daß das Behandlungsverhältnis immer häufiger einen öffentlichrechtlichen Charakter annimmt. Je seltener das Behandlungsverhältnis als privatrechtliches Vertragsverhältnis anzusehen ist, desto notwendiger wird es, die öffentlich-rechtliche Rechtssicherheitsgarantien zu verbessern, um das Recht des Patienten auf sachgemäße Behandlung sicherzustellen.

Die Bedeutung der Einwilligung des Patienten wird oft durch die Äußerung charakterisiert, daß die Einwilligung im allgemeinen die Voraussetzung für die Rechtmäßigkeit des Heileingriffs darstelle. Die Ausführung eines Heileingriffs ohne die Einwilligung des Patienten ist nach der herrschenden Auffassung bis auf Ausnahmefälle - wegen des Fehlens der Spezialkriminalisierung nicht als ein gegen das Leben, die körperliche Unversehrtheit (Gesundheit) oder die Freiheit gerichtetes Delikt strafbar. Zunächst kann ein auf disziplinarischem Wege zu sanktionierendes Fehlverhalten bzw. eine Unterlassung oder eine den Eintritt der Amtshaftung nach sich ziehende (andere) Verletzung der Amtspflichten vorliegen. Die Begründungen für jene Auffassungen und damit verbunden für die weitgehende Freistellung des Arztes vom allgemeinen Strafrecht variieren. Man hat entweder die Tatbestandsmäßigkeit der Körperverletzung verneint oder mehrere Rechtfertigungsgründe (nicht nur die Einwilligung des Patienten) für die Freistellung befürwortet. - Im Beschluß des Obersten Gerichtshofs Nr. 3938/81 (R 77/603) vom 1. April 1982 hatte die Nichteinholung der Einwilligung des Patienten zur Folge, daß der Arzt verpflichtet wurde, Schadensersatz zu leisten.

7 Bericht des Ombudsmanns des Reichstags aus dem Jahre 1973, S. 19-20.

8 Siehe die Weisungsschreiben Nr. 6814/02/78, 7023/02/79, 445/02/79 und das Rundschreiben 1875/1985. 
Im genannten Fall hatte es der Arzt unternommen, eine Geschwulst eines Patienten poliklinisch zu entfernen. Wie der Oberste Gerichtshof für nachgewiesen erachtete, hätte der Arzt in der Anfangsphase der Operation bemerken können, daß „die Geschwulst so eng mit dem Wadennerv verbunden war, daß bei der Entfernung der Geschwulst die Gefahr der Beschädigung des Nervs bestand“. Nach Ansicht des OGH hätte der Arzt wissen müssen, daß diese Gefahr durch Anwendung des neurochirurgischen Operationsverfahrens hätte vermieden werden können. Aus diesem Grund hätte der Arzt, ohne den Patienten auf diese Gefahr hinzuweisen und seine Einwilligung einzuholen, die Operation nicht fortsetzen dürfen. Indem er die Operation ohne die genannten Voraussetzungen fortsetzte, hatte der Arzt fahrlässig gehandelt und war für die teilweise Lähmung des Wadennervs und deren Folgen haftbar.

Die Nichtinformierung des Patienten und die Nichteinholung seiner Einwilligung war also für die Entstehung des Schadens in der Weise von Bedeutung, dass eine Informierung es dem Patienten ermöglicht hätte, sich an einen Neurochirurgen zu wenden, wobei der Schaden wahrscheinlich hätte vermieden werden können. Der Schaden, der aus dem nun angewandten Operationsverfahren resultierte, war offenbar bei diesem Verfahren eine sog. unvermeidliche Komplikation, die als solche nicht zu einem Schadensersatz berechtigt.

\section{$V$. Interessenabwägung und Pflichtenkollision}

In einem für die Menschenrechtskommission der Vereinten Nationen erstellten Bericht der WHO aus dem Jahre 1975 wird in summarischer Form konstatiert, daß das Recht auf Gesundheit seine positive wie auch seine negative Seile habe. Die positive Seite ist z.B. das Recht des Einzelnen auf Gesundheitspflege und Schutz vor ansteckenden Krankheiten, während die negative Seite darin besteht, daß es die Pflicht des Bürgers ist, zur Sicherung der Gesundheit anderer sich bestimmten Zwangsmaßnahmen zu unterwerfen. ${ }^{9}$ Einer Charakterisierung zufolge ist für die Medizinethik die Bestrebung kennzeichnend, in kritischer Weise einen Ausgleich zwischen den Grundrechten des Patienten und dem allgemeinen Interesse herzustellen. Dementsprechend hat man bei der Planung aller medizinrechtlichen Gesetzgebungsmaßnahmen verschiedene

9 Human Rights and Scientific and Technological Developments, United Nations, E/CN.4/1173 (1975). Eine neue Übersicht zum Verhältnis zwischen Medizin und Menschenrechten vom finnischen Standpunkt aus bieten Lahti / Kokkonen, Finnish National Report for the Handbook on Medicine and Human Rights, Division for Higher Educatlon and Research, DECS/ESR Mod h (86) 7, Council of Europe. 
Interessen gegeneinander abzuwägen. Auch bei der praktischen Anwendung des Medizinrechts wird eine solche Interessenabwägung häufig aktuell.

Als Beispiel einer Interessenabwägung und zugleich einer Pflichtenkollision sei folgende Frage angeführt: Wenn man das Selbstbestimmungsrecht des Patienten zum Ausgangspunkt nimmt, was bedeutet dies dann in Hinsicht auf die Pflichten des Arztes und des übrigen Pflegepersonals? In dem Arztgelöbnis, das in $\S 7$ Abs. 2 des Gesetzes über die Ausübung des Arztberufes verlangt wird, gelobt der Arzt, daß er allgemein anerkannte medizinische und empirische Behandlungsweisen anwenden wird. Der Umstand, daß die Einleitung und Durchführung der Behandlung in Übereinstimmung mit dem Patienten vorzunehmen ist, darf nicht die Pflicht implizieren, aufgrund einer dahingehenden Willensäußerung des Patienten von diesem im Gelöbnis kundgegebenen Grundsatz abzuweichen. Verweigert der Patient für einen bestimmten Eingriff seine Einwilligung, so ist er nach Möglichkeit in einer anderen medizinisch anerkannten Weise zu behandeln. In einigen solchen Verweigerungsfällen kann es die einzige Alternative des Arztes oder des übrigen Pflegepersonals sein, das Behandlungsverhältnis aufzukündigen.

Ein zweiter Beispielsfall: Während der Durchführung eines Eingriffs (z.B. einer Operation), zu dem der Patient seine Einwilligung gegeben hat, treten unerwartete Komplikationen auf; die Unterlassung eines Teileingriffs, zu dem der Patient keine Einwilligung gegeben hat oder den er vielleicht sogar ausdrücklich untersagt hat, würde zum Tod des Patienten führen. In dem Moment, in dem über die Vornahme dieses Teileingriffs die Entscheidung zu fällen ist, ist der Patient aber wegen seiner Bewußtlosigkeit zu einer aktuellen Willensbildung nicht imstande. Hier liegt folglich ein Pflichtenkonflikt vor: Sollte man den (vermuteten) Willen des Patienten respektieren oder die Lebensgefahr, in der dieser schwebt, abwenden? Dieses Problem ist besonders in den Fällen erörtert worden, in denen es ein Zeuge Jehovas aus religiösen Gründen abgelehnt hat, sich Bluttransfusionen geben zu lassen.

In einer älteren Stellungnahme des Zentralamts für Gesundheitswesen (1965) hatte man der letztgenannten Pflicht den Vorrang eingeräumt:

Wenn ein Arzt bei einer Operation die Bluttransfusion zur Rettung des Lebens des Patienten für unabdingbar erachtet, sie aber aus dem Grunde nicht durchführt, weil der Patient vor der Operation eine solche Maßnahme untersagt hat, und der Patient stirbt, so kann der Arzt allein schon aufgrund dessen strafrechtlich zur Verantwortung gezogen werden, daß er es unterlassen hat, einem in Lebensgefahr schwebenden Menschen zu helfen, ganz zu schweigen davon, daß er seine ärztlichen Pflichten vernachlässigt hat. 
Ich selbst halte den Inhalt des geltenden Gesetzes in dieser Sache nicht für ebenso eindeutig. Man kann auch - meines Erachtens sogar besser - die Auffassung begründen, daß die von seiten des Patienten geäußerte Ablehnung eines bestimmten Teileingriffs auch in derjenigen Phase der Behandlung zu respektieren ist, in der der Patient, z.B. in der Narkose während der Operation, zu einer aktuellen Willensbildung nicht imstande ist, und zwar auch dann, wenn die Blutübertragung zur Rettung seines Lebens unbedingt notwendig wäre. ${ }^{10}$ Hierbei gehe ich indes davon aus, daß der Patient bei seiner Ablehnung dieser Maßnahme die Tragweite seiner Entscheidung hat begreifen können. Des weiteren darf der Arzt keine Zweifel darüber hegen, daß der Wille des Patienten zum Zeitpunkt des Eingriffs ein anderer sein könnte. Deswegen sollte der Arzt anhand einer schriftlichen Erklärung oder der Eintragungen in die Krankenakten nachweisen können, daß der Patient über die Konsequenzen der Ablehnung einer Blutübertragung gewissenhaft aufgeklärt wurde und, obwohl er sich über die Bedeutung seiner Weigerung vollkommen im klaren war, an ihr festgehalten hatte. Es ist allerdings zu berücksichtigen, daß auch eine solche Verfahrensweise des Arztes, die man nicht für rechtmäßig hält, zu einem Wegfall des Schuldvorwurfs führen kann.

\section{Die Behandlung Sterbender}

Besonders interessant ist es, Einsicht in die Hintergrunderwägungen der im April 1982 erteilten Weisungen über die sog. terminale Behandlung, die Pflege von unheilbar Kranken bis zu ihrem Tod, zu nehmen. ${ }^{11}$ Laut der Einführung zu diesen Weisungen hat die Entwicklung der Medizin und der medizinischen Technologie es ermöglicht, auch Patienten mit der Prognose „unheilbar“ am Leben zu erhalten. Die Folge hiervon kann sein, daß ihr Leiden nur verlängert wird. Das Handeln zum Besten des Patienten oder - um den Wortlaut des Arztgelöbnisses zu verwenden - der Dienst am Mitmenschen unter Berücksichtigung der Humanität braucht in diesem Falle nicht unbedingt mehr in der Erhaltung des Lebens zu bestehen. In den Weisungen wird auch die Existenz anderer Werte anerkannt. Die terminale Behandlung beinhaltet zusätzlich zu einer guten, an den Symptomen orientierten Basispflege die persönliche Stützung des Patienten und seiner Angehörigen sowie alle sonstige die Menschenwürde respektierende Fürsorge.

10 In ähnlicher Richtung auch in einer neuen Stellungnahme das Zentralamt für Gesundheitswesen; siehe Rundschreiben Nr. 1865/1985, S. 7.

11 Weisungsschreiben des Zentralamts für Gesundheitswesen Nr. 3024/02/80. Siehe auch Kokkonen, Death and Dying, Paper for the World Congress on Medical Law, Gent 18 22 VIII 1985. 
Die Weisungen sind von Bedeutung hinsichtlich der Auslegung der Vorschriften des Strafgesetzes über den Schutz des Lebens. Aus den einschlägigen Vorschriften des Strafgesetzes (Kapitel 21) geht das Verbot der absichtlichen Tötung hervor. Somit ist zumindest die absichtliche Verkürzung des Lebens, die sog. aktive Euthanasie, verboten - alles andere würde gesetzgeberische Maßnahmen erfordern. Den besagten Weisungen zufolge kann bei einem in der Phase der terminalen Behandlung befindlichen Patienten auf komplizierte, den Patienten belastende, lebensverlängernde Maßnahmen verzichtet werden, wobei besonders danach zu streben ist, die Schmerzen zu lindern und die Angst vor dem Tode zu mindern. Dies impliziert die Zulassung einer passiven Euthanasie, wenn man unter diesem Begriff seiner ursprünglichen Bedeutung gemäß die medizinische Hilfeleistung beim Sterben versteht. (In den von der Medizinischen Akademie der Schweiz und den von der Bundesärztekammer der Bundesrepublik Deutschland 1976 und 1979 ratifizierten Richtlinien spricht man anstelle von terminaler Behandlung von Euthanasie oder Sterbehilfe.)

Es ist festzuhalten, daß 1969 bei der Reformierung der Strafgesetzvorschriften über die Tötung der Rechtsausschuß des finnischen Reichstags davon ausging, daß das Gesetz jedwede Euthanasie absolut verbot. Unter Euthanasie verstand man dabei die aus Gnade oder Mitleid erfolgte Beendigung des Lebens einer anderen Person. Der Ausschuß hielt die Frage für problematisch, ob und in welchem Umfang zur Pflege des Patienten auch die Sterbehilfe gehöre; die Grenzziehung zwischen medizinischer Behandlung und der in den Bereich des Strafrechts fallenden Tötung hatte sich nach Meinung des Ausschusses erschwert, da sich aufgrund der Entwicklung in der Medizin die Möglichkeiten, bestimmte Lebensfunktionen eines sterbenden Patienten aufrechtzuhalten, vermehrt hatten. $^{\mathbf{1 2}}$

Im großen und ganzen bleiben die Aussagen des Ausschusses darüber etwas im Unklaren, ob man bei dem absoluten Verbot der Euthanasie an Situationen wie die in den Weisungen über die terminale Behandlung gedacht hatte. Diese Weisungen bilden aber meiner Meinung nach ein starkes Argument dafür, die Vorschriften über die Tötung dahingehend auszulegen, daß die von den Weisungen bezeichnete passive Euthanasie nicht in den Bereich der wer strafrechtlichen Vorschriften fällt. Ich halte die Weisungen in juristischer Hinsicht jedoch diesbezüglich für problematisch, als in ihnen nicht eindeutig gefordert wird, daß die terminale Behandlung eines Patienten, der zur Willensäußerung fähig ist, im Einverständnis mit diesem durchzuführen ist. Auch vom Stand-

12 Lakivaliokunnan mietintö n:o 11/1969 valtiopäivät. 
punkt der Normenhierarchie ist die Rechtslage nicht eindeutig. Weiterhin kann man fragen, ob die Weisungen in erster Linie bei der Auslegung der Tatbestandsmäßigkeit, der Rechtfertigungsgründe oder der Entschuldigungsgründe wirken.

Meine zu den Weisungen über die terminale Behandlung vorgebrachten Bemerkungen veranschaulichen das Problem, das mit der Wahl der Ebene der medizinrechtlichen Regulierung zusammenhängt. Die vom Zentralamt für Gesundheitswesen erteilten Weisungen dürfen nicht im Widerspruch zum Gesetz bzw. zum Gewohnheitsrecht stehen. Auf der anderen Seite könnten in dem Fall, daß die Gesetzesvorschriften nicht eindeutig auslegbar sind, den Weisungen eine die Rechtsprechung modifizierende oder vereinheitlichende Funktion erwachsen. Gegen eine Regelung auf Gesetzesebene mögen starke Gründe sprechen. Der Rechtsausschuß des Reichstags, der sich mit der Euthanasie-Frage beschäftigte, war der Meinung, daß auch bei einer möglichst vorsichtigen Ausformulierung von strafrechtlichen Vorschriften über die Sterbehilfe diese zu Mißverständnissen hinsichtlich der Sicherheit des Patienten führen könnten. In den Weisungen des Zentralamts für Gesundheitswesen sind derartige Mißverständnisse leichter vermeidbar, da in ihnen die anzuwendenden Grundsätze viel ausführlicher dargelegt werden können.

Auf der anderen Selle ist es offensichtlich, daß Vorschriften auf Gesetzesebene im allgemeinen besser befolgt werden als untergeordnete Regeln, unter anderem auch aus dem Grund, daß ihr Inhalt besser bekannt ist und sie als stärker verpflichtend empfunden werden.

\section{Die Behandlung haftungsausschließender Gründe in der Praxis}

Oben habe ich in exemplarischer Form einige in der medizinischen Tätigkeit auftretende Situationen betrachtet, bei deren strafrechtlicher Beurteilung es in erster Linie um die mit den Rechtfertigungsgründen zusammenhängende Problematik geht. Die Entwicklung geht dahin, daß die für die medizinische Tätigkeit relevanten Rechtfertigungsgründe immer häufiger auf legislativem Weg geregelt werden. Die Folge einer solchen Entwicklung dürfte die Abnahme von rechtlich unklaren Pflichtenkollisionen und damit die Abnahme des Bedarfs sein, auf übergesetzliche Rechtfertigungs- oder Entschuldigungsgründe zurückzugreifen. Ich kann mich diesbezüglich der folgenden Aussage Albin Esers anschließen:

Ebenso wie das allgemeine Rechtfertigungsprinzip des 'überwiegenden Interesses' so weit wie möglich in bestimmten Rechtfertigungsgründen typisiert sein muß, so 
bedarf es auch im Schuldbereich aus Gründen der Rechtssicherheit der Typisierung der entschuldbaren Fälle in näher umgrenzten Entschuldigungsgründen. ${ }^{\mathbf{1 3}}$

Indes kann die Frage, in welchem Umfang man in der Praxis etwa in Fällen von Pflichtenkollisionen Rechtfertigungs- oder Entschuldigungsgründe als Argumentationshilfe heranzieht, nicht ganz eindeutig beantwortet werden. Strafprozesse, die mit medizinischer Tätigkeit zusammenhängendes Verhalten zum Gegenstand haben, sind in Finnland sehr selten. Fehlerhaftes Verhalten von Ärzten oder sonstigem Pflegepersonal wird in der Praxis vor allem im Rahmen der Disziplinar- oder Schadenshaftung beurteilt. Die zu verhängenden Disziplinarsanktionen sind im allgemeinen relativ mild, und für die Abdeckung von Schadensersatzansprüchen hat man zumeist eine Haftpflichtversicherung abgeschlossen. ${ }^{14}$ Dies trägt dazu bei, daß das Interesse an einer Differenzierung von Rechtfertigungs- und Entschuldigungsgründen als Formen des Haftungsausschlusses nicht besonders groß ist. Desgleichen bleiben solche Umstände, die auf die Beurteilung des Grades der Tatschuld und der Unzumutbarkeit normgemäßen Verhaltens einwirken, hierbei zumeist ohne jede Beachtung. Das neue Patientenversicherungssystem wird die Schadenshaftung von jeglichem individuellen Schuldvorwurf völlig unabhängig machen.

\section{Der Gesetzentwurf über die Rechte des Patienten}

Ich habe dieser Darstellung die wichtigsten Vorschriften aus dem oben erwähnten Gesetzentwurf über die Rechte des Patienten in der Anlage beigefügt. In diesen Vorschriften sollen die Grundsätze für die Behandlung und Betreuung von Patienten und Versuchspersonen festgelegt werden. Die Regelung ist freilich nicht einmal für jene Teile erschöpfend, für die im Gesetzentwurf hinsichtlich der jeweiligen Grundsätze Bestimmungen vorliegen. Hierzu einige Beispiele:

In $\S \S 2-4$ des Gesetzentwurfs finden sich die Bestimmungen über das Recht des Patienten auf Behandlung. In diesen Vorschriften ist $\mathrm{zu}$ lesen, daß das Recht des Patienten auf Behandlung sich nach seinem Gesundheitszustand, den verfügbaren gesundheitsfürsorgerischen Ressourcen und den allgemein anerkannten medizinischen und empirischen Verfahrensweisen bestimmt. Über die Pflicht zur Aufnahme der Behandlung, d.h. darüber, wessen Pflicht es ist, dem Patienten Behandlung zukommen zu lassen, wurden genauere Bestim-

13 Eser, Strafrecht I, 3. Aufl. 1980, S. 200-201.

14 Vgl. die Übersicht von Modeen, The System of Sanctions in Medical Care Relationships in Finnish Law, Scandinavian Studies in Law 1984, S. 105-122. 
mungen in dem Volksgesundheitsgesetz, in den Krankenhausgesetzen und in anderen Vorschriften über die Einrichtung der Gesundheitsfürsorge und Krankenpflege erlassen.

Das Recht des Patienten auf Information und Selbstbestimmung wird in $\S \S 5-7$ des Gesetzentwurfs geregelt. Diese Vorschriften wirken auf den ersten Blick recht detailliert; eine genauere Betrachtung zeigt aber, daß das Selbstbestimmungsrecht des Patienten in einer dem Ermessen erheblichen Spielraum lassenden Weise seinen Ausdruck gefunden hat. Als Hauptgrundsatz gilt, daß über die Behandlung des Patienten im Einverständnis mit diesem zu bestimmen ist. Wie sich die Einwilligung des Patienten in einen ärztlichen Heileingriff in der Praxis genauer gestaltet, wird in den genannten Paragraphen nur zum Teil festgelegt.

Besonders allgemein gehalten ist $\S 8$ über den Schutz der Daten des Patienten. In dieser Vorschrift wird im Grunde nur bestimmt, welche Angaben als Objekte des Datenschutzes gelten. Welche Personen die Schweigepflicht betrifft und welche Strafe für die Verletzung des Datenschutzgeheimnisses angedroht wird, bleibt offen und muß noch in Ausführungsvorschriften festgelegt werden. Auch die Beantwortung der Frage, in welchen Fällen die Weitergabe von Daten unzulässig, d.h. rechtswidrig ist, wird nach wie vor vom Gewohnheitsrecht abhängen. Mit anderen Worten: Man müßte auch diesbezüglich weiterhin unter anderem auf die allgemeinen Grundsätze über den Notstand und die Pflichtenkollision zurückgreifen.

Über die Struktur des besagten Gesetzentwurfs ist eine kritische Diskussion geführt worden. So ist z.B. gefragt worden, ob man nicht zumindest in einigen Vorschriften die Pflichten des Pflegepersonals niederschreiben sollte, wie man es in der Empfehlung betreffend die Stellung des Patienten, die in den Jahren 1982-84 im Europarat vorbereitet wurde, getan hat. ${ }^{15}$ Auch das Fehlen von Sanktionsvorschriften hat man für problematisch gehalten; in dem Gesetzentwurf wurde nicht dazu Stellung bezogen, in welchen Fällen ein die Rechte des Patienten verletzendes Verhalten die Realisierung z.B. der strafrechtlichen, der schadensersatzrechtlichen oder der disziplinarischen Haftung nach sich zieht. Wie ich oben dargelegt habe, würde der Erlaß eines solchen Gesetzes vom Standpunkt des Strafrechts aus vor allem eine deutlichere und verbindlichere Regelung der Rechtfertigungsgründe mit sich bringen. Diese Regelung könnte sich schon auf die Beurteilung der Tatbestandsmäßigkeit gewisser Handlungen auswirken.

15 Recommendation of the Committee of Ministers on the Legal Duties of Doctors vis-àvis their Patients and its Explanatory Memorandum, R (85) 3, Council of Europe. 
Hinsichtlich des künftigen Anwendungsbereichs der strafrechtlichen Sanktionsvorschriften möchte ich abschließend noch erwähnen, daß man nicht beabsichtigt, im Zusammenhang mit der zur Zeit betriebenen Gesamtreform des Strafgesetzes Strafvorschriften betreffend den eigenmächtigen Heileingriff zu erlassen. Man ist der Ansicht, daß für eine solche Spezialkriminalisierung kein ausreichender kriminalpolitischer Bedarf besteht.

\section{Anhang \\ Entwurf für ein Gesetz über die Rechte des Patienten ${ }^{\mathbf{1 6}}$

\author{
$\S 1$ \\ Anwendungsbereich
}

Dieses Gesetz betrifft die Rechte des Patienten insoweit, als sie nicht in anderer Weise gesetzlich bestimmt wurden.

Mit Patient ist in diesem Gesetz der Benutzer gesundheilsfürsorgerischer oder krankenpflegerischer Dienstleistungen gemeint. Paragraph 12 des Gesetzes findet indes auch Anwendung auf die wissenschaftliche Forschung an anderen Personen als an Patienten.

Mit Behandlung ist in diesem Gesetz die dem Individuum zukommende Gesundheitsfürsorge und Krankenpflege gemeint. Was in den Paragraphen 3, 9 und 13 des Gesetzes über den Arzt gesagt wird, gilt im Bereich der Zahnmedizin entsprechend für den Zahnarzt.

\section{$\S 2$}

Das Recht des Patienten auf sachgemäße Behandlung und Betreuung

Der Patient hat das Recht, in den Grenzen der Ressourcen, die der Gesundheitsfürsorge im betreffenden Fall zur Verfügung stehen, eine seinem Gesundheitszustand entsprechende Behandlung zu bekommen.

Der Patient ist gemäß den allgemein anerkannten medizinischen und empirischen Verfahrensweisen zu behandeln.

Der Patient ist so zu behandeln und zu betreuen, daß seine Menschenwürde, seine persönliche Integrität und seine Überzeugung wie auch sein Privatleben geachtet werden.

16 Terveydenhuollon oikeussuojatoimikunnan mietintö II (Anm.4). - Das endgültige Gesetz über die Stellung des Patienten (785/1992) ist als eine englischsprachige Übersetzung erhältlich: https://www.finlex./fi/fi/laki/kaannokset/1992/ en19920785_20120 690.pdf. 
Die individuellen Bedürfnisse des Patienten sind in seiner Behandlung und Betreuung zu berücksichtigen. Bei der Einrichtung der Behandlung und bei der Betreuung des Patienten ist ferner auch auf seine Muttersprache Rücksicht zu nehmen.

\section{$\S 3$}

\section{Beginn und Beendigung der Behandlung}

Bei dem Beschluß über den Beginn und die Beendigung der Behandlung sind die Patienten ohne Ansehen der Person zu behandeln.

Der Beschluß über die Aufnahme und die Beendigung der Behandlung ist von einem Arzt zu treffen.

Es ist danach zu streben, die Kontinuität der Behandlung des Patienten zu sichern.

\section{$\S 4$ \\ Die Aufnahme des Patienten in Behandlung}

Falls ein Patient nicht in Behandlung genommen werden kann, so ist er, abhängig von seinem Gesundheitszustand, auf die Warteliste zu setzen oder anderweitig in eine sachgemäße Behandlung zu überweisen.

Hat der Patient auf die Aufnahme in Behandlung zu warten, so sind ihm der Grund der Verzögerung sowie die voraussichtliche Dauer der Wartezeit mitzuteilen.

Ist der Patient einer Behandlung dringend bedürftig, so ist ihm ärztliche Behandlung zu gewähren oder er ist in der gesondert bestimmten Weise in Behandlung zu nehmen.

\section{$\S 5$ \\ Über das Recht des Patienten auf Information}

Der Patient hat das Recht, über seinen Gesundheitszustand sowie über solche mit seiner Behandlung zusammenhängenden Umstände informiert zu werden, die beim Beschluß über seine Aufnahme in Behandlung von Bedeutung sind.

Diese Information ist dem Patienten in einer solchen Weise darzubringen, daß er in der Lage ist, ihren Inhalt zu verstehen. Ist es wegen der Bewußtlosigkeit des Patienten oder wegen eines damit vergleichbaren Grundes nicht möglich, ihm die Information zu geben, so kann sie seinen nächsten Verwandten oder einer anderen ihm nahestehenden Person gegeben werden, sofern nicht der Patient ein solches Vorgehen untersagt hat. 
Der Patient hat das Recht, Einsicht in seinen Krankenbericht, in damit vergleichbare, mit der Behandlung zusammenhängende Akten oder technisch gespeicherte Dokumente zu nehmen.

Falls es jedoch offensichtlich ist, daß die Gewährung der Information das Leben oder die Gesundheit des Patienten ernstlich gefährden würde, so ist er zu einem Erhalt der Information nicht berechtigt.

\section{$\S 6$}

Das Selbstbestimmungsrecht des Patienten

Über die Behandlung des Patienten ist im Einverständnis mit ihm zu bestimmen. Untersagt der Patient einen bestimmten Eingriff, so ist er nach Möglichkeit in einer anderen medizinisch anerkannten Weise zu behandeln.

Ist der Patient wegen Bewußtlosigkeit oder eines anderen damit vergleichbaren Grundes nicht zu einer Willensäußerung imstande, so ist ihm die zur Abwendung der sein Leben oder seine Gesundheit bedrohenden Gefahr nötige Behandlung zu geben. Dem Patienten darf jedoch keine Behandlung gegeben werden, wenn es aufgrund einer diese betreffenden früheren Willensäußerung offensichtlich ist, daß er seine Einwilligung zu der Behandlung nicht geben würde.

\section{$\S 7$ \\ Die Stellung eines vermindert geschäftsfähigen Patienten}

Ist ein Patient wegen Geisteskrankheit, Schwachsinn oder Gestörtheit seines Geisteslebens nicht in der Lage, über die ihn betreffende Behandlung in kompetenter Weise zu bestimmen, so ist er im Einverständnis mit seinem Vormund oder dem ihm eigens bestellten Pfleger zu behandeln.

Ist ein minderjähriger Patient unter 12 Jahre alt oder ist er ansonsten wegen seines Alters, seiner Entwicklungsstufe oder der Art der Behandlung nicht in der Lage, über seine Behandlung zu bestimmen, so ist er im Einverständnis mit seinem Vormund zu behandeln.

Der Vormund oder der bestellte Pfleger haben nicht das Recht, eine zur Abwendung einer das Leben oder die Gesundheit des Patienten bedrohenden Gefahr unabdingbare Behandlung zu untersagen.

Ist ein vermindert geschäftsfähiger Patient in der Lage, über seine Behandlung in kompetenter Weise zu bestimmen, so hat er bei Vorliegen schwerwiegender Gründe das Recht, die Weitergabe von damit zusammenhängenden Informationen an seinen Vormund oder seinen bestellten Pfleger zu untersagen. 


\section{$\S 8$ \\ Der Datenschutz des Patienten}

Angaben über den Gesundheitszustand des Patienten, seine Krankheit und seine Familienverhältnisse und damit vergleichbare Angaben dürfen nicht an Außenstehende weitergegeben werden.

$$
\S 9
$$

Die Beschwerde (Beanstandungen des Patienten)

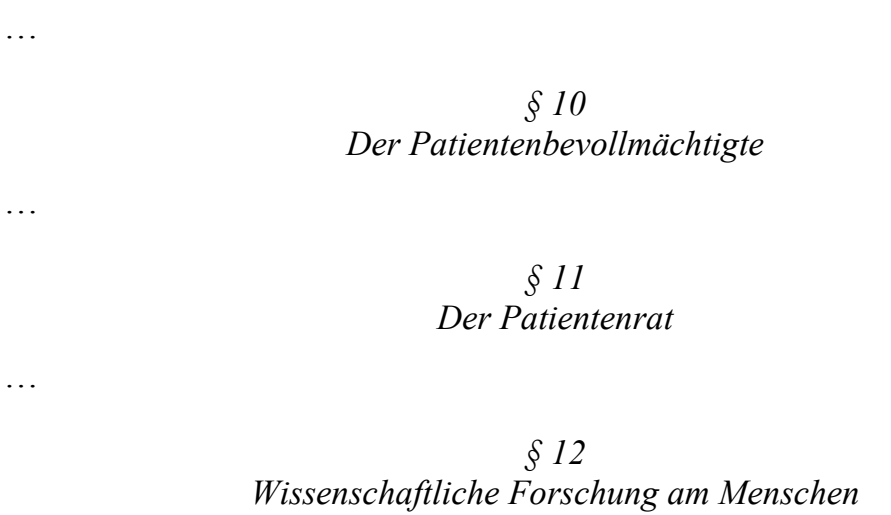

Die Vorschriften von $\S 2$ Abs. 2-4 sowie §§ 5-9 dieses Gesetzes über die Rechte des Patienten und die in seiner Behandlung zu befolgenden Grundsätze sind entsprechend auch dann anzuwenden, wenn in einer Einrichtung der Gesundheitsfürsorge oder Krankenpflege wissenschaftliche Forschung am Menschen betrieben wird.

$$
\S 13
$$

Die Ethischen Ausschüsse

$$
\S 14
$$

Die Befugnis zum Erlassen von Verordnungen

$$
\S 15
$$

Das Inkrafttreten des Gesetzes 

14.

\section{Strafrecht und Medizin. ${ }^{1}$ Aktuelle Reformpläne in Finnland}

1. Ich möchte mich in diesem Beitrag darauf beschränken, das Thema aus einem sehr eng gefaßten Blickwinkel zu betrachten, und zwar in erster Linie aus dem der in Finnland zur Zeit betriebenen Gesamtreform des Strafrechts. Ergänzende Gesichtspunkte finden sich in zwei anderen Artikeln von mir. ${ }^{2}$

Eingangs ist die Feststellung am Platze, daß die Rolle des Strafrechts als Regulator der medizinischen Tätigkeit in Finnland traditionell recht geringfügig ist. Zum Beispiel werden strafrechtliche Klagen gegen Ärzte oder sonstige Angehörige des Gesundheits- und Krankenpflegepersonals nur selten erhoben. Dies mag zum Teil darauf zurückzuführen sein, daß das gesamte Gesundheitsund Krankenpflegepersonal der Aufsicht des Zentralamts für Medizinalwesen untersteht und daß dieses in ihrer Aufsichtstätigkeit disziplinarische Mittel einsetzen und in das Berufsausübungsrecht der genannten Personalgruppen eingreifen kann.

Auch bei der Entwicklung der Gesetzgebung zur finnischen Gesundheitsfürsorge und Krankenpflege hat der Schwerpunkt auf anderen Dingen gelegen als auf der Effektivierung der juristischen Verantwortlichkeit und Sanktionierung. Das 1987 in Kraft getretene Gesetz über den Patientenschaden soll den Entschädigungsschutz der Patienten ausdrücklich in der Weise verbessern, daß das Vertrauensverhältnis zwischen Patient und Arzt gestärkt wird, während die Rechtsstreitigkeiten zur Erlangung von Schadensersatz hei Behandlungsfehlern zurückgehen. Mit einem vorgeschlagenen Gesetz über die Rechte des Patienten sollen die hinsichtlich der Rechtsstellung des Patienten zentralen Grundsätze geklärt werden, und bei der Befolgung dieser Grundsätze sollen in

1 Ein Beitrag zu einem ungarisch-finnischen Strafrechtsseminar, Budapest, 23.27.4.1990, mit kleinen Änderungen und Ergänzungen.

2 Siehe Raimo Lahti: Rechtfertigungs- und Entschuldigungsprobleme im Bereich medizinischer Tätigkeit, in Eser / Fletcher (Hrsg.): Rechtfertigung und Entschuldigung II. Freiburg i. Br. 1987, S. 1416 ff.; idem: Politische Implikationen und Probleme einer nationalen Patientenrechtsgesetzgebung, in: Pichler (Hrsg.): Einführung in die Patientenrechtspolitik. Schriftenreihe des Österreichischen Instituts für Rechtspolitik. Böhlau Verlag 1990, S. 73 ff. 
erster Linie administrative Steuerungs- und Überwachungsmittel angewandt werden ${ }^{3}$.

2. In der Entwicklung der Gesetzgebung zur Gesundheits- und Krankenpflege in Finnland hat die Bedeutung der traditionellen Rechtsbereiche (des Strafund Zivilrechts) also im Licht des oben Gesagten abgenommen. Desgleichen ist schon seit längerem die Ansicht vorherrschend gewesen, daß die das Leben, die körperliche Integrität und die Freiheit schützenden Vorschriften des Strafgesetzes sich nicht auf die normaleiweise vorkommenden Verletzungen der Integrität oder des Selbstbestimmungsrechts des Patienten anwenden lassen. Bezüglich dieser Vorschriften dürfte man bei der Gesamtreform des Strafgesetzes keine Änderungen vorschlagen. Die eiwähnten Verletzungen der Rechte des Patienten stellen natürlich im allgemeinen gegen die Dienst- und Berufspflichten des Pflegepersonals verstoßende Handlungen dar und haben normalerweise die Verhängung von administrativen Sanktionen zur Folge.

Es ist jedoch anzumerken, daß gewisse Entwicklungszüge der Medizin, der Biowissenschaften sowie der Medizinal- und Biotechnologie neue ethische, rechtliche und soziale Probleme aufgeworfen haben, bei deren Lösung sich die traditionellen ethischen und rechtlichen Normen sowie die Steuer- und Überwachungsmittel als unzulänglich erwiesen haben. Vor allem geht es um die Probleme, die von den Anwendungen der künstlichen Vermehrungs- oder Reproduktionsverfahren und der Gentechnik aufgeworfen werden. Die Entwicklung der biomedizinischen Technologie hat unter anderem die Mängel in dem Schutz, welchen die klassischen Freiheitsrechte bieten, sowie in den traditionellen Schutzobjekten des Strafrechts bloßgelegt. ${ }^{4}$

3. Als Teil der Gesamtreform des finnischen Strafgesetzes ist im Rahmen des sog. Strafgesetzprojekts ein vorläufiger Entwurf zu einem Kapitel des Strafgesetzes über Verletzungen des Schutzes des menschlichen Embryos, Fötus und Erbgutes ausgearbeitet worden. Der vorläufige Entwurf wurde in einer Arbeitsgruppe unter meiner Leitung vorbereitet, und der Entwurf trägt das Datum vom 22. Juni 1989 (siehe die Gesetzestexte im Anhang). Über die Ausgangspunkte dieser Reform wird in den Begründungen des Entwurfs folgendes geäußert:

3 Das Gesetz über die Stellung und Rechte des Patienten wurde im Jahre 1992 gegeben.

4 Siehe im allgemeinen Raimo Lahti: Criminal Law and Modern Bio-Medical Techniques. General Report. Revue Internationale de Droit Pénal 1988, S. 603 ff.; idem: Life's Beginnings: Law and Moral Dilemmas. in: Law and Moral Dilemmas Affecting Life and Death. In: Proceedings of the $20^{\text {th }}$ Colloquy on European Law. Glasgow, 10 12 September 1990. Strasbourg 1992, S. 60 ff. 
„Der Schutz des Lebens des noch ungeborenen Menschen hat neue Aktualität erhalten, weil sich die Methoden der künstlichen Vermehrung, der Behandlung der Infertilität, der medizinischen Genetik und der Fötusdiagnostik in den letzten Jahren rapide entwickelt haben. Die herkömmliche, den Fötus schützende Regulierung erstreckt sich nicht auf den außerhalb des weiblichen Organismus befindlichen menschlichen Embryo, welchen man durch künstliche Vermehrungsverfahren erzeugen kann. Die Entwicklung der biologischmedizinischen Techniken hat auch das Bewußtsein um einen neuen, zu schützenden Wert erhöht, die genetische Integrität des Menschen.

Die Steuerung der biologisch-medizinischen Forschung und der Anwendung der Technologie auf diesem Sektor hat sich an erster Stelle auf die berufsethischen Normen und diejenige allgemeine behördliche Überwachung zu stützen, der das Personal des betreffenden Bereichs unterzogen wird (als Beispiele die Überwachung, die das Zentralamt für Medizinalwesen über das Gesundheitsund Krankenpflegepersonal ausübt, oder die Amts-verantwortung der staatlichen Beamten und kommunalen Amtsinhaber). Strafrechtliche Mittel sollten auch in diesem Bereich der gesellschaftlichen Tätigkeit erst an letzter Stelle zu Gebote stehen, und die als strafbar bestimmten Taten müssen vom Standpunkt des Individuums oder der Gesellschaft aus besonders nachteilig und verwerflich sein.

Mit den vorzuschlagenden Strafvorschriften soll die Unverletzlichkeit des menschlichen Embryos, Fötus und Erbgutes geschützt werden. Zugleich soll ihr Zweck darin bestehen, die Integrität des noch ungeborenen, d.h. des werdenden, potentiellen Individuums zu schützen. Besonders unter den Handlungen, die die Integrität des menschlichen Erbguts verletzen oder gefährden, gibt es solche, die unseren Auffassungen von der Würde des Menschen in grundlegender Weise widersprechen.

Der dem werdenden menschlichen Leben bzw. dem potentiellen Individuum zu gewährende strafrechtliche Schutz ist jedoch nicht analog zu dem Schutz des Lebens, der Gesundheit oder Integrität, der dem geborenen, lebenden Menschen gebührt, sondern er ist relativer als der letztgenannte. Die Unantastbarkeit des Fötus durfte seit alters her zur Rettung des Lebens der schwangeren Frau verletzt werden. Die heutigen Vorschriften über den Schwangerschaftsabbruch erlauben den Abbruch unter wesentlich milderen Indikationen als früher und betonen so das Selbstbestimmungsrecht der Frau.

Die neue, den Schutz des menschlichen Embryos betreffende Strafvorschrift steht in engem Zusammenhang mit der Regelung von künstlichen Vermehrungsverfahren. Der vorzuschlagende strafrechtliche Schutz des Embryos 
würde unter im Gesetz genauer zu bestimmenden Voraussetzungen dann beiseite treten, wenn mit der Behandlung von Kinderlosigkeit und erblichen Krankheiten oder mit der auf solche Behandlung abzielenden Forschung verbundene Gesichtspunkte stark für die Erlaubung des Eingriffs in den Embryo sprechen würden.

Sämtliche Strafvorschriften des Kapitels verbindet das Ziel des Schutzes des ungeborenen menschlichen Lebens. Die für das Kapitel vorzuschlagende Vorschrift über den illegalen Eingriff in das Erbgut weicht indes in gewissen bedeutenden Punkten von den Strafvorschriften zum Schutz des Embryos und Fötus ab. In den Geltungsbereich dieser Vorschrift würden nur die emstesten, die Integrität des menschlichen Erbgutes verletzenden oder gefährdenden Tatformen fallen - mit anderen Worten solche, bei denen die die Menschenwürde verletzende Natur offenbar ist. Es scheint somit nicht möglich zu sein, daß man für die Verfahren, die durch die vorzuschlagende Vorschrift verboten werden, aufgrund einer Genehmigung Ausnahmen zuläßt. Die Vorschrift wäre des weiteren in der Hinsicht exzeptionell, als die Tatformen, die zur Zeit als möglich bekannt sind, sich auf ernstzunehmende Versuche zur künstlichen Erzeugung von hinsichtlich des Erbguts identischen Menschen, von sogenannten Chimärenindividuen oder von Mischformen zwischen Mensch und Tier (sog. Hybridenindividuen) beschränken.“

4. Die Gesamtreform des Strafgesetzes führt zu der Änderung von zahlreichen, den Sektor der Gesundheits- und Krankenpflege betreffenden Strafvorschriften. In das Kapitel des Strafgesetzes über gemeingefährliche Straftaten sollen u.a. Vorschriften über Gefährdung der Gesundheit einbezogen werden. Wegen Gesundheitsgefährdung soll u.a. derjenige bestraft werden, der in einer in der Vorschrift aufgelisteten Weise handelt (zum Beispiel Lebensmittel vergiftet oder schwere Krankheiten verbreitet), und zwar derart, daß die Tat eine allgemeine Gefahr für das Leben oder die Gesundheit hervorruft ${ }^{5}$.

Zahlreiche Strafvorschriften sind neu zu schreiben wegen des Grundsatzes, den man sich in der Strafgesetzreform zu eigen gemacht hat, daß alle Strafvorschriften, die die Androhung von Freiheitsstrafe beinhalten, im Strafgesetz zusammenzufassen sind. So wird vorgeschlagen, daß das mit „Straftaten gegen die Gesundheit und Sicherheit" betitelte Kapitel des neuen Strafgesetzes Strafvorschriften enthalten soll u.a. für Verletzungen der Lebensmittelgesetze, des Arzneimittelgesetzes, des Chemikaliengesetzes, des Gesundheits- und Krankenpflegegesetzes und des Gesetzes über ansteckende Krankheiten. Der

5 Siehe jetzt Kapitel $34 \S \S 4-5$ (Gesundheitsgefährdung anderer) § 4 im Stand von 2002 und $\S 5$ im Stand von 1995. 
Grund für die Kriminalisierung dieser unter Androhung von Geldstrafe oder geringer Freiheitstrafe verbotenen Taten liegt in der Gefahr dieser Taten für das Leben oder die Gesundheit der Menschen. In demselben Kapitel des Strafgesetzes soll auch eine Strafandrohung für illegale Ausübung gesundheits- und krankenpflegerischer Tätigkeit gegeben werden. ${ }^{6}$

5. Es wird vorgeschlagen, in das Straftaten gegen das Leben und die Gesundheit betreffende Kapitel des neuen Strafgesetzes eine sog. beschränkende Vorschrift aufzunehmen, derzufolge es nicht als Tötungsdelikt gilt, wenn unter Befolgung akzeptierter medizinaler Praxis man Behandlungsmaßnahmen aufgibt, mit denen das Leben eines todkranken Patienten erhalten wird. Die Absicht dieser Vorschrift über die sog. passive Euthanasie besteht darin, die Rechtslage zu klären und nicht sie zu ändern. Die beschränkende Vorschrift wird folgendermaßen begründet (siehe „Gesamtreform des Strafgesetzes II“, Publikationen der Gesetzgebungsabteilung des Justizministeriums, Nr. 1/1989, S. 231 f.): ${ }^{7}$

Die Entwicklung der Medizin hat es möglich gemacht, die Lebensfunktionen eines todkranken Patienten in Situationen aufrechtzuerhalten, wo man weiß, daß mit der Behandlung nur der Eintritt des Todes verzögert wird, ohne daß die Hoffnung besteht, daß der Patient durch die Behandlung erneut das Bewußtsein erlangt. Strafrechtlich problematisch sind nicht die Situationen, wo eine solche, das Leben „künstlich“ erhaltende Behandlung gar nicht erst begonnen wird. In der medizinalen Praxis sind auf jeden Fall Entscheidungen darüber zu fällen, ob man eine im Sinne einer Heilung offensichtlich ergebnislose Behandlung unterlassen solle. Der Umstand, daß durch diese Entscheidung der Tod früher eintritt, als wenn es bei der effektivsten den Tod hinauszögernden Behandlung der Fall gewesen wäre, kann nicht als ein durch Unterlassung verwirklichtes Verbrechen wider das Leben strafbar sein. Die Strafbarkeit der Unterlassung setzt eine rechtliche Handlungspflicht voraus. Die Grenzen dieser Handlungspflicht bestimmen sich wiederum nach der akzeptierten medizinalen Praxis.

Strafrechtlich problematisch ist dagegen die Situation, wo eine das Leben ,künstlich" erhaltende, aber erfolglose Behandlung begonnen wurde und über deren $\mathrm{Ab}$ bruch entschieden wird. Es ließe sich zum Beispiel ein Patient denken, dessen Gehirn zum größten Teil zerstört ist, bei dem aber durch maschinell aufrechterhaltenen Blutkreislauf eine geringe Gehirnfunktion bewahrt bleibt. Gemäß den Lehren über die Unterlassungsdelikte könnte man diese Situation so auslegen, daß zur Fortsetzung der Behandlung eine besondere rechtliche Pflicht bestehe und daß ein Abbruch der Behandlung somit ein durch Unterlassung verwirklichtes Verbrechen

6 Siehe jetzt Kapitel 44 (Über die Straftaten, die die Gesundheit und Sicherheit anderer gefährden); ausführlich im Jahre 2002 revidiert.

7 Siehe auch Karin Cornils: Nordische Länder. In Eser / Koch (Hrsg.): Materialien zur Sterbehilfe. Freiburg i.Br. 1991, S. 501 ff, 529 f. Eine solche beschränkende Vorschrift wurde in der endgültigen Revidierung des Kapitels 21 (Über Straftaten gegen Leben und Gesundheit) im Jahre 1995 nicht aufgenommen. 
wider das Leben wäre. Diese Auslegung entspricht jedoch nicht dem, was in der akzeptierten medizinalen Praxis als berechtigt angesehen wird.

Der Klarheit halber wird deshalb vorgeschlagen, in das Kapitel eine beschränkende Vorschrift über die terminale Behandlung aufzunehmen. Diese würde keine Veränderung gegenüber der jetzigen Praxis bedeuten. Die Vorschrift würde nur feststellen, daß eine terminale Behandlung nach akzeptierter medizinaler Praxis, bei der die Lebensfunktionen erhaltende Behandlungsmaßnahmen aufgegeben werden, nicht als Verbrechen wider das Leben gilt. Die Vorschrift würde nicht zu einer solchen aktiven Sterbehilfe berechtigen, bei der der Tod zum Beispiel durch eine tödliche Medikamentendosis unmittelbar herbeigeführt wird. Die Vorschrift würde auch nicht alle mit der terminalen Behandlung zusammenhängende rechtliche Probleme lösen. Zum Beispiel müßte man die Bedeutung des Willens und der Einwilligung gemäß allgemeiner Prinzipien in der Weise lösen, daß man den rechtlich gültigen, ernsthaften Willen, das Leben verlängernde Behandlungsmaßnahmen abzulehnen, respektiert, aber nicht den aktiven Willen der Person, den Tod zu suchen.

6. Ein zentrales rechtspolitisches Problem im Grenzbereich von Strafrecht und Medizin ist die Frage, wie psychisch abnorme Straftäter (Gesetzesbrecher) zu sanktionieren seien. Linie der Strafgesetzreform ist es gewesen, die in der derzeitigen Gesetzgebung angenommenen Grundlösungen weitgehend zu bewahren: Die Schuldunfähigkeit des einer Straftat Verdächtigen würde die Befreiung aus der strafrechtlichen Verantwortung zur Folge haben und nicht nur den Ausschluß der Anwendung gewisser Strafen (wie in Schweden), und über die eventuelle psychiatrische Behandlung des nicht $\mathrm{zu}$ Bestrafenden würden ausschließlich die Medizinalbehörden entscheiden.

Daß die Einteilung in Schuldfähige (,Zurechnungsfähige“) und Schuldunfähige bewahrt bleiben soll, basiert auf der Auffassung von den Zielen und den angestrebten Werten des strafrechtlichen Systems: Als Voraussetzung der Strafbarkeit gilt die Vorwertbarkeit der Tat, und mit der Strafe wird dem Täter die moralische Mißbilligung zum Ausdruck gebracht. Die Bestrafung einer schwer geisteskranken Person wäre sowohl unzweckmäßig als auch ungerecht.

Der Inhalt des Schuldprinzips, das man sich in der Reform des Strafgesetzes zu eigen gemacht hat, ist der, daß sich die Person in Anbetracht ihrer Fähigkeiten und ihrer äußeren Möglichkeiten auch hätte anders verhalten können, daß man von ihr aufgrund der allgemeinen Lebenserfahrung ein anderes Verhalten hätte verlangen können. Das so definierte Schuldprinzip nähert sich dem der sog. Integrationsprävention gemäßen Schuldkonzept an, das sich nach den Forde- 
rungen der allgemeinen Gesetzesachtung (der Aufrechterhaltung der Normen) bestimmt. ${ }^{8}$

Die neue, in den Allgemeinen Teil des Strafgesetzes aufzunehmende Vorschrift über die Zurechnunsfähigkeit würde deutlicher als die bisherige Vorschrift die normativ-psychologischen Kriterien zum Ausdruck bringen, auf die sich stützend man die strafrechtliche Bedeutung von Geisteskrankheit und damit vergleichbarer psychischer Abnormität beurteilt. ${ }^{9}$ Im Licht der jüngsten Gerichtspraxis (Entscheidungen des Obersten Gerichtshofs 1987:130 und 1988:98) scheint die Anwendung dieser Kriterien dahin zu führen, daß die aus strafrechtlicher Verantwortung befreiende Zurechnungsunfähigkeit strenger also seltener - als früher beurteilt wird.

Die Betrachtung der Gerichtspraxis zeigt auch eine strenger werdende Haltung gegenüber seelisch gestörten Straftätern (Psychopathen), mit anderen Worten: man hat seltener als früher aufgrund von verminderter Zurechnungsfähigkeit einen herabgesetzten Strafrahmen angewandt. In der Reform des Strafgesetzes soll eine solche Herabsetzung des Strafrahmens dem Ermessen überlassen werden. Dies dürfte wohl bedeuten, daß die Strafpraxis strenger wird, daß sich die Spezialprävention im Sinne einer „Ungefährlichmachung“ verstärkt und das Schwergewicht des traditionellen Schuldprinzips abnimmt.

Panu Minkkinen, ein kritischer Forscher der mit der Schuldunfähigkeit zusammenhängenden Fragen, hat eine solche (sich in der beschriebenen Entwicklung ausdrückende) Veränderung der Denkweise kritisiert, in deren Folge man die Vorschriften über die Schuldunfähigkeit nicht mehr als eine dem Rechtsstaat eigene Schutzmauer gegen eine übermäßige Anwendung der Strafgewalt des Staates sieht, sondern bei der diese Vorschriften zu dem sozialtechnologischen Denken entsprechenden Kriterien zur Wahl der zweckmäßigen Sanktion werden. Laut Minkkinen haben seine Forschungen gezeigt, daß Schuldunfähigkeit in der Praxis keineswegs eine Milderung der Sanktionen bedeutet, sondern die von den Medizinalbehörden verordnete psychiatri-

8 Über die Fragen des modernen Schuldstrafrechts siehe z.B. Claus Roxin: Was bleibt von der Schuld im Strafrecht übrig? Schweizerische Zeitschrift für Strafrecht 1987, S. $356 \mathrm{ff}$.

9 Die endgültig revidierte Vorschrift (Kapitel 3, § 4, Punkt 2; 515/2003) lautet: „Der Täter ist zurechnungsfägig, wenn er zum Tatzeitpunkt aufgrund von Geisteskrankheit, schwerer geistiger Behinderung, ernsthafter seelischer Störung oder Bewußtseinsstörung unfähig ist, die tatsächliche Natur oder die Rechtswidrigkeit der Tat einzusehen, oder wenn seine Fähigkeit, das eigene Handeln zu kontrollieren, aus einem derartigen Grund entscheidend herabgesetzt ist." Siehe Das finnische Strafgesetz. Übersetzung und Einführung von Karin Cornils, Dan Frände und Jussi Matikkala. Freiburg i.Br. 2006, S. 116. 
sche Behandlung ist im allgemeinen von längerer Dauer, als wie es die für die betreffende Tat verhängte Strafsanktion gewesen wäre. ${ }^{10}$

\section{Anhang}

\section{Vorläufiger Entwurf zur Änderung des Strafgesetzes (Justizministerium; 22.6.1989) $^{\mathbf{1 1}}$}

\section{Kapitel 22}

\section{Über die Verletzung des menschlichen Embryos, Fötus und Erbguts}

\section{§ 1. Illegaler Eingriff in den Embryo}

Wer ohne die im Gesetz vorgesehene Erlaubnis ein Experiment an einem lebenden menschlichen Embryo aufnimmt oder unbefugt in sonstiger Weise in einen solchen Embryo eingreift oder einzugreifen versucht, wird wegen illegalen Eingriffs in einen Embryo mit Geldstrafe oder mit höchstens einem Jahr Gefängnis bestraft.

Wegen illegalen Eingriffs in den Embryo ist auch der zu bestrafen, der in einer im Absatz 1 bezeichneten Weise in einen lebenden menschlichen Fötus eingreift oder einzugreifen versucht.

Nicht als illegaler Eingriff in den Embryo gilt eine medizinische Maßnahme, deren Zweck die Sicherung der Entwicklung des betreffenden Embryos oder Fötus oder die Feststellung einer Entwicklungsstörung desselben ist.

\section{$\S$ 2. Illegaler Schwangerschaftsabbruch}

Wer ohne die im Gesetz vorgesehene Erlaubnis oder ansonsten unbefugt die Schwangerschaft einer anderen Person abbricht, ist wegen illegalen Schwangerschaftsabbruchs mit Geldstrafe oder mit höchstens zwei Jahren Gefängnis zu bestrafen.

Der Versuch ist strafbar.

10 Siehe Minkkinen; „Ymmärrystä vailla“. („Des Gebrauchs der Vernunft nicht mächtig“.) Eine kriminologische Lizentiatabhandlung, Universität Helsinki, 1989.

11 In dem endgültig revidierten Kapitel 22 (373/2009) wurden diese Straftatbestände wesentlich beibehalten, wozu darin auch Strafbestimmungen gegen illegale Verhaltensweisen der assistierten Befruchtung aufgenommen sind. Siehe die englischsprachige Übersetzung des Strafgesetzes: The Criminal Code of Finland; Ministry of Justice: https://www.finlex.fi/fi/laki/kaannokset/1889/en18890039_20150766.pdf. 


\section{§ 3. Illegaler Eingriff in das Erbgut}

Wer

1) seitens ihres Erbguts identische Menschen durch Eingriff in die menschliche Samen- oder Eizelle oder den menschlichen Embryo erzeugt oder zu erzeugen versucht,

2) einen Menschen durch Vereinigung von menschlichen Embryos erzeugt oder zu erzeugen versucht,

3) ein lebendes Wesen durch Vereinigung von Samen- und Eizellen oder von Embryos von Mensch und Tier erzeugt oder zu erzeugen versucht,

ist wegen illegalen Eingriffs in das Erbgut mit Geldstrafe oder mit höchstens zwei Jahren Gefängnis zu bestrafen. 



\section{Perspektiven der Patientenrechtspolitik in Finnland}

Seit den 80er Jahren hat sich die Gesetzgebung auf dem Gebiet der Gesundheits- und Krankenpflege intensiv entwickelt. Das Gesetz über Patientenschäden $^{1}$ von 1986 und das Gesetz über die Stellung und Rechte des Patienten ${ }^{2}$ von 1992 sind typische Beispiele dafür. Gleichzeitig wurde allerdings die Position des Medizin- und Gesundheitsrechts als eigenständige Disziplin viel langsamer verstärkt.

Die klassischen Fragen des Medizinrechts, also des Verhältnisses zwischen Patient und Arzt (beziehungsweise Pflege- und sonstigem Personal), betreffen mehrere Rechtsgebiete, zum Beispiel das Zivil-, Straf- und Verwaltungsrecht. Auch die Haftungs- und Kontrollsysteme gliedern sich traditionell in diese drei Gruppen.

Eine solche traditionelle Differenzierung ist jedoch - zumindest in Finnland problematisch geworden. In Finnland ist der Anteil des öffentlichen Gesundheits- und Pflegewesens traditionell relativ hoch, Anleitung und Überwachung des Personals erfolgen vorwiegend durch administrative Mittel. Zivil- und strafrechtliche Klagen sind in Finnland selten, insbesondere nach dem Inkrafttreten des Gesetzes über Patientenschäden. Die jüngste Entwicklung der Gesetzgebung auf dem Gebiet der Gesundheits- und Krankenpflege ist dieser Differenzierung auch nicht gefolgt.

Kennzeichnend für diese neueste Tendenz ist, daß die Stellung des Patienten einheitlich und integrativ geregelt wurde. Besonders deutlich ist dies im Gesetz über Patientenrechte zu bemerken: Es betrifft sowohl die privat praktizierenden Ärzte als auch die öffentliche Gesundheits- und Krankenpflege. Nach landläufiger Meinung hat die Beziehung zwischen Patient und Arzt dadurch mehr und mehr die Charakterzüge eines öffentlich-rechtlichen Rechtsverhältnisses angenommen. Auf der anderen Seite ist man der Ansicht gewesen, daß

1 Vgl. zu diesem Gesetz (Nr. 585/1986) näher z.B.: Lahti 1995: $147 \mathrm{ff}$.

2 Vgl. zu diesem Gesetz (Nr. 785/1992) näher z.B.: Lahti 1994: 207 ff.; sowie: Pahlman et al 1996: $591 \mathrm{ff}$. 
jenes Gesetz an erster Stelle ein privatrechtliches und ausdrücklich ein personenrechtliches Gesetz sei.

Ein entsprechender Trend zur einheitlichen und integrativen Regelung betrifft die Haftung für Patientenschäden. Ein besonderes Gesetz wurde dafür erlassen und ein Patientenversicherungssystem eingeführt. Die Voraussetzungen für die Entschädigung weichen von den normalen Schadensersatzgründen ab, weil man keiner Person mehr eine Schuld nachzuweisen braucht, obgleich die Grundsätze, die bei der Festsetzung der Entschädigung angewandt werden, dem allgemeinen Schadensersatzrecht entsprechen. Andererseits sind die wichtigsten Verfahrensregeln, vom Standpunkt des Patienten aus gesehen, einfach und flexibel - entsprechend dem Gedanken einer dienstbereiten Verwaltung. Das Entschädigungssystem wird von privaten Versicherungsgesellschaften (eigentlich einem Konsortium) verwaltet, dem öffentlich-rechtlichen Patientenversicherungsausschuß kommt aber bei der Vereinheitlichung der Praxis eine wichtige Aufgabe zu.

\section{Warum eine zunehmende Regelung der Patientenrechte?}

Für Finnland können mehrere Faktoren angeführt werden, die diese Entwicklung erklären:

(a) Die Gesetzgebung spiegelte bis Ende der 80er Jahre in erheblichem Maße die Bestrebungen des Wohlfahrtsstaates wider: Die vom öffentlichen Haushalt getragenen Dienstleistungen für die Bürger wurden durch Gesetze vermehrt, Planung und Organisation der staatlichen und kommunalen Funktionen wurden konsequent entwickelt. ${ }^{3}$ Die jüngste Entwicklung in den 90er Jahren hat allerdings zu Sparmaßnahmen bei den öffentlichen Finanzen und zu einer „schlankeren“ Steuerung geführt, die Ressourcen der Gesundheits- und Krankenpflege wurden gekürzt. Zugleich hat sich der Einsatz der Ressourcen in einer Weise regional differenziert, die die Stellung des Patienten geschwächt hat.

(b) Die Zunahme medizinrechtlicher Regelungen scheint auch damit zusammenzuhängen, daß die individuellen Rechtsschutzgarantien, ebenso wie die Rechte des Verbrauchers und damit auch die des Patienten, in der öffentlichen Diskussion stärker als früher hervorgehoben werden. ${ }^{4}$ Auch die stärkere Betonung der Menschen- und Grundrechte wirkt in die gleiche Richtung. Während in der Anfangsphase des Gesetzgebungsprogramms Ende der 60er

3 Vgl. näher: Lahti 1990b: 75.

4 Vgl. näher: Lahti 1987: 1426. 
Jahre der Schwerpunkt noch auf der Behebung der grundlegenden Mängel lag, die mit den „klassischen“ Freiheitsrechten des Patienten verbunden waren (zum Beispiel die Abschaffung der Zwangskastration und die teilweise Reformierung des Gesetzes über Geisteskranke), so begann man um die Wende der 70er und 80er Jahre, auch Maßnahmen zur Verbesserung der Rechtsstellung des ,normalen“ somatischen Patienten auszuarbeiten. Im Zuge dieser Entwicklung fanden auch diejenigen Sektoren der medizinischen Tätigkeit Beachtung, in denen es zentral weder um die Rechte des Kunden / Patienten beziehungsweise die Verpflichtungen ihm gegenüber geht noch um starke Interessenkonflikte (anders als zum Beispiel bei der Behandlung von Geisteskrankheiten und ansteckenden Krankheiten).

Die erwähnten Maßnahmen haben also dazu geführt, daß die zwei Gesetze erlassen wurden, das Gesetz über Patientenschäden und schließlich das Gesetz über Patientenrechte. Für den Erlaß dieser Gesetze sprachen auch einige Wandlungen, die sich in der Struktur des Gesundheits- und Krankenpflegewesens vollzogen hatten: die Technisierung und Spezialisierung auf diesem Sektor sowie die Zunahme der Zahl von Krankenhäusern und sonstigen Behandlungseinrichtungen.

In den letzten Jahren wurden viele Fragen des Medizin- und Gesundheitsrechts vom Gesichtspunkt der Menschenrechte und Grundrechte geprüft - nicht zuletzt weil Finnland 1990 der Europäischen Menschenrechtskonvention beigetreten ist und 1995 eine Totalreform der Grundrechte in der finnischen Verfassung verwirklicht wurde. In den neuen Rechtsvorschriften zu den Grundrechten ist eine Bestimmung enthalten, nach der die öffentliche Gewalt jedem Bürger ausreichende Sozial-, Gesundheits- und Krankenpflegedienste zu gewährleisten und die Gesundheit der Bevölkerung zu fördern hat. Der Inhalt dieser Verpflichtung, die der öffentlichen Gewalt gestellt wurde, soll in separaten Gesetzen und Vorschriften genauer festgelegt werden, zum Beispiel in dem Gesetz über Patientenrechte.

(c) Die Entwicklung der biomedizinischen Technologie hat neue Regelungsbedürfnisse hervorgebracht und unter anderem die Mängel bloßgelegt, die in der Schutzfunktion der klassischen Freiheitsrechte sowie bei den traditionellen Schutzobjekten des Strafrechts bestehen. ${ }^{5}$ In das neue finnische Strafgesetz wird nach einem vorläufigen Entwurf ein Kapitel mit dem Titel „Über die Verletzung des menschlichen Embryos, Fötus und Erbguts“ aufgenommen, das

5 Vgl. z.B.: Lahti 1988: 603 ff. und Ders. 1992: 60 ff. 
neben dem illegalen Schwangerschaftsabbruch auch den illegalen Eingriff in den Embryo und das Erbgut reguliert. ${ }^{6}$

(d) In der jüngsten Diskussion wurden unter anderem die passive Euthanasie und das sogenannte Pflegetestament zur Sprache gebracht. Diese Diskussion hat die Auffassung verstärkt, daß es wichtig sei, die Rechtsordnung in einer Weise zu betrachten, die ihre Einheitlichkeit oder Integrativität betont. Der Meinungsaustausch betraf die Auslegung gewisser Bestimmungen im neuen Gesetz über Patientenrechte sowie das Kapitel über Straftaten gegen Leben und Gesundheit des 1995 reformierten Strafgesetzes. Im Gesetz über die Patientenrechte werden die allgemeinen Prinzipien des Selbstbestimmungsrechtes des Patienten und seines Rechtes auf Information reguliert. Gesondert wird bestimmt, daß ein Patient, der zum Beispiel wegen Bewußtlosigkeit nicht $\mathrm{zu}$ einer aktuellen Willensbildung imstande ist, nicht gegen seinen Willen behandelt werden darf, wenn er früher bereits ernsthaft und entschlossen seinen dementsprechenden Willen ausgedrückt hat. Einige Teilnehmer an dieser Diskussion haben bestritten, daß diese Bestimmung in solchen Konfliktsituationen juristisch verbindlich sei, in denen aufgrund der strafrechtlichen Vorschriften dem Arzt die Pflicht entsteht, den Patienten gemäß dem allgemein akzeptierten medizinischen Brauch zu behandeln. Die Bestimmung wurde dennoch in das Gesetz aufgenommen, um gerade diese ansonsten nicht regulierte Kollision der Pflichten in der Behandlungssituation zu lösen.

\section{Hintergründe zur Einführung der finnischen Patientenrechtsgesetzgebung}

Ein wichtiger rechtsideologischer Ausgangspunkt für die Entwicklung der Rechtsstellung des Patienten geht in Finnland auf die 60er Jahre zurück. In der regen Diskussion, die gegen Ende jenes Jahrzehnts geführt wurde, richtete man namentlich aus dem Blickwinkel der Rechtssicherheit des Individuums seine kritische Aufmerksamkeit auf verschiedene Zwangsmaßnahmen, gleichgültig ob diese nun unter der Bezeichnung der Strafe oder der Fürsorge und Behandlung liefen. Die Diskussion und die in ihrem Verlauf entstandenen Planungsdokumente bildeten einen wichtigen Anstoß für ein Gesetzgebungsprogramm, das in den folgenden 25 Jahren verwirklicht wurde.

Das umfangreiche Reformprogramm in der Sozial- und Gesundheitsfürsorge läßt sich aber nicht nur aus diesem rechtsideologischen Hintergrund erklären. Vor allem lagen die für einen modernen Wohlfahrtsstaat typischen Bestrebun-

6 Vgl. näher: Lahti 1990a: 89 ff. 
gen vor, die von der Gesellschaft getragenen Dienstleistungen für die Bürger zu vermehren, während zugleich Planung und Organisation der Funktionen der Gesellschaft konsequent entwickelt wurden.

Aufgrund des oben Gesagten läßt sich feststellen, daß in der Entwicklung der Gesetzgebung zur finnischen Gesundheits- und Krankenpflege zwei Grundtendenzen zu beobachten sind, zwischen denen Spannungen auftreten können: Zum einen die Stärkung der Freiheitsrechte des Patienten, besonders seines Selbstbestimmungsrechts, sowie der verfahrensmäßigen Rechtssicherheitsgarantien; auf der anderen Seite die Stärkung der sozialen Rechte des Patienten, unter anderem durch Vermehrung der gesundheitlichen Dienstleistungen und der Möglichkeiten des Zugangs zur Behandlung.

Vor der einheitlichen Überprüfung der Rechtssicherheitsnormen der Gesundheits- und Krankenpflege wollte die Regierung die Reformarbeit zu dem sogenannten Dienstleistungssystem der Gesundheits- und Krankenpflege zum Abschluß bringen. Diese Reformarbeit hat natürlich auch einen Einfluß auf die Rechtsstellung des Patienten, da bei der Entwicklung des Dienstleistungssystems die kommunale Selbstverwaltung eine Verstärkung erfuhr, indem die staatliche Steuerung in diesem Bereich verringert und besonders die Normensteuerung reduziert wurde. Auch bei der Inanspruchnahme der staatlichen Kostenbeteiligung ist die kommunale Beschlußfassung gestärkt worden. Und bei der Beschlußfassung über Fragen der Gesundheits- und Krankenpflege wurden gewisse Aufgaben und Zuständigkeiten von der staatlichen Verwaltung an die Ebene der Provinzialverwaltung delegiert.

In dem geschilderten Gesetzgebungsprogramm ist der Begriff der Rechtssicherheit wichtig gewesen: Ein Schutz, den die Rechtsordnung Personen und ihren Rechten gibt. Wie gut die Rechte eines Individuums in der Rechtsordnung eines Staates gesichert sind, wird von folgenden Umständen beeinflußt:

(a) Welche Rechte und Pflichten hat das Individuum gemäß der jeweiligen Rechtsordnung gegenüber anderen Individuen und Körperschaften?

(b) Durch welche Mittel kann das Individuum seine gesetzmäßigen Rechte erhalten und durchsetzen sowie Ansprüche abwehren, deren Erfüllung nicht zu seinen rechtlichen Pflichten gehört?

Bei der Verwirklichung der Rechtssicherheit im Gesundheits- und Krankenpflegewesen sind zwei Personengruppen voneinander zu unterscheiden: die Patienten und das Personal. Die Regelung der Rechtsstellung derer, die zur einen Gruppe gehören, hat gewöhnlich auch Einfluß auf die Rechtsstellung der Angehörigen der anderen Gruppe. So impliziert zum Beispiel die Gewährung eines bestimmten Rechtes für die Patienten im allgemeinen für die Angehöri- 
gen des Personals die Auferlegung einer gewissen Pflicht, und zwar auch dann, wenn die finanzielle Haftung in erster Linie bei den öffentlichen Körperschaften liegt, die die Gesundheitsdienste unterhalten.

Bei der Entwicklung des finnischen Rechtsschutzsystems im Gesundheits- und Krankenpflegewesen war man folgerichtig bestrebt, die Gegenüberstellung der Personengruppen zu vermeiden und nicht nur die Rechtssicherheit der Patienten zu verbessern, sondern auch diejenige der auf diesem Gebiet Tätigen. Das Vertrauen im Behandlungsverhältnis darf nicht in ein Mißtrauen umschlagen. Auf der anderen Seite ist daran zu erinnern, daß man in der Gesetzgebung, die die Erzeugung von Dienstleistungen für die Bürger und die Gewährung von Vorteilen betrifft, im allgemeinen bestrebt ist, vor allem die Stellung der schwächeren Partei, das heißt des Patienten, zu sichern.

Der erwähnte Ausgangspunkt hat sich in der Verwirklichung der finnischen Patientenrechtsgesetzgebung widergespiegelt. Die Kommission für Fragen der Rechtssicherheit innerhalb des Gesundheits- und Krankenpflegewesens, die 1982 ihren Bericht vorlegte, unterbreitete zweierlei Gesetzesvorschläge. Zum ersten schlug sie die Einführung eines gesetzlichen Patientenversicherungssystems nach schwedischem Modell vor; der andere Vorschlag betraf die Einführung eines Gesetzes über die Stellung und Rechte des Patienten (dafür gab es noch kein klares Vorbild). Folgende offizielle Begründungen wurden für die vorgeschlagenen Gesetze vorgebracht:

(a) Die Effektivierung und Technisierung sowie die zunehmend differenzierte Arbeitsteilung in der Gesundheits- und Krankenpflege haben die Wahrscheinlichkeit von Patientenschäden erhöht.

(b) Die Verbesserung des Entschädigungssystems für Patientenschäden sowie die Vereinheitlichung und Bestätigung der Rechte des Patienten sind zentrale Mittel, die Rechtssicherheit sowohl der Patienten als auch des Personals zu verbessern.

(c) Eine solche Regelung der Patientenrechte fördert das Vertrauensverhältnis zwischen diesen Personengruppen.

Zwei Gründe sprachen dagegen, auch in der Gesundheits- und Krankenpflege einem dem allgemeinen Schadensersatzrecht entsprechenden Haftungssystem eine ausreichend präventive Wirkung zuzuschreiben: Zum einen sei eine solche generalpräventive Wirkung bei den in Frage kommenden Fällen von nicht-grober Fahrlässigkeit fraglich; und zum anderen seien die Präventionswirkungen eher durch eine Verbesserung der Schulung und der ethischen Selbstkontrolle des Berufsstands sowie durch Entwicklung der beruflichen und administrativen Aufsicht über denselben anzustreben. 


\section{Zum Gesetz über Patientenschäden (1986)}

Das Gesetz über Patientenschäden wurde 1986 erlassen. Über die Nützlichkeit des Gesetzes bestand weitgehend Einigkeit. Nur die finanzielle Situation verzögerte den Erlaß des Gesetzes.

Der wichtigste Unterschied bezüglich der Grundlagen der Schadenshaftung gegenüber der früheren Rechtslage besteht darin, daß man niemandem mehr Fahrlässigkeit (Fehler oder Unterlassung) nachzuweisen braucht. Eine Ausnahme von diesem allgemeinen Grundsatz bilden die Fälle, in denen der Patient vorsätzlich oder durch grobe Fahrlässigkeit zur Entstehung des Schadens beigetragen hat - dann erhält der Patient keine Entschädigung aus der Patientenversicherung - oder der Schaden dem Patienten mit Vorsatz oder durch grobe Fahrlässigkeit zugefügt worden ist - dann kann die dem Patienten gezahlte Entschädigung beim Schadensverursacher zurückgefordert werden.

Bei der Bestimmung der Entschädigung wird, anders als bei der Sozialversicherung, der dem allgemeinen Schadensersatzrecht gemäße Grundsatz der vollen Entschädigung angewandt. So werden zum Beispiel Verdienstausfälle hundertprozentig erstattet und Schadensersatz wird auch für die immateriellen Schäden geleistet, etwa für Schmerz, bleibende Fehler oder Behinderung. Gemäß dem Gesetz über Patientenschäden wird jedoch kein Schadensersatz geleistet für geringfügige Schäden - das sind in der Praxis Schäden im Wert von weniger als 1.000 Finnmark - sowie für Sachschäden.

Der zu ersetzende Schaden, das heißt der sogenannte Patientenschaden, wird in den ersten Paragraphen des Gesetzes festgelegt. Es muß sich dabei um einen Personenschaden handeln, der dem Patienten im Zusammenhang mit der Gesundheits- oder Krankenpflege zugefügt worden ist. Als Patient wird auch jemand angesehen, der sich freiwillig einer klinischen medizinischen Untersuchung unterworfen hat. Ein eigentlicher Behandlungsfehler ist ein solcher, der mit Wahrscheinlichkeit durch die Untersuchung, durch medizinische und sonstige entsprechende Behandlung oder durch die Unterlassung einer solchen verursacht wurde. Als sogenannter Infektionsschaden wird ein Schaden entschädigt, der durch eine Ansteckung oder Entzündung verursacht wurde, die ihre Ursache in den Verhältnissen der Untersuchung, der medizinischen oder sonstigen entsprechenden Behandlung des Patienten hat. Entschädigt wird schließlich noch der sogenannte Unfallschaden, wenn der Unfall im Zusammenhang mit einer Untersuchung oder Behandlung gestanden hat, während des Krankentransports, bei einem Brand des Behandlungszimmers oder der Behandlungsgeräte oder im Zusammenhang mit einem anderen Schaden gesche- 
hen ist oder wenn der Unfall die Folge eines Fehlers der Krankenpflegegeräte oder -instrumente war.

Die allgemeine Voraussetzung der Patientenversicherung ist, daß die Folge einer Behandlung ungünstiger ist als der Zustand, der bei richtiger Behandlung der Krankheit zu erwarten gewesen wäre, die Folge also bei anderer Behandlung hätte vermieden werden können.

Im Zusammenhang mit der Gesundheits- und Krankenpflege können auch Schäden auftreten, die allein durch Medikamente verursacht werden. Solche Schäden werden gemäß dem Gesetz über Patientenschäden dann ersetzt, wenn sie durch ein falsches, dem Patienten verschriebenes oder verabreichtes Medikament oder durch falsche Dosierung des Medikaments verursacht worden sind. Dagegen wird ein Schaden, der durch ein Medikament verursacht wurde, dessen Verabreichung begründet war, aufgrund der Arzneimittelschadensversicherung ersetzt. Sie trat in Finnland im Jahre 1984 aufgrund eines Abkommens zwischen den Pharmaherstellern und -importeuren sowie den Versicherungsgesellschaften in Kraft.

In der Praxis sind folgende Ablehnungsgründe bei Schadensersatzanträgen vorgekommen: daß die Schadensfolge aus der Grundkrankheit herrühre und nicht aus ihrer Behandlung, daß der Unfall nicht mit der Behandlung in Verbindung gestanden habe, da $\beta$ der Schaden eine unumgängliche Komplikation der Behandlungsmaßnahme oder eine Folge des unvermeidlichen Risikos bei der Behandlung der Krankheit gewesen sei. Mit diesen Fragen sind Grenzziehungen verbunden, die auf Ermessen beruhen.

Gemäß dem Gesetz über Patientenschäden obliegt denjenigen die Versicherungspflicht, die gesundheits- und krankenpflegerische Tätigkeiten ausüben, das heißt den Betreibern der öffentlichen Gesundheits- und Krankenpflegedienste - in erster Linie Gemeinden und Gemeindeverbänden, über die staatliche Kostenbeteiligung auch dem Staat, sowie den privaten Pflegeeinrichtungen und Gewerbetreibenden.

Das bei der Entschädigung von Patientenschäden anzuwendende Verfahren sollte für den Antragsteller möglichst einfach sein. Für die Antragstellung wurden verständliche Formulare für die Schadensanzeige und den Entschädigungsantrag entwickelt, die leicht erhältlich sind, zum Beispiel in den verschiedenen Einrichtungen der Gesundheits- und Krankenpflege. Der Patientenversicherungsverein bearbeitet die Anträge relativ schnell. Ein mit der Stellungnahme des Vereins unzufriedener Antragsteller kann die Sache kostenlos beim Ausschuß für Patientenschäden behandeln lassen, einem in Verbindung mit dem Sozial- und Gesundheitsministerium tätigen neutralen 
Sachverständigengremium. Wer auch mit dem Beschluß dieses Ausschusses unzufrieden ist, kann gegen den Patientenversicherungsverein bei einem Gericht erster Instanz Klage erheben.

$\mathrm{Zu}$ den meßbaren positiven Wirkungen des Gesetzes gehört zum Beispiel, daß die Entschädigungsklagen, bei denen ein einzelner Schuldiger an einem Behandlungsfehler gesucht wird, fortgefallen sind, und auch strafrechtliche Klagen gegen das Personal sind viel seltener geworden.

Im Jahre 1997 erschien der Bericht einer Arbeitsgruppe, die vom Sozial- und Gesundheitsministerium eingesetzt worden war, um den möglichen Bedarf zur Reformierung des Gesetzes über Patientenschäden zu erörtern. Darin wird eine allgemeine Zufriedenheit mit dem geltenden Gesetz geäußert. Jedoch schlägt die Arbeitsgruppe auch einige Änderungen vor: Die Voraussetzungen der Schadenshaftung sollten teilweise genauer und eindeutiger formuliert werden. Dadurch würden die Gesamtkosten des Patientenversicherungssystems - jetzt ungefähr 100 Millionen Finnmark im Jahr, das heißt 20 Finnmark pro Einwohner - höchstens um 2 Millionen Finnmark zunehmen.

\section{Zum Gesetz über die Stellung und Rechte des Patienten (1992)}

Mit diesem Gesetz über Patientenrechte wurden die wichtigsten Grundsätze zur Behandlung und Betreuung des Patienten geklärt, vereinheitlicht und gestärkt. Es sollte sowohl den Interessen der Patienten wie denen des Personals dienen, wenn Meinungsverschiedenheiten über die Behandlung und Betreuung des Patienten möglichst flexibel in der jeweiligen Einrichtung der Gesundheits- oder Krankenpflege beigelegt werden können. Mit diesem Gesetz wurde ein neues Reaktionsmittel des Patienten eingeführt, die Beschwerde, sowie ein Patienten Ombudsmann-System gegründet.

Die ersten Meinungen zu diesem Gesetzesentwurf waren nicht so positiv wie zum Gesetz über Patientenschäden. Vor allem gab es Meinungsverschiedenheiten darüber, ob man Regelungen auf Gesetzesebene über die zentralen Rechte des Patienten benötige und wenn ja, ob es dann nicht besser wäre, die Pflichten des Gesundheits- und Krankenpflegepersonals festzulegen und klarere Sanktionsvorschriften für den Fall von Verstößen gegen diese Pflichten zu schaffen. Politisch war es offenbar von Bedeutung, daß die Gewerkschaft der Ärzte, der finnische Ärzteverband - der gegen Ende der 70er Jahre die Einführung eines Patientenversicherungssystems gefordert hatte - anfangs gegen den Erlaß eines besonderen Gesetzes über die Rechte des Patienten war. Gegen Ende der 80er-Jahre begann man im Sozial- und Gesundheitsministerium zu betonen, daß mehr Aufmerksamkeit auf die inhaltliche, qualitative 
Entwicklung der Dienstleistungen gerichtet werden solle. Dabei seien unter anderem die Individualität, Kontinuität, Vertraulichkeit und Gleichberechtigung bei den Dienstleistungen herauszustellen. Mit dem Gesetz über Patientenrechte könnten diese Ziele gefördert werden.

Nach allgemeiner Bewertung ${ }^{7}$ sind die wichtigsten Vorschriften des Gesetzes über Patientenrechte diejenigen, in denen die Information des Patienten, sein Selbstbestimmungsrecht, sein Datenschutz sowie sein Recht auf Einsichtnahme in die ihn betreffenden Dokumente geregelt werden. Als gewissen Kompromiß kann man ansehen, daß die Grundsätze über Behandlung und Betreuung des Patienten relativ unpräzise geregelt wurden und daß Sanktionsnormen in diesem Gesetz fehlen. Es war also die Absicht, „weiche“ Methoden für die Stärkung der Rechte des Patienten anzuwenden. Die wichtigste Wirkung scheint die Beeinflussung der Einstellungen von Patienten und Personal zu sein.

In der Weiterentwicklung des genannten Patientengesetzes sollte man die Reaktionsmittel des Patienten verstärken und das PatientenombudsmannSystem intensivieren. Bei der Stärkung des Selbstbestimmungsrechtes und anderer klassischer Rechte des Patienten ist es wichtig, die Bedeutung von Sanktionsandrohungen im Auge zu behalten und das Ganze nicht nur als symbolische Gesetzgebung zu sehen. Ich bin zum Beispiel der Ansicht, daß einige Stellungnahmen des Ausschusses für Patientenschäden in positiver Weise dazu beitragen, die dem Patienten gewährte Information zu vermehren. So hat der Ausschuß aufgrund einiger Entschädigungsanträge festgestellt, daß es nicht dem Patienten überlassen bleiben dürfe, den Nachweis einer unzureichenden Information zu erbringen, vielmehr hänge dieser Nachweis von den im Krankenbericht gemachten Eintragungen ab. Wenn diesen Eintragungen zufolge die verschiedenen Behandlungsalternativen im Gespräch mit dem Patienten nicht ausreichend erwogen worden sind, so kann der Mißerfolg der Behandlung eine Entschädigungspflicht nach sich ziehen, und zwar auch dann, wenn der Schaden die Folge einer unumgänglichen Komplikation ist, die an sich nicht zu einer Entschädigung nach dem Gesetz über Patientenschäden berechtigen würde.

\section{Schlußbemerkungen}

In Finnland wurde, als Teil eines langfristigen Reformprogramms, eine umfangreiche Patientenrechtsgesetzgebung verwirklicht. Auf diesem Gebiet ist

$7 \quad$ Vgl. z.B.: Pahlman et al. 1996: 593. 
Finnland ein führendes Land geworden. Gleichzeitig mit der Bestrebung, Stellung und Rechte des Patienten zu verstärken, wurden mit dieser Patientenrechtspolitik zwei maßgebliche Ziele verfolgt: das Vertrauen im Behandlungsverhältnis zwischen Patienten und Personal aufrechtzuerhalten und die qualitative Entwicklung der Dienstleistungen zu fördern. Was die Wirkungen der Gesetze über Patientenschäden (1986) und Patientenrechte (1992) betrifft, so sind die Erfahrungen im allgemeinen als positiv zu bezeichnen. Es ist jedoch wichtig, die Wirkungen dieser Gesetze ständig zu beobachten, zu bewerten und in den internationalen Meinungsaustausch zu bringen. Und es ist wünschenswert, die finnischen Erfahrungen im Rechtsvergleich zu nutzen. ${ }^{8}$

\section{Literaturverzeichnis}

BARNARD, K., 1996: Beyond Advocacy: W.H.O.'s patients' rights agenda for health protection and promotion and appropriate high quality care. Medicine and Law, vol. 15, S. 605-626.

LaHTI, Raimo, 1987: Rechtfertigungs- und Entschuldigungsprobleme im Bereich medizinischer Tätigkeit, in: A. Eser / G.P. Fletcher (Hrsg.), Rechtfertigung und Entschuldigung. Rechtsvergleichende Perspektiven II, Freiburg i.Br., S. 1415-1442.

Lahti, Raimo, 1988: Criminal Law and Modern Bio-Medical Techniques. General Report. Revue Internationale de Droit Pénal, vol. 59, S. 603-628.

Lahti, Raimo, 1990a. Strafrecht und Medizin, in: R. Lahti / K. Nuotio (Hrsg.), Towards a Total Reform of Finnish Criminal Law, Helsinki, S. 87-99.

Laht, RaIMo, 1990b. Politische Implikationen und Probleme einer nationalen Patientenrechtsgesetzgebung: Erfahrungen von Finnland, in : J.W. Pichler (Hrsg.), Einführung in die Patientenrechtspolitik, Böhlau Verlag, Wien, S. 73-85.

LAHTI, RAIMO, 1992: Life's beginnings: law and moral dilemmas, in: Law and moral dilemmas affecting life and death. Proceedings of the $20^{\text {th }}$ Colloquy on European Law, Glasgow, 10-12 September 1990, Council of Europe, Strasbourg, S. 60-81.

LaHTI, RaImo, 1994: Towards a Comprehensive Legislation Governing the Rights of Patients: The Finnish Experience, in: L. Westerhäll / C. Phillips (Hrsg.), Patients' Rights - Informed Consent, Access and Equality, Nerenius \& Santérus, Stockholm, S. 207-221.

8 Vgl. u.a.: Barnard 1996: 605 ff. 
Lahti, Raimo, 1995: The Finnish Patient Injury Compensation System, in: S.A.M. McLean (Hrsg.), Law Reform and Medical Injury Litigation, Dartmouth, Aldershot, S. 147-162.

Pahlman, I. ET Al., 1996: Three Years in Force: Has the Finnish Act on the Status and Rights of Patients Materialized? Medicine and Law, vol. 15, S. 591-603. 


\section{Medizinrecht in Finnland}

\section{Einleitende Bemerkungen}

Wenn man die Perspektiven des Medizinrechtes vom finnischen Gesichtspunkt aus betrachtet, ist einleitend folgendes zu bemerken. Einerseits ist seit den 80er Jahren die Gesetzgebung auf dem Gebiet der Gesundheits- und Krankenpflege intensiv weiterentwickelt worden. Das Gesetz über Patientenschäden vom Jahre $1986^{1}$ und das Gesetz über Patientenrechte vom Jahre $1992^{2}$ sind typische Beispiele für diese Entwicklung. Andererseits ist die Stellung des Medizinrechts als eigenständige Disziplin viel langsamer verstärkt worden. Bis jetzt gibt es keinen Lehrstuhl für Medizinrecht; der erste Privatdozent für Medizinrecht wurde Ende 1995 nominiert - und zwar an der Medizinischen Fakultät der Universität Tampere (der Nominierte war ein Verwaltungswissenschaftler, der sich in seinem Schaffen auf das Medizinrecht spezialisiert hatte) ${ }^{3}$. Die regelmäßige Unterrichtung in dieser Disziplin für Studenten an der Universität Helsinki wurde auf meine Initiative hin im akademischen Jahr 1996-97 begonnen, aber nur als ein Wahlfach und ohne festen Dozenten dafür. ${ }^{4}$

\section{Gründe für eine eigenständige Disziplin Medizinrecht}

Die klassischen Fragen des Medizinrechtes, das heisst diejenigen des Verhältnisses zwischen dem Patienten und dem Arzt (beziehungsweise dem sonstigen Pflegepersonal), betreffen mehrere Rechtsgebiete, wie z.B. das Zivil-, Straf-

1 Siehe zu diesem Gesetz (Nr. 585/1986) näher z.B. R. Lahti, The Finnish Patient Injury Compensation System, in: S.A.M. Mc. Lean (ed.), Law Reform and Medical Injury Litigation, Dartmouth, Aldershot 1995, S. 147-162.

2 Siehe über dieses Gesetz (Nr. 785/1992) näher z.B. R. Lahti: Towards a Comprehensive Legislation Governing the Rights of Patients: The Finnish Experience, in: L. Westerhälle \& C. Phillips (eds.), Patient's Rights - Informed Consent, Access and Equality. Nerenius \& Santérus, Stockholm 1994, S. 207-221 sowie I. Pahlman et al., Three Years in Force: Has the Finnish Act on the Status and Rights of Patients Materialized?, Med Law 15 (1996), 591-603.

3 Der betreffende Wissenschaftler ist Dr. I. Paaso. Zu seinen Publikationen siehe z.B. Current Challenges to the Principles of Medical Law and their New Interpretation, Med Law (1995) 14, 611-621.

4 Der Kursus wird unter meiner Leitung von den Mitgliedern einer Forschungsgruppe für Medizinrecht veranstaltet. 
und Verwaltungsrecht. Auch die Haftungs- und Kontrollsysteme gliedern sich traditionell in diese drei Gruppen: $\mathrm{Zu}$ erkennen ist eine Einteilung in zivil-, straf- und verwaltungsrechtliche Verantwortung und Sanktionen.

Eine so weit geführte Differenzierung ist jedoch - zumindest in Finnland problematisch geworden, weil die jüngste Entwicklung der Gesetzgebung auf dem Gebiet der Gesundheits- und Krankenpflege dieser Differenzierung nicht gefolgt ist. Kennzeichnend für diese Tendenz ist gewesen, daß die Stellung des Patienten einheitlich und umfassend - in einer integrativen Weise - geregelt wurde. Besonders deutlich ist dies im Gesetz über Patientenrechte zu bemerken: Dieses Gesetz betrifft sowohl die privatärztliche Tätigkeit als auch die öffentliche Gesundheits- und Krankenpflege. Nach landläufiger Meinung hätte dadurch die Beziehung zwischen Patient und Arzt mehr und mehr die Charakterzüge eines öffentlich-rechtlichen Rechtsverhältnisses angenommen. Auf der anderen Seite ist man der Ansicht gewesen, daß jenes Gesetz an erster Stelle ein privatrechtliches und ausdrücklich ein personenrechtliches Gesetz sei. Auch diese Meinungsverschiedenheit bei der Interpretation des Gesetzes zeigt, wie schwer es ist, die neue Gesetzgebung der traditionellen Einteilung in Rechtsgebiete gemäß zu klassifizieren.

Ein entsprechender Trend zur einheitlichen und umfassenden Regelung betrifft die Haftung für Patientenschäden. Es wurde dafür ein besonderes Gesetz erlassen und ein Patientenversicherungssystem eingeführt. Die Voraussetzungen für die Entschädigung weichen von den normalen Schadenersatzgründen ab, weil man keiner Person mehr ein Verschulden nachzuweisen braucht, obgleich bei der Festsetzung der Entschädigung dem allgemeinen Schadenersatzrecht gemäße Grundsätze angewandt werden. Andererseits sind die wichtigsten Verfahrensregeln vom Standpunkt des Patienten aus gesehen einfach und flexibel - entsprechend dem Gedanken einer dienstbereiten Administration. Das Entschädigungssystems wird von privaten Versicherungsgesellschaften (eigentlich einem Konsortium) verwaltet, aber dem öffentlich-rechtlichen Patientenversicherungsausschuß kommt eine wichtige Aufgabe bei der Vereinheitlichung der Praxis zu.

Diese finnischen Beispiele zeigen, wie die generelle Entwicklung der Gesetzgebung Wirkungen auf die wesentlichen Konzeptionen der jeweiligen Rechtsgebiete und ihre Rechtsdogmatik ausüben und dadurch Bedürfnisse für die Bildung neuer Begriffe sowie neuer Rechtsprinzipien und -theorien erzeugen kann. Zur Ergänzung der differenzierten traditionellen Rechtsgebiete und Rechtsdogmatik braucht man ein interdisziplinäres - sogar integratives Rechtsgebiet mit eigener Rechtsdogmatik: das Medizinrecht (oder Medizinund Gesundheitsrecht). 
Schon die einfache Tatsache, daß die medizinrechtliche Regulierung in vielen Ländern stark zugenommen hat, fordert die Entwicklung der diesbezüglichen Rechtswissenschaft heraus. Eine Forschungsaufgabe ist es dann, diese Zunahme der rechtlichen Regelung zu analysieren und zu erklären. Was Finnland betrifft, können mehrere Erklärungsfaktoren genannt werden.

1. In erheblichem Maße spiegelte die Gesetzgebung bis Ende der 80er Jahre die Bestrebungen des Wohlfahrtsstaates wider: Die vom öffentlichen Haushalt getragenen Dienstleistungen für die Bürger wurden gesetzlich vermehrt, während zugleich Planung und Organisation der staatlichen und kommunalen Funktionen konsequent entwickelt wurden ${ }^{5}$. Die jüngste Entwicklung in den 90er Jahren hat allerdings zu Sparmaßnahmen bei den öffentlichen Finanzen und zu einer „schlankeren“ Steuerung geführt. Die Ressourcen der Gesundheits- und Krankenpflege sind infolgedessen gekürzt worden. Zugleich hat sich der Einsatz der Ressourcen regional differenziert in einer Weise, die zu einer Schwächung der Stellung des Patienten geführt hat.

2. Die Zunahme medizinrechtlicher Regelungen scheint auch damit zusammenzuhängen, daß die individuellen Rechtsschutzgarantien ebenso wie die Rechte des Verbrauchers und damit auch die des Patienten in der öffentlichen Diskussion stärker als früher hervorgehoben werden. ${ }^{6}$ Auch die stärkere Betonung der Menschen- und Grundrechte hat eine in die gleiche Richtung gehende Wirkung. Während in der Anfangsphase des Gesetzgebungsprogramms, das Ende der 60er Jahre eingeleitet wurde, der Schwerpunkt noch auf der Behebung der grundlegenden Mängel lag, die mit den Freiheitsrechten des Patienten verbunden waren (zum Beispiel die Abschaffung der Zwangskastration und die teilweise Reformierung des Gesetzes über Geisteskranke), so begann man um die Wende der 70er und 80er Jahre Maßnahmen auch zur Verbesserung der Rechtsstellung des „normalen“ somatischen Patienten auszuarbeiten. Im Zuge dieser Entwicklung fanden auch solche Sektoren der medizinischen Tätigkeit Aufmerksamkeit, in denen es zentral weder um die Rechte des Kunden / Patienten beziehungsweise um die Verpflichtungen ihm gegenüber geht noch um starke Interessenkonflikte (anders als zum Beispiel

5 Siehe näher R. Lahti, Politische Implikationen und Probleme einer nationalen Patientenrechtsgesetzgebung: Erfahrungen in Finnland, in: J.W Pichler (Hrsg.), Einführung in die Patientenrechtspolitik, Wien 1990, S. 73-85 (75); idem, Finnland: Perspektiven der Patientenrechtspolitk, in: C. Kranich / J. Böcken (Hrsg.), Patientenrechte und Patientenunterstützung in Europa, Baden-Baden 1997, S. 21-30.

6 Siehe näher $R$. Lahti, Rechtfertigungs- und Entschuldigungsprobleme im Bereich medizinischer Tätigkeit, in: A. Eser / G.P. Fletcher (Hrsg.), Rechtfertigung und Entschuldigung, Rechtsvergleichende Perspektiven II, Freiburg 1987, S. 1415-1442 (1426). 
bei der Behandlung von Geisteskrankheiten und von ansteckenden Krankheiten). Die erwähnten Maßnahmen haben also dazu geführt, daß das Gesetz über Patientenschäden und zuletzt das Gesetz über Patientenrechte erlassen wurden. Für den Erlaß dieser Gesetze haben auch einige Wandlungen gesprochen, die sich in der Struktur des Gesundheits- und Krankenpflegewesens vollzogen haben: die Technisierung und Spezialisierung auf diesem Sektor sowie das quantitative Anwachsen der Krankenhäuser und sonstigen Behandlungseinrichtungen.

In den letzten Jahren sind viele Fragen des Medizin- und Gesundheitsrechts unter dem Gesichtspunkt der Menschenrechte und der Grundrechte geprüft worden - nicht zuletzt deswegen, weil Finnland 1990 der Europäischen Menschenrechtskonvention beigetreten ist und 1995 eine Totalreform der Grundrechte in der finnischen Verfassung verwirklicht wurde. In den neuen Rechtsvorschriften zu den Grundrechten ist eine Bestimmung enthalten, gemäß der die öffentliche Gewalt einem jeden Bürger ausreichende Sozial-, Gesundheits- und Krankenpflegedienste zu gewährleisten und die Gesundheit der Bevölkerung zu fördern hat. Der Inhalt dieser der öffentlichen Gewalt auferlegten Verpflichtung soll genauer in separaten Gesetzen und Vorschriften festgelegt werden, zum Beispiel in dem Gesetz über Patientenrechte.

3. Die Entwicklung der biomedizinischen Technologien hat neue Regelungsbedürfnisse mit sich gebracht und hat unter anderem die Mängel in dem Schutz, welchen die klassischen Freiheitsrechte bieten, sowie in den traditionellen Schutzobjekten des Strafrechts bloßgelegt. ${ }^{7}$ In das neue finnische Strafgesetz wird nach einem vorläufigen Entwurf ein Kapitel mit dem Titel „Über die Verletzung des menschlichen Embryos, Fötus und Erbguts“ aufgenommen werden, das außer dem illegalen Schwangerschaftsabbruch auch den illegalen Eingriff in den Embryo und das Erbgut regulieren würde. ${ }^{8}$

In der jüngsten Diskussion sind unter anderem die passive Euthanasie und das sogenannte Pflegetestament zur Sprache gebracht worden. Diese Diskussion hat die Auffassung verstärkt, daß es wichtig sei, die Rechtsordnung in einer Weise zu betrachten, die ihre Einheitlichkeit oder Integrativität betont.

7 Siehe z.B. R. Lahti, Criminal Law and Modern Bio-Medical Techniques, General Report, Revue Internationale de Droit Penal 1988, S. 603-628, und idem: Life's beginnings: law and moral dilemmas, in: Law and moral dilemmas affecting life and death, Proceedings of the 20th Colloquy on European Law, Glasgow, 10-12 September 1990, Strasbourg 1992, S. 60-81.

8 Siehe näher R. Lahti, Strafrecht und Medizin, in: R. Lahti / K. Nuotio (eds.), Towards a Total Reform of Finnish Criminal Law, Helsinki 1990, S. 87-99 (89-92). 
Der Meinungsaustausch hat der Auslegung gewisser Bestimmungen gegolten, die in dem neuen Gesetz über Patientenrechte und dem Kapitel über die Straftaten gegen das Leben und die Gesundheit des 1995 reformierten Strafgesetzes enthalten sind. In dem erstgenannten Gesetz werden die allgemeinen Prinzipien des Selbstbestimmungsrechtes des Patienten und seines Rechtes auf Information reguliert. Gesondert wird bestimmt, dass, wenn ein Patient z.B. wegen Bewußtlosigkeit nicht zu einer aktuellen Willensbildung imstande ist, er aber früher bereits ernsthaft und entschlossen seinen die Behandlung betreffenden Willen ausgedrückt hat, er nicht gegen seinen Willen behandelt werden darf. Einige Teilnehmer an dieser Diskussion haben die juristische Verbindlichkeit dieser Bestimmung in solchen Konfliktsituationen in Frage gestellt, in denen aufgrund der strafrechtlichen Vorschriften für den Arzt die Pflicht betsteht, den Patienten gemäß dem allgemein akzeptierten medizinischen Brauch zu behandeln. Die Bestimmung wurde dennoch in das Gesetz aufgenommen, um gerade diese ansonsten nicht regulierte Kollision der Pflichten in der Behandlungssituation zu lösen.

\section{Zusammenfassende Gesichtspunkte über den interdisziplinären Standort des Medizinrechts}

Der Standort des Medizinrechts ist nicht leicht zu definieren. Es ist interdisziplinär, aber zwischen welchen Rechts- und anderen Wissenschaftsfächern ist es angesiedelt? Das Medizinrecht sollte wohl wesentlich davon bestimmt sein, von welcher Art die rechtlichen Regelungen und deren juristische Systematisierung sind und wie die aktuellen Regelungsbedürfnisse beschaffen sind. Einerseits sind diese Bedürfnisse gemeinsam für die internationale Gemeinschaft und für Regionen (wie für Europa; als Beispiel sei an das Menschenrechtsübereinkommen zur Biomedizin des Europarates erinnert); andererseits variieren die Modelle der Regelungen nach den nationalen Traditionen.

Oben habe ich über die Entwicklung der Regelungen und die aktuellen Regelungsbedürfnisse vom finnischen Gesichtspunkt aus berichtet. Die Erfahrungen in Finnland sprechen für ein integratives Rechtsgebiet und eine juristische Systembildung dafür. Als Ergänzung dazu sei noch erwähnt, daß in Finnland der Anteil des öffentlichen Gesundheits- und Pflegewesens relativ hoch ist und daß traditionell die Anleitung und Überwachung des Pflegepersonals vorwiegend durch administrative Mittel erfolgen. Zivil- und strafrechtliche Klagen sind in Finnland selten, insbesondere nach dem Inkrafttreten des Gesetzes über Patientenschäden. Vor diesem Hintergrund betrachtet wird es verständlich, daß das Medizinrecht in Finnland häufig eng mit dem Sozialrecht und dem sonsti- 
gen Verwaltungsrecht verknüpft wird. Viele der auf diesem Gebiet Tätigen sprechen daher lieber vom Medizin- und Gesundheitsrecht.

Für die Verstärkung des Medizinrechts ist es äußerst wichtig, daß es in enger Wechselwirkung nicht nur mit den traditionellen Rechtsgebieten, sondern auch mit anderen Wissenschaftsfächern steht. $\mathrm{Zu}$ diesen gehören die Medizin, besonders die forensische Medizin und die Psychiatrie, sowie die Verwaltung der Gesundheits- und Krankenpflege, die Pflegewissenschaft, die angewandte Philosophie (besonders Medizinethik) und auch solche ganz neue Fächer wie Gesundheitssoziologie und -ökonomie. Vom finnischen Gesichtspunkt aus betrachtet ist es notwendig, wirksame Beziehungen mit den Repräsentanten der wichtigsten Institutionen dieser Fächer zu schaffen, um das Medizin- und Gesundheitsrecht als eigenes Fach mit einem Lehrstuhl etablieren zu können.

\section{Rückblick auf die neuere Entwicklung}

Der Standort des Medizinrechts ist während der letzten Jahre in Finnland gestärkt worden. Seit dem akademischen Jahr 1996/97 ist die regelmäßige Unterrichtung in dieser Disziplin an der Universität Helsinki fortgesetzt worden, obgleich bis auf weiteres nur als ein Wahlfach und ohne festen akademischen Lehrer dafür. 2001 ist eine neue medizinrechtliche Doktorarbeit über die Intimsphäre und den Datenschutz des Patienten erschienen; ${ }^{9}$ andere Dissertationen - über das Selbstbestimmungsrecht des Patienten, über die medizinische Forschung am Menschen sowie über die Stellung des menschlichen Embryos und Fötus - sind kurz vor der Vollendung. Der oben erwähnte Privatdozent I. Paaso ist im Herbst 2002 zur Ernennung als Professor für öffentliches Recht, insbesondere Medizinrecht, an der Universität Lapplands (Rovaniemi) für kompetent erachtet worden.

Im Hinblick auf das Medizinrecht ist das Menschenrechtsilbereinkommen zur Biomedizin des Europarates (4. April 1997) von großer Bedeutung. Finnland hat dieses Übereinkommen 1997 unterzeichnet, jedoch noch nicht ratifiziert. Dieser Aufschub ist jedoch nicht aus prinzipiellen Zweifeln erfolgt, sondern beruhte darauf, dass gewisse Gesetzesänderungen hierfür erforderlich sind und diese eine relativ lange Vorbereitungszeit erfordern. Ein in dieser Hinsicht besonders wichtiges Gesetz betrifft die medizinische Forschung an Menschen, Embryonen und Föten; dieses Gesetz wurde im Jahre 1999 erlassen. ${ }^{\mathbf{1 0}}$ Die

9 L. Lehtonen, The Patient's Right to Privacy (English Summary), Helsinki 2001. Lehtonen ist jetzt sowohl Dr. jur. als auch Dr. med.

10 Gesetz Nr. 488/1999, dessen englischsprachiger Titel lautet; Medical Research Act. Siehe auch R. Lahti, Country Report Finland, in: J. Taupitz (Hrsg.), Das Menschen- 
wachsende Bedeutung des Übereinkommens (sowie die Entwicklung der biomedizinischen Technologie) hat auch dazu beigetragen, dass das Begriffspaar Medizin- und Biorecht oft als die treffenste Benennung des neuen Rechtsgebiets angesehen wird.

rechtsübereinkommen zur Biomedizin des Europarechts - taugliches Vorbild für eine weltweit geltende Regelung?, Berlin 2002, S. 573-576. 



\section{Ärzliche Eingriffe und das Selbstbestimmungsrecht des Individuums}

\section{Einführung}

Ein charakteristischer Zug für die Entwicklung des Medizinrechts hat darin bestanden, dass die Stellung des Patienten und seine Rechte verstärkt worden sind. ${ }^{1}$ In Finnland sind die Reform der Gesetze über die Schwangerschaftsunterbrechung, die Sterilisation und Kastration (1970), das Gesetz über Patientenschäden (585/1986) sowie das Gesetz über die Stellung und die Rechte des Patienten (das so genannte Patientengesetz; 785/1992) bedeutende Schritte in dieser Entwicklung gewesen. Zugleich haben seit den 90er Jahren die Menschen- und die Grundrechte begonnen, in der Gesetzgebung und im Rechtsdenken allgemein eine stärkere Rolle zu spielen. Den wichtigsten medizin- und biorechtlichen Ausdruck hat diese Entwicklung in dem Europäischen Übereinkommen über Menschenrechte und Biomedizin² (im Folgenden kurz das Biomedizin-Übereinkommen) gefunden, das am 4. April 1997 unterzeichnet wurde, auch wenn Finnland es bislang noch nicht ratifiziert hat. Dieses Übereinkommen ergänzt die Konvention zum Schutze der Menschenrechte und Grundfreiheiten (kurz die europäische Menschenrechtskonvention, EuMRK; 1950, 1998) im Gebiete der Biomedizin, und seine Wirkung begrenzt sich nicht auf die Staaten, die es in Kraft gesetzt haben. ${ }^{3}$ Zur Ergänzung des Biomedizin-Übereinkommens sind zudem Zusatzprotokolle über das Klonen von menschlichen Lebewesen, über den Gebrauch von menschlichen Organen und

1 Zu Überblicke über das Thema siehe z.B. Lahti, Finnland: Perspektiven der Patientenrechtspolitik, in: Kranich / Böcken (Hrsg.), Patientenrechte und Patientenunterstützung in Europa, 1997, S. 21; Roscam Abbing, Rights of Patients in the European Context, European Journal of Health Law 11 (2004), S. 7.

2 Convention for the Protection of Human Rights and Dignity of the Human Being with regard to the Application of Biology and Medicine (Convention on Human Rights and Biomedicine), European Treaty Series (ETS) 164. Das Übereinkommen trat international am 1.12.1999 in Kraft.

3 Siehe näher Eser (Hrsg.), Biomedizin und Menschenrechte, 1999; Taupitz (Hrsg.), Das Menschenrechtsübereinkommen zur Biomedizin des Europarates - taugliches Vorbild für eine weltweit geltende Regelung? 2002; Gevers, Hondius \& Hubben (eds.), Health Law, Human Rights and the Biomedicine Convention, 2005. 
menschlichem Gewebe sowie über die biomedizinische Forschung abgefasst worden. ${ }^{4}$

Von den Rechten des Patienten wird im Allgemeinen das Selbstbestimmungsrecht (die Autonomie) des Patienten als besonders bedeutsam hervorgehoben. In geringfügiger Abweichung von dieser Akzentuierung werden im Artikel 1 des Biomedizin-Übereinkommens als Gegenstand und Ziel des Übereinkommens der Schutz der Würde (dignity) und der Identität aller menschlichen Lebewesen sowie die Wahrung ihrer Integrität und ihrer sonstigen Rechte und Grundfreiheiten in den Anwendungen der Biologie und Medizin festgelegt. ${ }^{5}$ In dem am 29. Oktober 2004 von der Europäischen Union unterzeichneten Übereinkommen steht im Band II der Grundrechtecharta als Titel des Kapitels I die Würde des Menschen, und die Artikel II-61 und 63 bestimmen die Unverletzlichkeit der Menschenwürde sowie das Recht auf persönliche Integrität. Das in Artikel 8 der EMRK genannte Recht auf Achtung des Privat- und Familienlebens enthält in der Praxis des Europäischen Gerichtshofes für Menschenrechte (EGMR) auch das Recht auf persönliche Integrität und das Selbstbestimmungsrecht des Individuums. ${ }^{\mathbf{6}}$

In Anbetracht des Obigen habe ich für die Überschrift das Selbstbestimmungsrecht des Individuums ${ }^{7}$ gewählt, um den Kerngehalt desjenigen Rechtes zu beschreiben, dessen Rechtsentwicklung ich im Lichte finnischer Regelungsbeispiele beleuchten möchte. Ich behandle in meinen Beispielen nicht nur den Schutz des Patienten vor Verletzungen seiner Menschenwürde und seines Selbstbestimmungsrechtes. In meinen Beispielen geht es um ärztliche Eingriffe in das Selbstbestimmungsrechts des Individuums, mit anderen Worten: die betrachteten, unabhängig von dem Willen des Behandelten vorgenommenen Maßnahmen haben die Mitwirkung eines Arztes vorausgesetzt. Von daher richte ich meine Aufmerksamkeit nicht nur auf die Stellung des Patienten, sondern auch auf die des Arztes. Die Beispiele beschreiben die Entwicklung des Medizinrechtes, da in den zu betrachtenden Situationen eine nicht zufrie-

$4 \quad \mathrm{Zu}$ diesen Zusatzprotokollen siehe ETS 168 (12.1.1998), ETS 186 (24.1.2002) und ETS 195 (25.1.2005).

5 Siehe jedoch Dute, in: Health Law, Human Rights and the Biomedicine Convention (a.a.O. Fn. 3), S. 3, 10: „Apparently, the principle of individual self-determination ist the core of the Convention".

6 Siehe EGMR Pretty gegen das Vereinigte Königreich (29.4.2002), Punkt 61.

7 In dem führenden medizinrechtlichen Werk im englischen Recht leitet Andrew Grubb die Achtung der körperlichen Unversehrtheit des Menschen aus dessen Selbstbestimmungsrecht ab und sieht dieses (,that every person's body is inviolate“) als das Grundprinzip an. Siehe Grubb, Consent to Treatment: Competent Patient, in: Grubb \& Laing (eds.), Principles of Medical Law, 2004, Kapitel 3, besonders die Abschnitte 3.01-3.09. 
den stellende oder unterschiedlich interpretierbare Regelung zu legislativen Reformen geführt oder zumindest einen Anlass zu rechtspolitischen Erwägungen geboten haben. Im Hintergrund aller Beispielssituationen hat in der Hinsicht auch meine persönliche Erfahrung gestanden, da ich in unterschiedlichen Funktionen zu den in ihnen bezeichneten Regelungslösungen oder Auslegungsstellungnahmen (in der Weise wie in dem jeweiligen Abschnitt dargestellt wird) beigetragen habe.

Die Beispielssituationen sind die folgenden: die Streichung der Zwangskastration aus dem Gesetz über die Verstärkung des Geschlechts (Abschnitt 2); die Verstärkung des Selbstbestimmungsrechtes des Patienten (3) und die dieses sichernden Rechtsbehelfe (4). In den Schlussfolgerungen (5) möchte ich die Ergebnisse meiner Betrachtung konzentriert darlegen und einige rechtspolitische Aspekte vorbringen.

\section{Zur Streichung der Zwangskastration aus dem Gesetz über die Verstärkung des Geschlechtes von Transsexuellen}

Dem Komitee über das Abtreibungsgesetz, das in den Jahren 1967-1968 unter dem Vorsitz der Professorin Inkeri Anttila zusammenkam, hatte man die Aufgabe gestellt, eine Reform der im Jahre 1950 erlassenen Gesetze über die Schwangerschaftsunterbrechung, die Sterilisation und die Kastration auszuarbeiten. ${ }^{8}$ Das zentrale Ziel bei der Reformierung dieser Gesetze war es, das Selbstbestimmungsrecht des Individuums zu verstärken und die von den Gesetzen über die Sterilisation und die Kastration erlaubten Zwangsmaßnahmen abzuschaffen. ${ }^{9}$ Dieses Ziel spiegelte die gegen Ende der 60er Jahre begonnene gesellschafts- und kontrollpolitische Diskussion wider, in der aus dem Gesichtswinkel des Rechtsschutzes des Individuums die Zwangsmaßnahmen kritisiert wurden, und zwar ungeachtet dessen, ob sie als Strafe oder im Namen von Fürsorge und Behandlung verfügt worden waren. Diese Diskussion hatte eine erhebliche Auswirkung auf die später durchgeführten

8 Siehe den Bericht des Abtreibungsgesetzeskomitees. Komiteebericht 1968: A 11(1969). - Ich fungierte als Sekretär dieses Komitees sowie als stellvertretender Sekretär des Wirtschaftsausschusses des Parlamentes bei der Behandlung der genannten Gesetze.

9 Siehe genauer Lahti, Vuoden 1970 abortti-, sterilisaatio- ja kastraatiolainsäädäntö (Die Gesetzgebung vom Jahre 1970 über die Schwangerschaftsunterbrechung, die Sterilisation und die Kastration), in: Festskrift utgiven i anledning av Juristklubben Codex' 30årsjubileum, Helsingfors 1970, S. 67. 
gesetzgeberischen Reformen im Bereich des Strafrechts sowie des Sozial- und Gesundheitswesens. ${ }^{\mathbf{1 0}}$

Zwangskastrationen (die Entfernung oder Zerstörung von Geschlechtsdrüsen) hatte man besonders in den frühen fünfziger Jahren für Personen verfügt, die wegen ihres Geschlechtstriebs als gefährlich galten - an erster Stelle Sexualstraftäter - und zwar ungeachtet ihres Willens. Die Streichung der Zwangskastration aus dem Gesetz wurde in erster Linie damit begründet, dass eine solche Maßnahme, die tief in die körperliche Unversehrtheit des Individuums eingreift, die Rechte des Individuums stärker verletzte als vom Standpunkt der Gesellschaft aus für notwendig erachtet wurde. Ein unabdingbarer Bedarf an Zwangskastrationen hat nicht bestanden, da aufgrund der Gerichtsstatistiken die Rückfallquote bei Sexualstraftaten gering war und da man mit diesen Maßnahmen nicht einmal die erhofften therapeutischen oder kriminalpräventiven Wirkungen erzielt hat. ${ }^{11}$ Als Begründung appellierte man also an den Schutz der körperlichen Unversehrtheit, der in dem im $\S 6$ der damaligen Regierungsform (1919) ${ }^{\mathbf{1 2}}$ festgeschriebenen Grundrecht - dem Schutz des Lebens und der persönlichen Freiheit - mit enthalten war, aber diese Vorschrift wurde nicht ausdrücklich genannt und ihre grundgesetzlichen Einschränkungsvoraussetzungen wurden nicht erwogen.

In der finnischen Diskussion hatte der Strafrechtler Bruno A. Salmiala schon in einem 1951 veröffentlichten Artikel die Zwangskastration vehement kritisiert und dabei auf die Grundsätze des Rechtsstaates und der Humanität sowie auf Beispiele aus verschiedenen Ländern verwiesen, in denen die Gesetze über die Zwangskastration als Menschenrechtsverletzungen oder als Verstöße gegen das im Grundgesetz festgeschriebene Verbot von grausamen und unmenschlichen Strafen aufgehoben worden waren. ${ }^{\mathbf{1 3}}$ Der Verfassungsprofessor Paavo Kastari hat sich in seiner Schrift über den grundgesetzlichen Schutz der Bürgerrechte mit gutem Grund gewundert, warum man bei einer solchen Kritik nicht direkt an die Grundrechtsvorschriften der Regierungsform und ihre

10 Zu dieser Diskussion siehe Lahti, Voluntary or Compulsory Treatment? in: Jus Medicum 7:II, Gent 1982, S. 23.

11 Siehe Komiteebericht 1968: A 11 S. 77-79 und die Regierungsvorlage 106/1969.

12 Die Regierungsform war bis zur Einführung des neuen Grundgesetzes (731/1999) das wichtigste Grundgesetz Finnlands.

13 Salmiala, Onko pakkokastratio oikeus- ja kulttuurivaltiossa hyväksyttävä reaktiomuoto rikoksen seurauksena (Ist die Zwangskastration in einem Rechts- und Kulturstaat annehmbar als eine Reaktionsform infolge von Verbrechen)? Defensor Legis 32 (1951), S. 130. 
Einschränkungsvoraussetzungen (wie die von einer Einschränkung eines Grundrechtes geforderte qualifizierte Gesetzgebungsordnung) appelliert hat. ${ }^{14}$

Freiwillige Kastration ist auch in dem neuen Gesetz (282/1970) zulässig geblieben, wobei man damit ausschließlich eine solche Kastration gemeint hat, die aus ernsthaftem Ersuchen der betroffenen Person vorgenommen wurde, die das 20. Lebensjahr vollendet hat und die nicht geisteskrank, geistig schwer behindert oder seelisch schwer gestört gewesen ist. Das Zentralamt für Gesundheitswesen hat einem derartigen Ersuchen stattgeben können, wenn Grund zu der Annahme bestand, dass dem Antragsteller aus seinem Geschlechtstrieb schwere seelische Leiden erwachsen und nur eine Kastration diese mildern könnte. Als man diese Voraussetzungen niederschrieb, hat man transsexuelle Personen - also solche Personen, die zum Zweck einer Geschlechtsumwandlung einen genitalchirurgischen Eingriff beantragen - nicht in Betracht gezogen, da man sich der besonderen Bedürfnisse dieser Menschen nicht bewusst war.

In den 80er Jahren begann man jedoch aufgrund von einzelnen Anträgen, dieses Gesetz auch auf diese Personen - und nur auf diese Personen - anzuwenden, nachdem man sich im Jahre 1984 strenge Kriterien zu den Voraussetzungen, die gegeben sein mussten, zu Eigen gemacht hatte (vor allem was die medizinische Diagnosestellung der Transsexualität, die Ernsthaftigkeit der Entscheidung des Antragstellers, den Ausschluss einer späteren Reue und die Prognose bezüglich des Gelingens der Geschlechtsumwandlungsoperation betraf). ${ }^{15} \mathrm{Zu}$ Anfang des Jahres 2003 trat das Gesetz über die Verstärkung des Geschlechts von Transsexuellen (563/2002) in Kraft, wodurch zugleich das Kastrationsgesetz aufgehoben wurde. Das neue Gesetz verlangt, dass die Verstärkung des Gegengeschlechts zum biologischen Geschlecht des Antragstellers auf einer medizinischen Klärung der Transsexualität und auf verschiedenen im Gesetz aufgeführten zusätzlichen Kriterien beruht (wie zum Beispiel auf der Fortpflanzungsunfähigkeit und der Volljährigkeit der jeweiligen Person).

Das Interessante an der beschriebenen gesetzgeberischen Entwicklung ist die sehr starke Verstärkung des Selbstbestimmungsrechts des Individuums: Zuerst wird die die körperliche Unversehrtheit und die geschlechtliche Identität

14 Kastari, Kansalaisvapauksien perustuslainturva (Der verfassungsmäßige Schutz der Bürgerrechte), Vammala 1972, S. 157.

15 Ich fungierte als ein rechtskundiges Mitglied in dem sachverständigen Organ des Zentralamtes für Gesundsheitswesen beinahe die ganze Geltungsdauer des Kastrationsgesetzes. 
verletzende Sicherungsmaßnahme, das heißt die gegen den Willen des Betroffenen erfolgende Entfernung der Geschlechtsdrüsen, verboten. Als Ergebnis der Entwicklung wird eine Geschlechtsumwandlungsoperation erlaubt, und zwar aufgrund einer Diagnose auf Transsexualität, welche als Störung angesehen wird - und als eine dieser Diagnose angemessene genitalchirurgische Behandlung -, und dem Betroffenen wird zur Sicherung der transsexuellen Identität und zum Schutz gegen Diskriminierung der Schutz des Privatlebens gewährt.

Bei der Ausarbeitung des genannten Gesetzes aus dem Jahre 2002 wurden die Vorschriften des Menschenrechtsübereinkommens und des Grundgesetzes über das jedem Menschen zukommende Selbstbestimmungsrecht berücksichtigt. Aus der Praxis des Europäischen Gerichtshofes für Menschenrechte wurde geschlossen, dass der vom Artikel 8 des EuMRK gewährleistete Schutz des Privatlebens vom Staat die Anerkennung der geschlechtlichen Identität des Menschen bei solcher behördlichen Tätigkeit verlangt, bei der das Geschlecht von Bedeutung ist. Man war jedoch noch nicht zu der Ansicht vorgedrungen, dass diese deutliche Stellungnahme des Gerichts sich auch auf den Zusammenhang zwischen der transsexuellen Identität und den Schutz des Privatlebens erstreckt. ${ }^{16}$ In der Entscheidung des EGMR Christine Goodwin gegen das Vereinige Königreich (11. Juli 2002) wurde der Rechtszustand klarer gestaltet: Das Recht auf Achtung des Privatlebens einer Person, die sich von einem Mann in eine Frau hatte umwandeln lassen, und ihr Recht auf Eheschließung (MRÜ Artikel 8 und 12) waren dem EGMR zufolge verletzt worden, da die Geschlechtsumwandlung und die Ehe mit einem Mann rechtlich nicht anerkannt worden war.

Nach herkömmlicher Rechtsauffassung hat der Mensch nicht völlig frei über seine körperliche Unversehrtheit bestimmen können, mit anderen Worten: die vorsätzliche Selbstschädigung ist in solchen Fällen als verboten angesehen worden, bei denen die Tat schwerwiegende oder unbehebbare Folgen hatte und bei denen ein hohes Risiko der Reue bestand. ${ }^{17}$ Die beschriebene Rechtsentwicklung, die das Selbstbestimmungsrecht des Individuums betont, schränkt den Bereich der verbotenen Selbstschädigung ein und entspricht somit auch

$16 \mathrm{Zu}$ den Dokumenten der Ausarbeitung des Gesetzes von 2002 siehe besonders Regierungsvorlage 56/2001. Siehe im Allgemeinen Transsexualism, medicine and law, Council of Europe 1995.

17 Vgl. zur deutschen Rechtslage, z.B. Eser, Rechtfertigungs- und Entschuldigungsprobleme im Bereich medizinischer Tätigkeit, in: Eser / Fletcher (Hrsg.), Rechtfertigung und Entschuldigung II, 1988, S. 1443; Jescheck / Weigend, Lehrbuch des Strafrechts, Allgemeiner Teil, 5. Aufl. 1996, § 34, III (Einwilligung bei der Körperverletzung). 
der Rechtsauffassung, der zufolge Eingriffe in die körperliche Unversehrtheit, bei denen die Einwilligung des Betroffenen vorliegt, als nicht strafbar zu gelten haben (siehe unten den Abschnitt 3). Bei der Beurteilung der Gesetzesvorlage des Jahres 2002 habe ich die Ungenauigkeit der Regelung auf Gesetzesebene und ihre Uneinheitlichkeit in der Praxis der Anwendung des Verfahrens der Verstärkung des Geschlechts kritisiert, die sich daraus ergab, dass in dezentralisierter Form die Magistrate der Städte darüber bestimmten. ${ }^{18}$

\section{Zur Verstärkung des Selbstbestimmungsrechts des Patienten}

Über das Selbstbestimmungsrecht des Patienten ist ausführlich geschrieben worden. ${ }^{19}$ Im Folgenden erörtere ich eigene Beobachtungen und stütze mich dabei auf die schrittweise erfolgte Verstärkung dieses Prinzips: von den behördlichen Stellungnahmen, die das Prinzip anerkennen, bis zur Regelung der Stellung des Patienten im Patientengesetz sowie in einem separaten Abschnitt (4) bis zu den Rechtsbehelfen, die diese Regelung mit sich bringt. Als Ausgangspunkt für die Betrachtung der finnischen Entwicklung eignet sich ein Artikel von Inkeri Anttila zu dem Thema aus dem Jahre 1944: „Benötigt der Arzt zur Durchführung seiner Aufgabe die Einwilligung des Patienten?“ Auf dasselbe Thema ist Anttila zwei Jahre später in ihrer Dissertation zurückgekommen. ${ }^{20}$ Anttilas zentrale Schlussfolgerung war die, dass ein vom Arzt vorgenommener Heileingriff nicht den Tatbestand der Körperverletzung erfülle, dass aber die Einwilligung des Patienten die Voraussetzung für die rechtmäßige Tätigkeit des Arztes sei. Anttila hielt es in einem Rechtsstaat für selbstverständlich, dass das Individuum das Recht haben müsse, über eine so persönliche Sache wie die Fürsorge für die eigene Gesundheit selbst zu entscheiden. ${ }^{21}$

18 Mein Sachverständigengutachten an den Gesetzesausschuss des Parlaments vom 21.2.2002 aufgrund der Regierungsvorlage 56/2001.

19 Z.B. in den nordischen Ländern sind drei Monographien (Dissertationen) geschrieben worden: Rynning, Samtycke till medicinsk vård och behandling, Uppsala 1994; Sinding Aasen, Pasientens rett til selvbestemmelse ved medisinsk behandling; Pahlman, Potilaan itsemääräämisoikeus (Das Selbstbestimmungsrecht des Patienten), Helsinki 2003. Siehe auch Lahti, Rechtfertigungs- und Entschuldigungsprobleme im Bereich medizinischer Tätigkeit, in: Rechtfertigung und Entschuldigung II, a.a.O. (Fn. 17), S. 1415, 1427; Eser, ibid. S. 1451.

20 Anttila, Lakimies 42 (1944), S. 1; dies., Loukatun suostumus oikeudenvastaisuuden poistavana perusteena (Die Einwilligung des Verletzten als Rechtfertigungsgrund), Vammala 1946, S. 172.

21 Anttila, a.a.O. (Fn. 20), S. 174. 
Anttila hat sich in ihren Stellungnahmen in erster Linie auf die deutsche Strafrechtsdoktrin gestützt. ${ }^{22}$ Die Auffassung von der Nichterfüllung des Tatbestands der Körperverletzung wegen der sozialen Nützlichkeit (soziale Adäquanz) des Arztes hat sich bei uns ebenso stark eingebürgert wie die Auffassung, dass es dem Arzt obliegt, die Einwilligung des Patienten einzuholen, und diese Aspekte haben die späteren gesetzgeberischen Entscheidungen beeinflusst (siehe unten). Es sei hier angemerkt, dass eine richtungweisende Entscheidung für die Einwilligungslehre des Common-law-Rechtes bereits aus dem Jahre 1914 vorliegt, als der Richter Cardozo in dem Fall Schloendorff gegen die Society of New York Hospital das Recht des Patienten bekräftigte, über seine körperliche Unversehrtheit zu bestimmen. ${ }^{23}$ In der ärztlichen Ethik, bei der traditionell im paternalistischen Geiste die Förderung der Gesundheit des Patienten betont wurde, hat sich der Grundsatz des Selbstbestimmungsrechts des Patienten erst dann zu verstärken begonnen, als in den Beschlüssen des Internationalen Militärgerichtshofes bei den Nürnberger Prozessen die so genannten Nürnberger Vorschriften über die Durchführung von medizinischen Experimenten an Menschen bestätigt worden waren. Dieselben Vorschriften waren auch für die Entwicklung der ,informed consent"-Lehre im Medizinrecht der angelsächsischen Länder von Bedeutung. ${ }^{24}$ Die Forderung nach Einwilligung der Versuchsperson wurde danach auch in die 1966 angenommenen Konvention der Vereinten Nationen (UNO) über bürgerliche und politische Rechte aufgenommen (im Artikel 7 der Konvention). ${ }^{\mathbf{2 5}}$

Die erste deutliche behördliche Stellungnahme im Sinne der von Anttila vertretenen Einwilligungslehre bestand in einer vom Ombudsmann des Parlaments im Jahre 1973 entschiedenen Beschwerde. ${ }^{26}$ In seinem aufgrund der Beschwerde erstellten Gutachten war das Zentralamt für Gesundheitswesen

22 Zur gegenwärtigen Situation in der deutschen Doktrin siehe z.B. Eser, in: Rechtfertigung und Entschuldigung II, a.a.O. (Fn. 17); Jescheck / Weigend, a.a.O. (Fn. 17).

23 Die häufig zitierte Stelle in diesem Beschluss (1914) 211 NY 125 lautet: „Every human being of adult years and sound mind has a right to determine what shall be done with his own body; and a surgeon who performs an operation without his patient's consent commits an assault, for which he is liable in damages". Zu dem Beschluss und seinen Auswirkungen siehe Grubb, in: Principles of Medical Law, a.a.O. (Fn. 7), Punkt 3.04.

24 Zur gegenwärtigen Common-law-Rechtslage, was „informed consent“ betrifft, siehe z.B. Mason \& McCall Smith's Law and Mecical Ethics, 7th ed. (by Mason \& Laurie), 2006, Kapitel 10.

25 Als eine im genannten Artikel 7 bezeichnete unmenschliche Behandlung wurde u.a. die Zwangssterilisation von Frauen angeführt. Zur Praxis des UN-Menschenrechtskomitees siehe Joseph et al., The International Covenant on Civil and Political Rights, Cases, Materials and Commentary, 2nd ed., 2005, S. 254.

26 Siehe den Bericht des Ombudsmanns des Parlaments aus dem Jahre 1973, S. 19. 
der Ansicht gewesen, dass die Willensbekundung des Patienten nicht immer eine den Arzt absolut bindende Bedeutung haben könne. So habe zum Beispiel bei einer Operation der Arzt erst im Verlauf der Operation die endgültige Entscheidung über den angemessenen Eingriff zu treffen. Nach Erachten des Ombudsmanns Kaarlo L. Ståhlberg war die Bedeutung der Willensbekundung des Patienten von dem Standpunkt aus zu evaluieren, dass ,unser Rechtssystem diesbezüglich auf die körperliche Unversehrtheit des Menschen und den damit verbundenen Grundsatz des Selbstbestimmungsrechts aufbaut". Eine Abweichung davon sei nicht auf das objektive Interesse des Patienten oder auf die analoge Anwendung der Vorschriften betreffend die Erste-Hilfe- und die Behandlungspflichten des Arztes zu gründen. Eine entsprechende Auffassung habe ich in einem 1972 veröffentlichten Artikel zum Ausdruck gebracht, in dem ich die auf die Stellung des Patienten anzuwendenden Grundsätze der körperlichen Unversehrtheit und des Selbstbestimmungsrechts aus dem $\S 6$ der Regierungsform abgeleitet habe. ${ }^{27}$

Dieser Beschluss des Ombudsmanns hat sich rasch auf die Politik des Zentralamtes für Gesundheitswesen ausgewirkt. In einer Entscheidung einer Beschwerde aus dem Jahre 1975 ist das Zentralamt der Auffassung des Ombudsmanns gefolgt: Auch wenn die Entfernung eines Tumors, den man während einer Operation entdeckt hat, als medizinisch begründet und als einen im Voraus betrachtet für den Patienten völlig ungefährlichen Eingriff ansehen könnte, so müsse man dafür zuerst die Einwilligung des Patienten einholen, sofern bei der Entfernung des Tumors keine Dringlichkeit geboten oder sofern die Maßnahme nicht unbedingt erforderlich sei. Der Standpunkt, der das Selbstbestimmungsrecht von Patienten und Versuchspersonen anerkannte, wurde gegen Ende der 70er Jahre in Richtschreiben des Zentralamtes über die klinischen Untersuchungen von Medikamenten (6814/02/78) und über die Stellung des Unterrichtspatienten (7023/02/79) ausgedrückt. Diffiziler gelagert waren die Fälle, zu denen das Zentralamt für Gesundheitswesen um den Wechsel der 70er und 80er Jahre Stellung zu beziehen hatte. In einem Fall ging es um die Verweigerung der Annahme von Bluttransfusionen, in einem anderen Fall um die Einstellung zur Zwangsernährung eines Strafgefangenen, der in den Hungerstreik getreten war. ${ }^{28}$

27 Siehe Lahti, Potilaalta hoitotoimenpiteeseen hankittavan suostumuksen oikeudellista arviointia (Die Einwilligung des Patienten zur Heilbehandlung in rechtlicher Würdigung), in: Rikosoikeudellisia kirjoituksia III, Vammala 1972, S. 64.

28 In beiden Fragen hatte ich dem Zentralamt für Gesundheitswesen ein Sachverständigengutachten erteilt; siehe meine Gutachten vom 8.8.1980 (6930/102/79) und vom 28.7.1981 (4545/101/81). 
Die Schwierigkeit bei der Erwägung dieser Fälle liegt in der Kollision von Rechten und Pflichten, die zum Teil in unterschiedliche Richtungen weisen. In beiden Fällen entsteht ein Konflikt in der Situation, wo der Patient oder Gefangene wegen Bewusstlosigkeit oder eines sonstigen derartigen Grundes nicht mehr zu einer aktuellen Willensbildung in der Lage ist, auch wenn er zu einer früheren Phase seinen festen Willen kundgetan hatte. Wiegt dann die Pflicht, die auf religiöser Überzeugung des Patienten basierende Verweigerung der Annahme von Bluttransfusionen zu respektieren, mehr als die aus der Rechtsordnung abzuleitende Pflicht bzw. das Recht, sein Leben zu retten? Lässt sich der Strafgefangene, der mittels Zwang und unter Nutzung medizinischen Sachverstandes zu ernähren ist, mit dem Patienten vergleichen, also wenn eine ähnliche Ermessenssituation vorliegt wie bei dem Zeugen Jehovas, der sich weigerte, Bluttransfusionen anzunehmen? ${ }^{29}$

Meine Antwort in den Gutachten bestand darin, der Pflicht des Arztes den Vorrang vor dem Selbstbestimmungsrecht des Patienten und des Gefangenen einzuräumen, wenn kein Grund zu der Annahme besteht, dass der Wille des Betroffenen bei der Erwägung des ärztlichen Eingriffs in der kritischen Phase einen anderen Inhalt hätte. Auf der anderen Seite könnte man das Recht des Arztes, eine derartige, in Lebensgefahr befindliche Person zu retten, auch mit dem Notstand begründen. In seinen Stellungnahmen vom 9. Oktober 1980 und 31. Juli 1981 ist das Zentralamt für Gesundheitswesen zu Schlüssen gelangt, die das Selbstbestimmungsrecht des Patienten und des Gefangenen betonten. Die Schussfolgerungen wichen von früheren behördlichen Auslegungen ab, in denen den rechtlichen Aspekten, die für die Pflicht der Lebensrettung sprachen, beim Vorliegen eines kritischen Zustands der Vorrang eingeräumt worden war. Der Standpunkt, auf eine Zwangsernährung von Gefangenen zu verzichten, wurde zentral in der Erklärung begründet, die 1995 in Tokio vom Weltärztebund verabschiedet wurde und der zufolge eine Person, die die Folgen der Verweigerung der Nahrungsaufnahme versteht, nicht zwangsernährt werden dürfe.

In Finnland hat es in den 80er Jahren und im Jahre 1990 Gefangene gegeben, die in den Hungerstreik getreten waren. Die Frage nach ihrer rechtlichen Stellung löste in den Behörden in dem Maße Unsicherheit aus, dass das Jus-

29 Zur diesen Fragestellung siehe z.B. Jung \& Schroth, Das Strafrecht als Gegenstand der Rechtsangleichung in Europa, GA 130 (1983), S. 241, 255; Lahti, in: Rechtfertigung und Entschuldigung II, a.a.O. (Fn. 17 ), S. 1429; Eser, ibid. S. 1449. Zur letzten deutschen Rechtslage siehe z.B. Ulsenheimer, Der Arzt im Konflikt zwischen Heilauftrag und Selbstbestimmungsrecht des Patienten - in dubio pro vita? Festschrift für Albin Eser, 2005, S. 1225. 
tizministerium am 14. Dezember 1990 zur Klärung der Sache eine Arbeitsgruppe einsetzte. ${ }^{30}$ Die Beurteilung der Arbeitsgruppe über den vorliegenden Rechtszustand hat sich indes kaum von der oben erwähnten Stellungnahme des Zentralamtes für Gesundheitswesen unterschieden. Man war der Ansicht, dass keine rechtliche Pflicht bestehe, einen im Hungerstreik befindlichen, zu gültiger Willensbildung fähigen Gefangenen zwangsweise zu ernähren, wenn auch die Anwendung der Notstandsvorschrift des Strafgesetzbuches für möglich gehalten wurde, falls das Leben oder die Gesundheit des Betroffenen wegen der Verweigerung der Nahrungsaufnahme unmittelbar und ernsthaft bedroht ist. In dem Bericht der Arbeitsgruppe wurde ferner die Ansicht vertreten, dass die Verstärkung des Selbstbestimmungsrechts des Patienten durch das vorgeschlagene Patientenrechtgesetz die Anwendung des Notstandsgesetzes ausschließen würde und dass auch die Reformierung der Vorschriften über die Grund- und Menschenrechte das Selbstbestimmungsrecht des Individuums und das Recht auf körperliche Unversehrtheit in der Relation zu anderen Grundrechten verstärken würde. ${ }^{31}$

Die vom Sozial- und Gesundheitsministerium eingesetzte Kommission hatte in ihrem 1982 erschienenen Bericht vorgeschlagen, dass ein Gesetz über Patientenschäden und ein Gesetz über die Rechte des Patienten zu erlassen seien. ${ }^{32}$ In das Gesetz über die Rechte des Patienten seien unter anderem solche Vorschriften aufzunehmen, die das Recht des Patienten auf Aufklärung und Selbstbestimmung betreffen. In solchen Fällen, in denen der Patient bewusstlos ist, oder in ähnlichen dringlichen Fällen, in denen dieser nicht zu einer aktuellen Willensbildung in der Lage ist, wurde verlangt, dass dem Patienten Behandlung zukomme, ausgenommen den Fall, dass man es aufgrund einer früheren ernsthaften Willensbekundung des Patienten für offenbar halten müsste, dass der Patient diese Eingriffe ablehnen würde. Als ein typisches Beispiel für eine solche Situation wurde ein Zeuge Jehovas genannt, der aus religiöser Überzeugung die Annahme von Bluttransfusionen verweigert. ${ }^{33}$

30 Siehe Bericht der Hungerstreik-Arbeitsgruppe vom 30.5.1991, Gesetzesausarbeitungsabteilung des Justizministeriums. - Ich fungierte als Vorsitzender dieser Arbeitsgruppe.

31 Bericht der Hungerstreik-Arbeitsgruppe, S. 77.

32 Komiteeberichte 1982:29 und 1982:65. - Ich fungierte als Vorsitzender dieser 15köpfigen Kommission, die für die Fragen der Rechtssicherheit im Bereich der Gesundheitsfürsorge und Krankenpflege eingesetzt worden war.

33 Komiteebericht 1982:65, S. 45 und 6 § des Gesetzesvorschlags. 


\section{4. Über die Rechtsbehelfe, die das Selbstbestimmungsrecht des Patienten gewährleisten}

Das Gesetz über Patientenschäden wurde 1986 erlassen und das Patientengesetz sechs Jahre später. ${ }^{34}$ Mit dem Gesetz über Patientenschäden wurde der schadenersatzrechtliche Schutz des Patienten verbessert, indem ein gesetzlich vorgeschriebenes Versicherungssystem in Gebrauch genommen wurde, bei dem sich die Haftungsprinzipien nicht auf den Nachweis individueller Schuld, sondern auf die Verursachung von im Gesetz festgelegten, in der Gesundheitsfürsorge inakzeptablen Risiken aufbauten und bei der für die Kosten der Versicherung die Akteure im Gesundheits- und Krankenpflegewesen aufkommen. Durch die Regulierung der Stellung und der Rechte des Patienten auf Gesetzesebene im Patientengesetz wurden die individuellen, mit der medizinischen und menschlichen Behandlung des Patienten verbundenen Rechte klarer herausgestellt und verstärkt. Die Gesetzesvorschriften haben eine stärker bindende Kraft als die berufsethischen Vorschriften; sie werden in demokratischer Weise verabschiedet, und die rechtliche Information deckt die Gesellschaft samt ihren verschiedenen Instanzen in einem weiteren Umfang ab.

Bemerkenswerte Züge bei beiden Gesetzen waren die, dass in ihnen sowohl die öffentliche als auch die private Gesundheitsfürsorge und Krankenpflege geregelt wird und dass das Ziel von beiden darin besteht, im Zuge der Verstärkung der Rechtsschutzes des Patienten die Voraussetzungen für eine vertrauliche Patienten-Arzt-Beziehung zu wahren. $\mathrm{Zu}$ der Zeit, als diese Gesetze erlassen wurden, hatte das Grundrechts- und Menschenrechtsdenken sich gerade erst zu stärken begonnen. So war zum Beispiel die Europäische Menschenrechtskonvention erst ein Jahr vor der Einbringung der Regierungsvorlage zu einem Gesetz über die Stellung und die Rechte des Patienten ratifiziert worden, und zwar nachdem Finnland im Jahre 1990 dem Europarat beigetreten war. Zwar werden die Menschenrechtsübereinkommen, die eine Auswirkung auf die Rechte des Patienten haben, in den Begründungen der Regierungsvorlage erläutert, aber nur in recht groben Zügen. ${ }^{35}$

Im Patientengesetz nimmt die Regelung des Selbstbestimmungsrechts des Patienten einen bedeutenden Teil der Rechtsvorschrift ein. Als Grundsatz wird

$34 \mathrm{Zu}$ diesen Gesetzen siehe Lahti, Towards a Comprehensive Legislation Governing the Rights of Patients, in: Westerhäll \& Phillips (eds.), Patient's Rights - Informed Consent, Access and Equality, Stockholm 1994, S. 207; Ders., The Finnish Patient Injury Compensation System, in: McLean (ed.), Law Reform and Medical Injury Litigation, Dartmouth 1995, S. 147.

35 Regierungsvorlage 185/1991, S. 5-6. 
in den Begründungen der wichtigsten Vorschrift (§ 6) das Recht des Patienten definiert, über Eingriffe in seine körperliche Unversehrtheit selbst zu bestimmen. Der zentrale Gehalt in der Vorschrift wird wie folgt ausgedrückt: „Über die Behandlung des Patienten ist im Einverständnis mit ihm zu bestimmen.“ Bezweckt wird hiermit, dass die Einwilligung des Patienten zur Voraussetzung für die Zulässigkeit ärztlicher Eingriffe gemacht wird, wenngleich bei geringfügigen Behandlungsmaßnahmen die ausdrückliche Zustimmung des Patienten nicht unbedingt erforderlich ist.

Die wichtigste Bedeutung des Selbstbestimmungsrechts des Patienten geht aus seinem in $\S 5$ festgeschriebenen Recht auf Aufklärung sowie seinem Recht hervor, eine bestimme Behandlung oder einen bestimmten Eingriff abzulehnen. Man solle also „die rechtlich gültige, ernsthafte Entscheidung, zum Beispiel lebensverlängernde Maßnahmen abzulehnen, achten“. Ein solcher, zu einem früheren Zeitpunkt geäußerter Wille (Patientenverfügung) sei auch dann zu respektieren, wenn der Patient wegen Bewusstlosigkeit oder aus einem anderen Grund nicht mehr zu einer aktuellen Willensbildung in der Lage sei (§ 8). Wenn ein Arzt gemäß $\S 22$ des Gesetzes über die Dienstellungen im Gesundheitswesen (Dienstellungsgesetz; 559/1994) über eine ärztliche Untersuchung, über die Diagnostizierung einer Krankheit und über die Behandlung derselben bestimmt, so besteht die Mitbestimmung des Patienten darin, dass er - falls mehrere verschiedene Behandlungsalternativen gegeben sind - nach Möglichkeit in einer anderen, medizinisch akzeptablen Weise zu behandeln ist als in einer solchen Weise, die er selbst ablehnt (Patientengesetz § 6.1). ${ }^{36}$

Die Vorschriften des Patientengesetztes sind in ihren Formulierungen allgemein gehalten; im Gesetz sind keine einklagbaren subjektiven Rechte und daher auch keine neuen Rechtsbehelfe oder Rechtsfolgesysteme geschaffen worden - mit Ausnahme der Möglichkeit einer recht „milden“ Mahnung und der effektivierten Patientenberatung durch eine eigene Institution des Patientenbeauftragten (siehe $\S 10-11$ ). Das Gesetz wurde als eine qualitative Entwicklung der Funktionen des Gesundheitswesens begründet, ohne dass man einen Bedarf gesehen hätte, die Ressourcen zu verstärken. ${ }^{37}$

Drei Jahre nach dem Inkrafttreten des Patientengesetzes wurden dessen Auswirkungen unter anderem durch verschiedene Befragungen und Interviews untersucht. Man gelangte zu der Ansicht, dass sich das Patientengesetz auf die praktischen Funktionen im Gesundheitswesen ausgewirkt und die Rechte des Patienten gefördert habe. Die Regulierung des Selbstbestimmungsrechtes des

36 Siehe Regierungsvorlage 185/1991, S. 16-18.

37 Regierungsvorlage 185/1991, S. 11. 
Patienten wurde für recht „milde“ gehalten, und bei der Verwirklichung des Gesetzes seien weiterhin Probleme aufgetreten. Ferner hat man den Wunsch ausgedrückt, dass die Verbindlichkeit und Regulierung der Patientenverfügungen klarer definiert würden. ${ }^{38}$

Die Regelung des Selbstbestimmungsrechts des Patienten hat indes auch Kritik auf sich gezogen, und zwar nicht nur wegen der Mängel, die in den praktischen Anwendungen aufgetreten sind, sondern vor allem wegen diverser Gesetzesänderungsbedürfnisse, die sich aus den Bestimmungen des Biomedizin-Übereinkommens ergeben haben, da beabsichtigt ist, dieses Übereinkommen in Finnland in Kraft treten zu lassen. Der Artikel 5 des Biomedizin-Übereinkommens setzt in einer deutlicher formulierten Form als der $\S 6$ des Patientenrechtsgesetzes die freie und auf Aufklärung basierende Einwilligung (,,free and informed consent") des Patienten voraus. Aus dem Artikel 6, der die Stellung eines volljährigen geistig Gestörten oder Behinderten betrifft, wurde der Bedarf abgeleitet, den $\S 6$ des Patientenrechtsgesetzes (489/1999) dahingehend zu ändern, dass die Fassung eines wichtigen Beschlusses zur Behandlung eines geistig Gestörten oder Behinderten die Einwilligung seines gesetzlichen Vertreters oder eines nahen Angehörigen oder eines sonstigen Angehörigen voraussetzt.

Wegen der gewachsenen Kritik hat das Sozial- und Gesundheitsministerium sodann eine Arbeitsgruppe eingesetzt, die in ihrem Bericht vorgeschlagen hat, die Forderung, nach der für wichtige Behandlungsmaßnahmen die ausdrückliche Einwilligung des Patienten einzuholen sei, in den $\S 6$ des Patientengesetzes aufzunehmen, in dieselbe Vorschrift einen neuen Absatz aufzunehmen, in dem die Patientenverfügung deutlicher definiert wird, und die Stellung eines volljährigen geistig gestörten oder behinderten Patienten deutlicher zu regeln (unter anderem indem man vorschreibt, dass die von dem Patienten ernannte Person - der oder die Pflegebevollmächtigte - an der Fassung des Beschlusses über die anzuwendende Behandlung teilnimmt). ${ }^{39}$

Die erläuterte Entwicklung indiziert die wachsende Auswirkung der Menschenrechtsbestimmungen - vor allem des Biomedizin-Übereinkommens darauf, wie sich der Inhalt des Selbstbestimmungsrechts des Patienten ausformt. Die Wirkung schlägt sich entweder in neuen Auslegungen geltenden

38 Siehe Pahlman et al., Three Years in Force: Has the Finnish Act on the Status and Rights of Patients Materialized? Medicine and Law 15 (1996), S. 591.

39 Bericht der Projektgruppe, die den Bedarf der Reformierung de $\S 6$ des Patientengesetzes geklärt hat, Bericht der Arbeitsgruppe des Sozial- und Gesundheitsministeriums 2003:25. Zu den Fragen der Patientenverfügung und der Behandlungsermächtigung siehe besonders Pahlman, Potilaan itsemääräämisoikeus, a.a.O. (Fn. 19), Kapitel 7. 
Rechts oder in Reformen des Rechts nieder. Ich selbst habe mich früher bereits mit den Fragen der Beschneidung von Knaben sowie der Euthanasie und der Pflege von sterbenden Menschen als Beispiele für derartige Auswirkungen der Menschenrechtsbestimmungen befasst. Bei der Beschneidung von Knaben verstärkt die Berücksichtigung der Bestimmungen des Biomedizin-Übereinkommens den Schutz der körperlichen Unversehrtheit von Minderjährigen, da zugleich die auf die Körperverletzungsvorschriften angewandte, die Strafbarkeit einschränkende Auslegungslehre über die soziale Adäquanz enger umgrenzt wird. ${ }^{40}$

Die vermehrte Akzeptanz der medizinischen Euthanasie wiederum schwächt insofern den Schutz des Lebens, als verlangt wird, diesen gegen das Selbstbestimmungsrecht eines todkranken Menschen und die Forderungen der Menschenwürde abzuwägen: Wenn bei einer solchen Abwägung den letztgenannten Grundsätzen mehr Gewicht gegeben wird, so akzeptiert man zumindest gewisse Formen der ärztlichen Sterbehilfe, die in dieser Form verwirklicht dem Willen des Betroffenen entsprechen, in Würde zu sterben. ${ }^{41}$

Eine interessante Frage dreht sich um die unter anderem von dem BiomedizinÜbereinkommen verlangten Rechtsschutzmittel sowie um die Steuerungs- und Kontrollsysteme zur Verwirklichung der im Übereinkommen bezeichneten Rechte und zur Überwachung und Sanktionierung von Verletzungen dieser Rechte (siehe Kapitel VIII der Konvention). Ist die Situation in Finnland in dieser Hinsicht zufrieden stellend? Kennzeichnend für das finnische Gesundheitswesen ist die zentrale Stellung eines administrativen Steuerungs- und Kontrollsystems, wobei die vom Zentralamt für Gesundheitswesen ausgeübte, dem Dienstellungsgesetz entsprechende Kontrolle eine besondere Rolle spielt. So kann man kraft dieses Gesetzes gegen Ärzte Disziplinarmaßnahmen ergreifen und die ärztlichen Rechte begrenzen, wobei ihre Pflichten in allgemeinerer Form im $\S 15$ des besagten Gesetzes bestimmt werden. Für beamtete Ärzte gelten zudem die Vorschriften über die Amtsdelikte gemäß Kapitel 40 des

40 Siehe genauer meine am 14.6.1999 als juristisches Mitglied vorgebrachte abweichende Meinung in der Publikation Eettisyyttä terveydenhuoltoon (Ethik in die Gesundheitsfürsorge und Krankenpflege), Nationaler Ethikrat für Gesundheitswesen, 2002, S. 42). Entsprechend in dem Bericht des Ombudsmanns des Parlaments von 1999, S. 273, und die Beschlüsse der Oberstaatsanwältin Päivi Hirvelä auf Absehen von Strafverfolgung vom 30.6.2004. Vgl. den Bericht der Arbeitsgruppe des Sozial- und Gesundheitsministeriums 2003:39, in dem die Erlassung eines besonderen Gesetzes zur Rechtfertigung dieser Handlungen vorgeschlagen wird, wenn sie aufgrund von religiösen oder kulturellen Traditionen vorgenommen werden.

41 Siehe genauer Lahti, Euthanasia, in: Hollo (ed.), Finnish Legal System and Recent Development, Helsinki 2006, S. 81. 
Strafgesetzbuches. Für die Anwendung des allgemeinen Strafrechtes hat es indes bei uns keinen schwerwiegenden kriminalpolitischen Bedarf gegeben, da Kriminalisierung die ultima ratio sein sollte. Wie aus dem Obigen hervorgeht, hat die soziale Nützlichkeit der Pflege von Patienten bei uns von alters her die Anwendung der Vorschriften über die Körperverletzung auch dann ausgeschlossen, wenn die Einwilligung des Patienten nicht in sachgemäßer Weise eingeholt worden war.

Im Jahre 1995 wurde bei der Reformierung des 21. Kapitels (578/1995) des finnischen Strafgesetzbuches (finn. StGB) die Berechtigung von Behandlungsmaßnahmen in gewissem Maße erwogen. Eine die passive Sterbehilfe (passive medizinische Euthanasie) betreffende Einschränkungsvorschrift wurde abgelehnt, da man der Ansicht war, dass die gewohnheitsrechtliche Praxis nach wie vor am besten die Situation reguliere. Auch wenn zum Beispiel Behandlungsmaßnahmen, die Schmerzen verursachen, auf den ersten Blick den reformierten Tatbestand der Körperverletzung (finn. StGB 21:5) erfüllen, werde die Strafbarkeit der Tat im Allgemeinen durch „die Einwilligung des Verletzten oder einen anderen Rechtfertigungsgrund“ beseitigt. ${ }^{42}$

Unabhängig von dem Wortlaut dieser Begründungen bleibt meiner Meinung nach die Frage offen, ob bei diesen Behandlungsmaßnahmen die Strafbarkeit wegen der Nichterfüllung des Tatbestandes oder wegen eines Rechtfertigungsgrundes ausgeschlossen bleibt. Bei der Erwägung des Geltungsbereichs des Tatbestandes ist bemerkenswert, dass Kap. 21 des finn. StGB laut seiner Überschrift gegen das Leben und die Gesundheit gerichtete Delikte betrifft.

Als der Reformvorschlag im Gesetzesausschuss des Parlaments behandelt wurde, hat man mich um Kommentare zu der Beziehung zwischen dem Patientengesetz und dem zu erneuernden Kapitel 21 des Strafgesetzbuches gebeten. Ich habe gesagt, dass es wichtig sei, die Rechtsordnung als Ganzes zu berücksichtigen. Die Vorschriften des Patientengesetzes würden somit entweder direkt über die Straftatbestände oder über die Auslegung der Entlastungsgründe das Ermessen darüber beeinflussen, ob es sich bei einer Handlung, die ein Arzt an einem Patienten vornimmt, um eine strafbare Tat im Sinne des Kap. 21 des finn. StGB handelt. ${ }^{43}$

Die Berücksichtigung der Gesamtheit der Rechtsordnung impliziert vor allem die Beachtung der Grundrechts- und Menschenrechtsbestimmungen, wie ich oben in den Fällen der Beschneidung von Knaben und der medizinischen

42 Regierungsvorlage 94/1993, S. 91, 96.

43 Siehe mein Sachverständigengutachten für den Gesetzausschuss vom 25.5.1994 aufgrund der Regierungsvorlage 94/1993. 
Euthanasie dargelegt habe. Die Rechtsentwicklung kann dabei bezüglich des von den Vorschriften des Kap. 21 des finn. StGB bezweckten Schutzes in beide Richtungen gehen. So halte ich es zum Beispiel nicht für ausgeschlossen, dass man sich in den Fällen, wo das Selbstbestimmungsrecht des Patienten schwer verletzt worden ist, die Auslegung zu Eigen macht, dass die Vorschriften betreffend die Körperverletzung angewandt werden. Es ist jedoch anzumerken, dass die Vorschriften über die Körperverletzung (finn. StGB 21:5-7) die Verletzung der körperlichen Unversehrtheit eines anderen Menschen nicht erschöpfend kriminalisieren und dass sich die Auslegung weitgehend eingebürgert hat, dass sie auf medizinische Behandlungsmaßnahmen nicht anzuwenden seien. ${ }^{44}$ Eine andere Möglichkeit bestünde darin, eine besondere Strafvorschrift über die Verletzung des Selbstbestimmungsrechts des Patienten zu erlassen. ${ }^{45}$ Eine derartige, mit Geldstrafe angedrohte Vorschrift gilt bereits für medizinische Untersuchungen, die ohne die Einwilligung des Betroffenen vorgenommen werden (siehe das diesbezügliche Gesetz, 488/1999, § 27 Punkt 1).

Bislang hat es meines Wissens nur einen einzigen Fall gegeben, wo die Verletzung des Selbstbestimmungsrechts des Patienten zu einem Gerichtsverfahren wegen eines Amtsdeliktes geführt hat. Der Ombudsmann des Parlaments Riitta-Leena Paunio hat am 16. September 2004 den Oberstaatsanwalt dazu aufgefordert, einen beamteten Arzt der vorsätzlichen Verletzung seiner Amtspflichten anzuklagen, da dieser die körperliche Unversehrtheit eines geistig gestörten und behinderten Patienten in der Weise verletzt hat, dass er diesem unter Narkose ohne Einwilligung sämtliche Zähne gezogen hat. ${ }^{46}$ Das Amtsgericht Vaasa, das die Sache rechtskräftig entschieden hat, hat am 9. Februar 2005 den Arzt kraft $\S 11$ Kap. 40 des finn. StGB mit einer Verwarnung bestraft, da dieser eine wichtige Behandlungsmaßnahme durchgeführt hatte, ohne vorher den gesetzlichen Vertreter des Patienten oder einen nahen Angehörigen angehört und deren Einwilligung zu dem Eingriff eingeholt zu haben. Der Arzt habe mit seiner Vorgangsweise das Selbstbestimmungsrecht des Patienten verletzt, und die Vorwerfbarkeit der Tat bleibe ungeachtet dessen bestehen,

44 Der Umstand, dass die beschriebene Auslegung in der Gerichtspraxis nicht deutlich bekräftigt worden ist, obwohl sie sich in der übrigen behördlichen Praxis weitgehend eingebürgert hat, schließt es meines Erachtens aus, dass man sie für gewohnheitsrechtlich halten könnte.

45 Eine besondere Strafvorschrift über die eigenmächtige Heilbehandlung ist im österreichischen StGB (§ 110) enthalten. Siehe auch z.B. Jescheck / Weigend, a.a.O. (Fn. 17), $\S 34$, III.3.

46 Bericht des Ombudsmanns des Parlaments aus dem Jahr 2004, S. 223. 
dass „für den Eingriff selbst im Nachhinein eine zahnmedizinische Motivation" gefunden wurde. 47

Artikel 24 des Biomedizin-Übereinkommens verlangt, dass ein ungerechtfertigter Schaden, der von einem medizinischen Eingriff im Sinne der Konvention verursacht wurde, entschädigt wird. In Finnland hat man auf Verletzungen des Rechtes des Patienten auf Aufklärung und Selbstbestimmung die Vorschriften des Gesetzes über den Schadensersatz (412/1974) oder des Patientenschadengesetzes nur sehr vorsichtig angewandt. In der Entscheidung des Obersten Gerichtshofes 1984 II 163 - es ging in dem Fall darum, dass ein Zahnarzt einem Patienten vier Vorderzähne gezogen hatte, die noch hätten plombiert werden können -, die dem letztgenannten Gesetz vorausging, war die Mehrheit der Ansicht, dass als Begründung für die Entschädigung des Personenschadens das Fehlen einer annehmbaren medizinischen Motivation gelte, während die Minderheit mit der Stimmenverteilung von $1 \mathrm{zu} 4$ der Ansicht war, dass der erstrangige Entschädigungsgrund darin liege, dass die Einwilligung des Patienten gefehlt hatte. ${ }^{\mathbf{4 8}}$

Als im Jahre 1998 das Patientenschadengesetz reformiert wurde (879/1998), wurde ein Augenmerk auf die Bedeutung des Rechtes des Patienten auf Aufklärung und Selbstbestimmung gelegt, und zwar bei der Anwendung des $\S 2$ Absatz 1 Punkt 1 des gerade reformierten Gesetzes und bei der Abwägung dessen, ob ein verursachter Personenschaden mit hoher Wahrscheinlichkeit hätte vermieden werden können, wenn man die Vorgangsweise mit dem Standard einer erfahrenen Fachkraft in der Gesundheitsfürsorge vergleicht. Dabei kann die Frage zur Abwägung kommen, ob der Schaden hätte vermieden werden können, wenn man den Patienten genauer über das mit der Behandlung verbundenen Risiko des Auftretens von Komplikationen unterrichtet hätte und er, nachdem er sich eine Vorstellung von den Risiken gemacht hatte, die Behandlung abgelehnt hätte. Als Maßstab für die Aufklärung des Patienten galt auch in diesem Fall der Standard eines erfahrenen Facharztes, und der

47 Urteil des Amtsgerichts Vaasa vom 9.2.2005 Nr. 05/85 (R 04/894). In den Begründungen des Urteils wird außer auf finn. StGB 40:11 auch auf die $\S \S 3.2,5,6.2-3$ und 9.1 des Patientengesetzes und auf $\S 15.1-2$ des Dienststellungsgesetzes verwiesen.

48 In einer unveröffentlichten Entscheidung des Obersten Gerichtshofes vom 1.4.1982 Nr. 3938/81 (R 77/603) gelangte man zu der Ansicht, der Arzt sei schadenersatzpflichtig, wenn die unterbliebene Aufklärung des Patienten und die nicht erfolgte Einholung seiner Zustimmung in einem solchen Kausalzusammenhang mit der Entstehung des Schadens gestanden habe, dass eine Aufklärung es dem Patienten ermöglicht hätte, sich an einen Neurochirurgen zu wenden und dass bei einer von diesem durchgeführten Operation das Misslingen der Behandlung wahrscheinlich hätte verhindert werden können. 
Patient habe zu beweisen, dass er, falls er sich der Risiken bewusst gewesen wäre, den riskanten Eingriff abgelehnt hätte. ${ }^{49}$

In der Praxis des Ausschusses für Patientenschäden sind nur wenige Fälle vorgekommen, in denen ein Recht auf Schadenersatz zugestanden wurde. Die Beispiele betreffen unter anderem die mit einem neuartigen Endoskopieverfahren verbundenen Risiken und die unterbliebene Aufklärung über die Alternativen zu diesem Verfahren, die Anwendung eines vom Patienten unerwünschten Anästhesieverfahrens bei der Implantation eines künstlichen Gelenks und die Ausschabung der Nasennebenhöhlen im Zusammenhang mit der Entfernung von Polypen entgegen den mutmaßlichen Willen des Patienten. ${ }^{\mathbf{5 0}}$ Meiner Ansicht nach werden dem Patienten zu strenge Forderungen auferlegt, wenn als Maßstab für die Aufklärung der Standard eines Facharztes gesetzt und dem Patienten die Beweispflicht auferlegt wird. ${ }^{51}$ Die sachgemäße Aufklärung des Patienten gewinnt dann eine größere Bedeutung, wenn der Grund für die Maßnahme bzw. Operation relativ ist und auf anderen Motiven als auf rein medizinischen beruht, wie es zum Beispiel bei einer kosmetischen Augenoperation der Fall ist. ${ }^{\mathbf{5 2}}$

Auf den Umfang des Entschädigungsrechtes des Patienten hat es einen Einfluss, wenn die Verletzung des Selbstbestimmungsrechts des Patienten in der Zukunft als solche für eine verbotene (strafbare), den Personenschaden verursachende Tat angesehen wird. Dabei wird die Verletzung des Selbstbestimmungsrechtes betont und nicht nur die (damit verbundene) Verletzung des Rechtes auf Aufklärung. Der Arzt, der wegen einer Verletzung seiner Amtspflicht, im speziellen wegen der Verletzung des Selbstbestimmungsrechts des Patienten, verurteilt wird, ist verpflichtet, auch für den aus der Verletzung

49 Siehe Regierungsvorlage 91/1998, S. 23.

50 Zu den Fallbeschreibungen siehe Palonen et al., Potilas- ja lääkevahingot (Patientenund Arzneimittelschäden), Helsinki 2005, S. 125.

$51 \mathrm{Zu}$ der Kritik in oben genannter Hinsicht siehe Paaso, Potilaan tiedonsaantioikeus terveydenhuollossa (Das Recht des Patienten auf Information), Helsinki 2001, S. 350; Pahlman, Potilaan itsemääräämisoikeus, a.a.O. (Fn. 19), S. 202, 209.

52 Als ich als stellvertretendes Mitglied des Ausschusses für Patientenschäden an der Entscheidung des Falls einer kosmetischen Augenoperation (1003/2004) teilhatte, war ich im Unterschied zu der Mehrheit des Ausschusses der Meinung, dass selbst seltene Komplikationen, die bei recht kommerziell vermarkteten kosmetischen Maßnahmen auftreten, leichter eine Entschädigungshaftung als normal begründen können, wenn der Patient über die Risiken nicht ausreichend informiert wurde. Das dem Patienten übergebene Papier, aus dem hervorging, dass die einschlägigen Eintragungen in den Patientendokumenten fehlten, hat sich meines Erachtens zugunsten des Patienten ausgewirkt in der unklaren Beweissituation, ob eine sachgemäße Information erteilt wurde oder nicht. 
heraus entstandenen Personenschaden Schadenersatz zu leisten. ${ }^{\mathbf{5 3}}$ Desgleichen ist zu berücksichtigen - und zwar unabhängig von der Erweiterung des Bereichs der Strafbarkeit -, dass die neue Vorschrift über die Entschädigung von Leiden im Gesetz über den Schadenersatz - mit anderen Worten: der am 1. Januar 2006 in Kraft getretene $\S 6$ (509/2004) - als einen Grund für eine derartige Entschädigung unter anderem eine schwere Verletzung der körperlichen Unversehrtheit festlegt, wenn diese mit Vorsatz oder aus grober Fahrlässigkeit geschehen ist. In den Begründungen zu der Gesetzesänderung ist von unter Zwang vorgenommenen medizinischen Eingriffen die Rede, was indes auf einen hohen Schweregrad der Tat verweist. ${ }^{\mathbf{5 4}}$

\section{Schlussfolgerungen}

Die oben besprochenen Regelungsbeispiele zeigen - wenn auch in bruchstückhafter Form - die Entwicklung des Medizinrechts in Situationen, wo es um ärztliche Eingriffe in das Selbstbestimmungsrecht des Individuums geht. Die Beispiele veranschaulichen die Verstärkung des Grundrechts- und Menschenrechtsdenkens auf solchen die ärztliche Tätigkeit betreffenden verschiedenen Gebieten, auf denen problematische Fragen bisher vorwiegend aus dem Gesichtswinkel des Strafrechts betrachtet worden sind.

Aus diesen Regulierungsbeispielen geht hervor, dass sich die Praxis der Anwendung von Menschenrechten und Grundnormen dynamisch gestaltet. So lassen sich zum Beispiel die langfristigen Auswirkungen der europäischen Menschenrechtskonvention oder des Biomedizin-Übereinkommens auf die Anwendung und Reformierung des finnischen Rechts nicht leicht in aller Exaktheit voraussagen. In meinen oben vorgebrachten Stellungnahmen habe ich einige derartige Auswirkungen vorhergesagt oder befürwortet.

Die Menschen- und Grundrechte haben in unserer Rechtsordnung eine neue, diese vereinheitlichende Wertebasis geschaffen, und zwar in einer Situation, als die Entwicklung ansonsten in Richtung einer Diversifizierung der Rechts-

53 Siehe den Beschluss des Amtsgerichts Vaasa vom 9.2.2005 (Fn. 47), in dem einem Patienten wegen eines Personenschadens, d.h. wegen eines bleibenden kosmetischen Schadens sowie wegen Schmerzen, ein Schadenersatz von insgesamt 10.696 Euro zuerkannt wurde.

54 Siehe Regierungsvorlage 167/2003, S. 57. Forscherin im Medizinrecht Anja Hannuniemi spricht sich für eine bedeutend weiter reichende Entschädigung von Leiden für Verletzungen des Selbstbestimmungsrechts des Patienten aus: Skadestånd för kränkningar av patienters självbestämmanderätt $\mathrm{i}$ det personrättsbaserade medicinalrättsliga systemet, Tidskrift utgiven av Juridiska Föreningen i Finland 140 (2004), S. 324, 337. 
ordnung gegangen ist und sogar die Gefahr einer Atomisierung bestanden hat. Die Verstärkung der Menschen- und Grundrechte hat zudem eine positive, vereinheitlichende Auswirkung auch auf das Medizinrecht - und das Biorecht - gehabt. Das Vordringen des Biorechts an die Seite des Medizinrechts hängt damit zusammen, dass vor allem die Entwicklung von Anwendungen der Gentechnik und der Fortpflanzungsmedizin neue ethisch-rechtliche Probleme aufgeworfen hat. Diese haben im Hintergrund der Abfassung des BiomedizinÜbereinkommens gestanden. In der Präambel des Übereinkommens wird konstatiert, dass mit ihm die Grundrechte und Grundfreiheiten von menschlichen Lebewesen in biologischen und medizinischen Anwendungen geschützt werden sollen. - Schon vor dem Biomedizin-Übereinkommen haben wir zusammen mit dem Jubilar Heike Jung im Rahmen der wissenschaftlichen Aktivitäten der Internationalen Strafrechtsvereinigung (Association Internationale de Droit Pénal) das Thema "Strafrecht und moderne bio-medizinische Behandlung" behandelt und eine Resolution darüber vorbereitet. In der Resolution plädierten wir für international einheitliche Standards und Regeln, die wenn möglich - auf der internationalen Ebene und als verbindliche rechtliche Regelungen eingeführt werden sollten. ${ }^{55}$

Es ist erstrebenswert, diesem neuen, sich verselbständigenden Rechtsbereich Medizin- und Biorecht gemeinsame Begriffe und Prinzipien sowie eine Rechtssystematik zuzuerkennen und diese auszuformulieren. Bei der Entwicklung von gemeinsamen Grundsätzen kommt der Wechselwirkung zwischen den berufsethischen Normen des Gesundheitswesens und den mit diesen verbundenen Menschenrechtsnormen eine besonders große Bedeutung zu. ${ }^{\mathbf{5 6}}$

Wenn die Anwendungen der Biomedizin - vor allem der Gentechnik und der Fortpflanzungstechnologie - auch bei uns in zunehmendem Maße unter anderem aufgrund des Konvergenzdruckes von europäischen oder internationalen Normen reguliert werden, so hat man in der Rechtsordnung zum einen die Unverletzlichkeit der Menschenwürde und den Schutz der individuellen und genetischen Integrität anzuerkennen und zum anderen die von den verschiedenen Menschen- und Grundrechten ausgedrückten Prinzipien gegeneinander

55 Siehe Droit Pénal et Techniques Biomédicales Modernes, Revue Internationale de Droit Pénal (RIDP) 59 (1988): Jung, S. 831 (deutscher Bericht); Lahti, S. 603 (Generalbericht). Professor Albin Eser war Veranstalter des Kolloquiums. Eine deutschsprachige Version des Berichts von Jung ist in ZStW 100 (1988), S. 3 mit dem Titel „Biomedizin und Recht“ publiziert worden. Über die Resolution siehe RIDP 61 (1990), S. 91, 115 und Jung, ZStW 102 (1990), S. 667.

56 Siehe auch Eser / Just / Koch (Hrsg.), Perspektiven des Medizinrechts, 2004, wo man für ein ,integratives Medizinrecht“ plädiert. 
abzuwägen, sofern sie nicht absoluter Natur sind. Unsere Gesetzgebung hat sich auf der Grundlage dieser Ausgangspunkte weiter zu entwickeln. Die Abwägung von in verschiedene Richtungen weisenden Menschen- und Grundrechten benötigt als Stützung die Ergebnisse einer multidisziplinären und mehrere Rechtsbereiche umfassenden Forschung. 
18.

\section{Die Knabenbeschneidung als Problem der multikulturellen Gesellschaft}

\section{Einführung}

Die Zulässigkeit und die Voraussetzungen für die praktische Durchführung der medizinisch nicht indizierten, religiös begründeten Beschneidung von Knaben (medizinisch wird diese Maßnahme auch Zirkumzision genannt) haben in den letzten zwei Jahrzehnten in Finnland von Zeit zu Zeit einen regen Austausch von unterschiedlichen Meinungen verursacht. In der Debatte hat man, je nach Blickwinkel, zum einen den Schutz der körperlichen Unversehrtheit der nicht einwilligungsfähigen Knaben, zum anderen die bestimmten Gemeinschaften zukommende Religionsfreiheit, den Schutz der Kultur von Minderheiten und den Schutz des Familienlebens angeführt. ${ }^{1}$ Eine ähnliche Diskussion wird auch in verschiedenen anderen Ländern geführt, zuletzt in Deutschland aufgrund des Urteils des LG Köln vom 7. Mai 2012. ${ }^{2}$ In der internationalen Debatte hat sich das Hauptaugenmerk auf die medizinisch nicht notwendige Beschneidung von Mädchen und Frauen konzentriert, deren Verwerflichkeit in den westlichen Rechtskulturen unumstritten ist, wenn auch über die Mittel zur Bekämpfung dieses Brauchs teilweise Meinungsverschiedenheiten bestehen. ${ }^{3}$

Bedeutende amtliche Stellungnahmen zur Knabenbeschneidung sind in Finnland das Gutachten des Ethischen Beirats für nationale Gesundheitsversorgung (ETENE) vom 15. Juni 1999 - bei dem ich als juristisches Mitglied des Beirats

1 Siehe im Allgemeinen Lahti, Infant Male Circumcision, in: Rynning \& Hartlev (eds.), Nordic Health Law in a European Context, Martinus Nijhoff Publishers 2012, S. 216 ff. m.w.H.

2 Siehe besonders Beulke - Dießner, „(...) ein kleiner Schnitt für einen Menschen, aber ein großes Thema für die Menschheit“. Warum das Urteil des LG Köln zur religiös motivierten Beschneidung von Knaben nicht überzeugt. ZIS 7/2012, S. 338 ff. m.w.H.; Putzke, Die strafrechtliche Relevanz der Beschneidung von Knaben, in: Festschrift für Rolf Dietrich Herzberg, Mohr Siebeck 2008, S. 669 ff.

3 Über die internationale Diskussion siehe besonders Denniston et al. (eds.), Circumcision and Human Rights, Springer 2009. Siehe auch z.B. Oba, Female Circumcision as Female Genital Mutilation: Human Rights or Cultural Imperialism? Global Jurist 3/2008 (www.bepress.com/gj/vol8/iss3/art8); Gozdecka, Religion and Legal Boundaries of Democracy in Europe. University of Helsinki 2009, S. 166 ff. (http:// ethesishelsinki.fi). 
eine abweichende Meinung zu Protokoll gegeben habe -, und die Beschwerdeentscheidung der zweiten Ombudsfrau des finnischen Parlaments vom 30. November 1999. Eine offizielle Untersuchung der Sache liegt vor im Bericht der vom finnischen Sozial- und Gesundheitsministerium eingesetzten Arbeitsgruppe (2003) über den Bedarf an gesetzgeberischen Maßnahmen bezüglich der Knabenbeschneidung, der ergänzt wird durch eine von der Arbeitsgruppe zusammengestellte Studie über die einschlägigen Praktiken in verschiedenen Ländern (2004).

In ihren Beschlüssen auf sanktionsartiges Absehen von Strafverfolgung vom 30. Juni 2004 hat die Oberstaatsanwältin Päivi Hirvelä die Ansicht vertreten, dass sich ein Arzt der Körperverletzung und die Väter der Anstiftung dazu schuldig gemacht hätten, indem ohne sachgemäße Einwilligung sowie unter Vernachlässigung der von den operativen Eingriffen verlangten Hygieneanforderungen und der gesundheitlichen Vorsichtsmaßnahmen an kleinen Knaben eine religiös-rituelle Beschneidung vorgenommen wurde. Die muslimischen Väter hatten einen aus dem Ausland gebürtigen Arzt damit beauftragt, bei ihnen zu Hause an ihren Söhnen die Zirkumzision vorzunehmen, welche danach wegen Komplikationen weitere medizinische Maßnahmen erforderlich machte.

Bei einem ähnlichen Fall, der wegen einer Anklage auf Körperverletzung zu verhandeln war, ist vor kurzem eine Entscheidung der obersten Gerichtsinstanz in Finnland ergangen. In dem Präjudiz KKO 2008:93 des Obersten Gerichtshofs wurde im Falle einer religiös begründeten Beschneidung zu einer vom Staatsanwalt erhobenen Anklage auf Körperverletzung Stellung bezogen. In dem betreffenden Fall wurde die Sache als Strafsache verhandelt, aber die dabei behandelten prinzipiellen Probleme beschränken sich nicht auf das Strafrecht, sondern im Grunde geht es darum, was für einen juristischen Standpunkt man zur Zirkumzision einnehmen soll, welche rechtlich relevanten Argumente für und gegen die Verwerflichkeit der Knabenbeschneidung sprechen und wie diese gegeneinander abzuwägen seien. Damit verbunden ist die Frage, ob diejenigen Zirkumzisionen, die nach sachgemäßer Prüfung als akzeptierbar angesehen werden, solche operativen Maßnahmen sind, die in den Bereich der öffentlichen Gesundheitsversorgung fallen, und wenn ja, mit welchen Mitteln sie zu finanzieren seien.

Im Folgenden möchte ich die rechtlich-ethische Diskussion beleuchten, die in Finnland seit dem Beginn der 90er Jahre über diese Sache geführt worden ist. Im Mittelpunkt meiner Analyse steht das Präjudiz KKO 2008:93 und seine Bedeutung. Diese Entscheidung und ihre Begründungen sind von erheblichem, auch internationalem Interesse, unter anderem wegen der Abwägung der 
Grund- und Menschenrechte sowie wegen der wissenschaftlichen Diskussion über das Verhältnis von multikultureller Gesellschaft und Strafrecht.

\section{Finnische Reaktionen auf die Beschneidung von Knaben in den 90er Jahren}

Die Aufmerksamkeit für diese Sache wurde im Jahre 1992 durch ein an die finnischen Kommunen adressiertes Schreiben des Sozial- und Gesundheitsministeriums erweckt, in dem empfohlen wurde, die Beschneidung von Knaben in den Einrichtungen der öffentlichen Gesundheitsversorgung vornehmen zu lassen. Bei der Praxis, die sich die in Finnland lebenden Juden und Tataren zu Eigen gemacht hatten, hatte es keinen Bedarf gegeben, auf Dienstleistungen der öffentlichen Gesundheitsversorgung zurückzugreifen, aber die Lage hatte sich mit der ansteigenden Zuwanderung von Menschen aus islamischen Ländern geändert.

In einem von 12. August 1997 datierten Brief an den Ombudsmann des Parlaments kritisierte man die an den Universitätskrankenhäusern vorgenommenen Zirkumzisionen und bat den Ombudsmann darum, die Sache zu klären. Die zweite Ombudsfrau des Parlaments, Riitta-Leena Paunio, die diese Beschwerdesache am 30. November 1999 entschieden hat, beurteilte die Frage zuerst allgemein vom rechtlichen Standpunkt und gelangte dann zu den folgenden, meiner Meinung nach begründeten, Schlussfolgerungen: Die Einrichtungen der öffentlichen Gesundheitsversorgung sind aufgrund des Gesetzes über die Stellung und die Rechte des Patienten sowie in Anbetracht der Gesetze und Vorschriften über die Pflicht zur Bereitstellung der kommunalen Gesundheitsund Krankenpflege nicht dazu verpflichtet, medizinisch nicht indizierte Zirkumzisionen vorzunehmen. Obwohl Paunio dergleichen Maßnahmen nicht eindeutig für gesetzeswidrig erklärt hat mit Hinblick darauf, dass es über sie keine ausdrücklichen Vorschriften oder Bestimmungen gab und dass das Sozial- und Gesundheitsministerium Anfang der neunziger Jahre empfohlen hatte, einer Durchführung dieser Maßnahmen im Rahmen der kommunalen Gesundheitsversorgung positiv gegenüberzustehen, war sie der Ansicht, dass die Beschneidung von kleinen, nicht einwilligungsfähigen Knaben ohne medizinische Indikation vom rechtlichen Standpunkt aus sehr fragwürdig sei. Ein solcher chirurgischer Eingriff sollte laut Paunio nicht in den Einrichtungen der öffentlichen Gesundheitsversorgung vorgenommen werden, bevor nicht das Kind selbst in der Lage sei, seine auf Wissen basierende Einwilligung dazu zu erteilen. 
In dem Gutachten des ETENE-Beirats vom 15.6.1999, das der Beschwerdeentscheidung der Ombudsfrau des Parlaments voranging, vertrat die Mehrheit des Beirats die Ansicht, dass solche medizinisch nicht indizierten Zirkumzisionen ethisch akzeptabel und auch in den Einrichtungen der öffentlichen Gesundheitsversorgung durchzuführen seien, die an Mitgliedern der jüdischen und der islamischen Religionsgemeinschaft vorgenommen werden. Auf diese Weise würde man der Intoleranz und der Geringschätzung religiöser Traditionen vorbeugen. Außerdem war man der Auffassung, dass man mit der Praxis der Billigung derartiger Beschneidungen die Kinder vor schädlichen Schmerzerfahrungen schützen würde, wenn die Maßnahmen von erfahrenen Fachkräften der Gesundheitsversorgung durchgeführt werden.

Als Mitglied des ETENE-Beirats, das mit seiner Meinung in der Minderheit blieb, habe ich die Stellungnahme der Mehrheit deswegen kritisiert, weil in ihr derjenige Aspekt des Kindeswohles nicht ausdrücklich gewichtet wurde, dem gemäß man in die körperliche Integrität einer nicht einwilligungsfähigen Person - außer in gesondert festgelegten Fällen - nur dann eingreifen darf, wenn die Maßnahme für diese von unmittelbarem gesundheitlichem oder sonstigem Nutzen ist. Zur Unterstützung dieser Begründung habe ich auf das Übereinkommen des Europarates über Menschenrechte und Biomedizin ${ }^{4}$ verwiesen, das Finnland zwar sofort unterzeichnet, damals aber noch nicht ratifiziert hatte. Des Weiteren habe ich darauf hingewiesen, was in den Unterlagen zur Ausarbeitung der Grundrechtsreform (969/1995) über das Verhältnis verschiedener Grundrechte zueinander und ihre Abwägung gesagt worden ist. Mit Verweis auf die Freiheit der Religion und des Gewissens dürfe man keine solchen Handlungen begehen, die die Menschenwürde oder sonstige Grundrechte verletzen oder gegen die Grundlagen der Rechtsordnung verstoßen. Alles in allem war ich der Ansicht, dass die Zulassung von medizinisch nicht notwendigen Zirkumzisionen vom Standpunkt der finnischen Rechtsordnung aus höchst fragwürdig sei. ${ }^{5}$

\section{Die amtlichen Klärungen des Jahres 2004}

Die Einstellung zur medizinisch nicht indizierten Knabenbeschneidung nahm eine neue Wende, als das Sozial- und Gesundheitsministerium zusammen mit dem Finnischen Gemeindeverband in seinem Rundschreiben vom 3. März 2003 seine Empfehlung vom Anfang der 90er Jahre erneuerte, obwohl die

4 Oviedo 4.4.1997, SEV Nr. 164; im Folgenden kurz Biomedizinkonvention.

5 Siehe auch Lahti, Ärztliche Eingriffe und das Selbstbestimmungsrecht des Individuums, in: Festschrift für Heike Jung, Nomos 2007, S. 511 ff. (522). 
Befolgung dieser Empfehlung die Ignorierung der Auffassung der zweiten Ombudsfrau Riitta-Leena Paunio bedeutete - also derjenigen Instanz, der die Überwachung der Gesetzlichkeit zukam. Zur selben Zeit erwog die Oberstaatsanwältin Päivi Hirvelä die Erhebung einer Anklage aufgrund des Verdachts auf Körperverletzung gegen einen Arzt und einen muslimischen Vater. Wegen der widersprüchlichen Ansichten bezüglich der Gesetzlichkeit des genannten Rundschreibens sowie allgemein bezüglich der Akzeptierbarkeit der Zirkumzision bestand daher nun der dringende Bedarf, beim Sozial- und Gesundheitsministerium die genannte Arbeitsgruppe einzuberufen, was am 11. April 2003 geschah. Bei der Zusammensetzung der Arbeitsgruppe wurde eine möglichst umfangreiche Sachkenntnis der Mitglieder angestrebt, und Archiater Risto Pelkonen fungierte als Vorsitzender der Arbeitsgruppe. Außerdem wurde Kristina Stenman damit beauftragt, zur Unterstützung der Arbeit der Gruppe eine Studie zu erstellen, in der die einschlägigen Praktiken der Knabenbeschneidung im In- und Ausland geklärt werden.

Den Vorschlägen der Arbeitsgruppe des Sozial- und Gesundheitsministeriums zufolge sind medizinisch nicht indizierte Knabenbeschneidungen unter Stattgabe gewisser Voraussetzungen zuzulassen. Dabei ging die Arbeitsgruppe von dem Wohl des Kindes aus, das jedoch aus einem breiteren Blickwinkel betrachtet wurde als aus rein gesundheitlicher Sicht, indem man „die sozialadäquaten Grundlagen, die aus den Hintergründen der religiösen und kulturellen Traditionen erwachsen“, hervorhob. Die Voraussetzungen für die Zirkumzision sollte man nach schwedischem Vorbild ${ }^{6}$ in einem gesonderten Gesetz festlegen, da mit dieser operativen Maßnahme in die körperliche Integrität des Knaben eingegriffen werde. Die Beschneidung dürfe nur von einem approbierten oder mit einer Erlaubnis ausgestatteten Arzt vorgenommen werden, und zwar unter Einwilligung der Personensorgeberechtigten des Knaben. Des Weiteren schlug die Arbeitsgruppe in ihrem Bericht vor, dass die Knabenbeschneidungen im Rahmen der öffentlichen Gesundheitsversorgung durchzuführen seien, in gleicher Weise wie medizinisch indizierte Eingriffe. Laut Kristina Stenman, die die Klärungsarbeit geleitet hatte, sollte man für Knaben die Vornahme der Zirkumzision unter sicheren Bedingungen und mit denselben Begründungen in allen Landesteilen zulassen. Auch nach ihrer Ansicht würde ein gesondertes Gesetz nach schwedischem Vorbild die Sachlage klären.

6 Siehe Lag om omskärelse av pojkar (2001:499) [Gesetz über die Beschneidung von Knaben]. 
Diese amtlichen Klärungen haben nicht zu einem Vorschlag betreffend die Erlassung eines gesonderten Gesetzes geführt. Vermutlich hat sich darauf der Umstand ausgewirkt, dass am Amtsgericht Tampere in der Sache der Knabenbeschneidung Klage erhoben wurde und man beim Sozial- und Gesundheitsministerium die gesetzkräftige Rechtsnorm eines Gerichts abwarten wollte welche dann im Präjudiz KKO 2008:93 erging. Nach dieser Entscheidung hat man am Ministerium, das für die Ausarbeitung des Gesetzesvorschlags zuständig gewesen war, wohl gemeint, dass sich mit der in der Entscheidung enthaltenen Rechtsnorm die Rechtslage geklärt habe und dass somit für gesonderte gesetzgeberische Maßnahmen kein Bedarf mehr bestehe.

\section{Der Hauptinhalt des Präjudizes KKO 2008:93}

Im Präjudiz KKO 2008:93 vertrat der oberste Gerichtshof Finnlands die Ansicht, dass die Handlungsweise einer alleinerziehenden muslimischen Mutter, die ihren viereinhalb Jahre alten Sohn aus religiösen Gründen hatte beschneiden lassen, nicht für rechtswidrig anzusehen sei und dass die Vorgehensweise also keine strafbare Körperverletzung ${ }^{7}$ (entweder in Mittäterschaft oder als Anstiftung zur Tat) sei. Bei der Entscheidung lautete die rechtliche Kernfrage, ob der von der Beschneidung implizierte Eingriff in die körperliche Unversehrtheit des Knaben (die irreversible Entfernung der Vorhaut vom männlichen Glied) den Tatbestand der Körperverletzung erfülle und - falls diese Frage zu bejahen sei - ob man die hinter dem Eingriff stehenden religiösen, kulturellen und sozialen Motive unter Stattgabe etwaiger sonstiger Voraussetzungen für solche Gründe halten könnte, die die strafrechtliche Verantwortlichkeit ausschließen. Unter Anklage stand nur die Personensorgeberechtigte des Jungen, denn die Person, die den Eingriff vorgenommen hatte, blieb unbekannt, auch wenn es nach der Beweisführung des Obersten Gerichtshofs wahrscheinlich ein Arzt gewesen war.

Im Präjudiz KKO 2008:93 zum Urteil des Appellationsgerichtes Turku vom 14. März 2007 war das Endergebnis dasselbe wie die einstimmige Entscheidung des Obersten Gerichtshofes vom 17. Oktober 2008, wenn auch die Begründungen erheblich voneinander differierten. Dagegen war der unterste Gerichtszug, das Amtsgericht Tampere, der Ansicht gewesen, dass der Tatbestand der Körperverletzung erfüllt und kein Rechtfertigungsgrund vorgebracht worden sei. Das Gericht hielt die rechtswidrige Vorgehensweise der Angeklag-

7 Siehe finnisches StGB 21:5-7. Das finnische Strafgesetz ist in der Übersetzung und Einführung von Karin Cornils, Dan Frände und Jussi Matikkala erschienen worden: Schriftenreihe des Max-Planck-Instituts für ausländisches und internationales Strafrecht, Duncker \& Humblot 2006. 
ten jedoch wegen eines Verbotsirrtums ${ }^{8}$ für entschuldbar und hat die Anklage deswegen zurückgewiesen.

Von den rechtlichen Problemen, die die Knabenbeschneidung aufwirft, wurde in der Entscheidung ein direkter Standpunkt zur folgenden Frage bezogen: Stellt die medizinisch nicht indizierte Beschneidung, die eine sorgeberechtigte Person an ihrem Sohn vornehmen lässt, der aufgrund seines Alters noch nicht in der Lage ist, über die Maßnahme selbst zu entscheiden, gemäß der Anklage eine strafbare Anstiftung oder eine sonstige Teilnahme an der Körperverletzung dar oder nicht? Nach Ansicht des Obersten Gerichtshofs wurde der Tatbestand des Köperverletzungsdelikts erfüllt: Die Vorgangsweise erfüllte grundsätzlich den äußeren Tatbestand der Körperverletzung oder zumindest der leichten Körperverletzung.

Da der Oberste Gerichtshof jedoch entschieden hat, die Anklage zurückzuweisen, muss man zum zweiten fragen, mit welchen Gründen eine solche Verletzung der körperlichen Unversehrtheit als nicht strafbar angesehen wird, also entweder dadurch, dass man das Vorliegen des Tatbestandes eng auslegt oder indem man einen solchen Eingriff für eine rechtmäßige (akzeptable) oder entschuldbare (verständliche) Vorgehensweise hält. Bei den Gründen für den Ausschluß der Strafbarkeit, die im Kapitel 4 des Strafgesetzbuches geregelt werden, wird in Folge der Strafgesetzesreform (515/2003) eine deutlichere und konsequentere Unterscheidung zwischen den strafrechtlichen Rechtfertigungsund Entschuldigungsgründen getroffen. Den Begründungen des Obersten Gerichtshofs zufolge ging es um die Beurteilung, ob Rechtswidrigkeit, oder genauer gesagt: ein die Rechtswidrigkeit ausschließender Grund, ein Rechtfertigungsgrund, vorgelegen habe, wenn auch die Formulierung des Standpunktes nicht ganz klar ist. Man ist da der Ansicht, dass sich der Tatbestand der Körperverletzung „grundsätzlich“ verwirklicht habe. Die Erwägung eines Rechtfertigungsgrundes ist in der Entscheidung als Abwägung von in verschiedenen Richtungen gehenden Grund- und Menschenrechten durchgeführt worden, ohne in diesem Zusammenhang auf den in der Strafrechtstheorie entwickelten Begriff der Sozialadäquanz zu verweisen - anders als in der ähnlichen Entscheidung des Obersten Gerichtshofs Schwedens vom 29. September 1997, Nr. B $2237 / 96^{9}$.

8 StGB 4:2.

9 Siehe die Sammlung der Entscheidungen Nytt juridiskt arkiv 1997 s. 636-645 (NJA 1997:107). Dazu kritisch Ravn, Omskœrelse i strafferetten [Beschneidung im Strafrecht], in: Kriminalistisk årbog 1998, Kopenhagen Universität 1999, S. 141 ff. 
Sachlich gesehen hat man sich im Präjudiz KKO 2008:93 meiner Meinung nach einen von den Entlastungsgründen des Strafrechts nicht regulierten, das heißt einen nicht in einem Gesetz niedergeschriebenen neuen Rechtfertigungsgrund zu Eigen gemacht ${ }^{10}$; die Alternative wäre eine die Tatbestandsmäßigkeit der Körperverletzung einschränkende Auslegung gewesen. Das Endergebnis wirkt sich entgegen dem strafrechtlichen Legalitätsprinzip nicht zu Gunsten des Angeklagten aus. Vom Standpunkt der hinter dem Legalitätsprinzip stehenden Werte (der Vorhersagbarkeit und der Gleichheit) aus wäre es jedoch wünschenswert, dass man solche sich zu Gunsten des Angeklagten auswirkenden Ausnahmegründe auch in einem Gesetz regulierte. Bei der Beurteilung von KKO 2008:93 - wie im Allgemeinen bei Präjudizen - muss man als der Rechtsquellenlehre entsprechende Einschränkung die untersuchbaren Charakteristika des Falls und die aus diesen Umständen erwachsende unterschiedliche Interpretierbarkeit dessen beachten, in welchem Maße die im Präjudiz enthaltene Rechtsnorm sich zu einem neuen Straftatmerkmal verallgemeinern lässt. Ferner bleibt Unklarheit darüber bestehen, ob eine solche in einem einzelnen Präjudiz erteilte Rechtsnorm in der Rechtspraxis gewohnheitsrechtlich wird. Darauf hat wiederum der Umstand einen Einfluss, mit welcher Überzeugungskraft die Entscheidung, sich auf Rechtsquellen stützend, argumentiert worden ist.

\section{Zur Abwägung von Grund- und Menschenrechten im Präjudiz KKO 2008:93}

Dem Obersten Gerichtshof zufolge war die zentrale Rechtsfrage also die, ob man die hinter der Knabenbeschneidung stehenden religiösen, kulturellen und sozialen Motive für solche Gründe halten kann, die diese den Tatbestand der Köperverletzung erfüllende Vorgehensweise rechtfertigen. In der Entscheidung wird als damit verbundene Hintergrundangabe vorgebracht, dass die medizinisch nicht indizierte Knabenbeschneidung in vielen Gemeinschaften eine weltweit verbreitete Erscheinung und eine übliche Maßnahme sei, und zwar aus religiösen, kulturellen oder sozialen Gründen. Man schätzt, dass in Finnland jährlich rund 200 Zirkumzisionen vorgenommen werden, die nicht medizinisch indiziert sind. Die auf religiösen oder kulturellen Traditionen beruhende Knabenbeschneidung ist, dem Obersten Gerichtshof zufolge, soweit man weiß, in keinem Land direkt verboten, wenn auch in Schweden darüber ein gesondertes Gesetz erlassen wurde.

10 Siehe ähnlich Frände, Allmän straffrätt [Allgemeines Strafrecht], Helsinki 2012, S. 147 f. 
Bei den Muslimen beruht die Knabenbeschneidung auf religiösen Traditionen und ist in den einschlägigen Gemeinschaften tief verwurzelt. Laut dem Obersten Gerichtshof beweist die in der Sache vorgebrachte Studie, dass die Beschneidung einen festen Teil der Identität der männlichen Mitglieder der Gemeinschaft bildet und dass die muslimischen Knaben im Alter zwischen vier und dreizehn Jahren durch die Beschneidung in die religiöse und soziale Gemeinschaft aufgenommen werden (Punkt 8 der Begründungen). Diesbezüglich stützen sich die Begründungen nach meiner Beobachtung mehr oder weniger direkt auf den obenerwähnten Bericht der Arbeitsgruppe des Sozialund Gesundheitsministeriums.

Die eigentlichen Begründungen des Obersten Gerichtshofes bilden eine Abwägung von in verschiedene Richtungen wirkenden Grund- und Menschenrechten, deren Ergebnis darüber entscheidet, ob es überzeugende Gründe für die Annahme eines ungeschriebenen Rechtfertigungsgrundes gibt. Eine solche Abwägung ist in den Beschlüssen der Gerichte recht selten gewesen, obgleich es in der Entscheidungstätigkeit im Anwachsen begriffen ist. Im Strafrecht setzen das Analogieverbot sowie das Verbot ungenauer Regulierung im Legalitätsprinzip einer Abwägung zu Ungunsten des Angeklagten Grenzen. Wie oben konstatiert wurde, hat man sich auf den Begriff der Sozialadäquanz als einen im Gesetz nicht regulierten, von strafrechtlicher Verantwortung befreienden Grund stützen können. Der Oberste Gerichtshof Schwedens hat diesen Begriff als eine in den ungeschriebenen Entlastungsgründen erscheinende Kollision zwischen dem strafrechtlichen Schutzinteresse und einem diesem entgegengesetzten Interesse definiert: Die aus religiösen Gründen vorgenommene Knabenbeschneidung habe die Anforderungen der Sozialadäquanz in der Hinsicht erfüllt, als die Einwilligung der Eltern vorgelegen hat und den anderthalb bis siebenjährigen Kindern kein allzu großer Schmerz zugefügt wurde (obwohl die Zirkumzisionen ohne Betäubung vorgenommen wurden und bei vier von den sechs betroffenen Jungen der Eingriff zu Infektionen geführt hatte) ${ }^{11}$.

Die Begründungen des Präjudizes KKO 2008:93 sind erheblich ausführlicher als die des entsprechenden schwedischen Beschlusses, und die Abwägung ist differenzierter. Bei der die Grund- und Menschenrechte betreffenden Argumentation ist man bestrebt gewesen, die in Frage kommenden Rechte vollständig zu identifizieren und sie gegeneinander abzuwägen, mit anderen Worten: man hat versucht, sie in eine Rangordnung zu bringen und sie zu gewichten,

11 NJA 1997 (Fn. 9), S. 642 ff. 
und das offensichtliche Ziel hat darin bestanden, die in verschiedene Richtungen wirkenden Rechte in optimaler Weise zu berücksichtigen.

Vor der genaueren Analyse dieser Abwägung möchte ich das Augenmerk auf den Mangel in den Begründungen richten, dass in dem Beschluss des Obersten Gerichtshofes die Biomedizinkonvention des Europarates nicht einmal erwähnt wird. Zwar war die Konvention zu der Zeit, als die von den Anklagen bezeichneten Taten begangen und die Urteile gefällt wurden, noch nicht ratifiziert, aber Finnland hatte sie im Jahre 1997 unterzeichnet, und als ein im Jahre 1999 international in Kraft getretenes internationales Übereinkommen hat es schon damals eine bedeutende und zulässige Rechtsquelle abgegeben. Von dieser Biomedizinkonvention hat man auch gesagt, dass es in der Praxis des Europäischen Gerichtshofes für Menschenrechte (EGMR) bei dessen Anwendung der vom Europarat ausgearbeiteten Europäischen Menschenrechtskonvention einen ,europäischen Standard“ bilden und sich auch auf die Anwendung dieser Konvention in Hinsicht auf Staaten auswirken werde, die die Biomedizinkonvention nicht ratifiziert haben. ${ }^{12}$ Finnland hat im Jahre 2009 die Biomedizinkonvention und deren zwei Zusatzprotokolle ratifiziert, und zwar in der Weise, dass diese zum 1. März 2010 den Rang von zu befolgenden Gesetzen (23/2010) einnehmen. Somit sind sie zu verbindlichen Rechtsquellen geworden, die sich bei der Anwendung der einschlägigen einheimischen Gesetzgebung in Zukunft vor allem auf die Auslegung auswirken werden.

Die Begründungen des Obersten Gerichtshofes, in denen die in der Sache bedeutsamen Grund- und Menschenrechtsnormen behandelt werden, sind meiner Meinung nach an sich sachgemäß - mit der Ausnahme des Umstands, dass die Biomedizinkonvention ohne Beachtung geblieben ist. Die relevanten Vorschriften des Grundgesetzes und dessen Vorarbeiten sowie die Artikel der Europäischen Menschenrechtskonvention und die damit verbundenen Entscheidungen des EGMR ebenso wie die Artikel der Konvention über die Rechte des Kindes werden in verdienstvoller Weise geklärt. Von den Grundund Menschenrechten wird der Schutz des Familienlebens dem Schutz der körperlichen Integrität und der Religionsfreiheit zur Seite gestellt.

In dem Abschnitt, in dem die verschiedenen Begründungen miteinander evaluiert werden, wird als Kernfrage bei der Abwägung der in verschiedene Richtungen weisenden Grund- und Menschenrechte die Frage aufgeworfen, ob

12 Siehe im Allgemeinen z.B. Roscam Abbing, The Convention on Human Rights and Biomedicine, European Journal of Health Law 1998, S. 377 ff. (380); Nys, The Biomedicine Convention as an Object and a Stimulus for Comparative Research, European Journal of Health Law 2008, S. 273 ff. (277). 
das Recht des männlichen Kindes auf körperliche Unversehrtheit seine Sorgeberechtigten daran hindere, für das nicht einwilligungsfähige Kind über einen solchen Beschneidungseingriff zu entscheiden, der medizinisch nicht indiziert ist, jedoch zu den religiösen Traditionen der Familie gehört, und dessen Akzeptierbarkeit somit sowohl mit dem Schutz des Familienlebens als auch mit der Religionsfreiheit verbunden ist. In den Begründungen wurde der Schutz der persönlichen Integrität des Kindes für stark erachtet, und zwar auch in Beziehung zu den Rechten, die den Personensorgeberechtigten zukommen: dem Schutz des Familienlebens und der Religionsfreiheit. Eine solche Akzentuierung, die sich auch die Vorarbeiten zu Grundgesetzreform stützt, ist wichtig, wenn man diese Grund- und Menschenrechte in eine Rangordnung bringt.

Bei der Bestimmung dessen, wie die genannten Grund- und Menschenrechte zu gewichten und gegeneinander abzuwägen seien, war die Argumentation des Obersten Gerichtshofes, vereinfacht ausgedrückt, die folgende: „Eine in Form einer religiös begründeten, medizinisch sachgemäßen Beschneidung erfolgender Eingriff in die körperliche Unversehrtheit des Knaben kann man hinsichtlich des Gesamtwohls des Kindes für vertretbar und auch als Gesamtheit beurteilt für eine dermaßen geringfügige Maßnahme halten, dass die Vorgehensweise der Personensorgeberechtigten des Kindes bei der Veranlassung der Beschneidung an ihrem Kind nicht für eine solche die Interessen und Rechte des Kindes verletzende Tat anzusehen ist, die als Körperverletzung strafbar wäre“ (Punkt 26). Unabhängig vom eigenen Willen des kleinen Jungen ist somit die mit der Einwilligung der Personensorgeberechtigten an ihm erfolgende Beschneidung gerechtfertigt, wenn sie sowohl für das Gesamtwohl des Kindes vertretbar als auch einen geringfügigen Eingriff in seine körperliche Unversehrtheit darstellt.

Das Kriterium des Gesamtwohls des Kindes setzt dem Obersten Gerichtshof zufolge voraus, dass es der Zweck der operativen Maßnahme ist, das Wohlergehen des Kindes und seine Entwicklung zu fördern, und dass die Maßnahme auch objektiv beurteilt nicht den Interessen des Kindes widerläuft. Bezüglich dessen stützt man sich an einer früheren Stelle der Begründungen in erster Linie auf den Bericht der Arbeitsgruppe des Sozial- und Gesundheitsministeriums vom Jahre 2003, und zwar auf die aus dem Text hervorgehende Auffassung, dass die aus religiösen Gründen erfolgende Beschneidung ausdrücklich für den zu beschneidenden Knaben selbst, für die Entwicklung seiner Identität sowie für seine Integration in seine religiöse und soziale Gemeinschaft von positiver Bedeutung sei.

Die Zirkumzision wird in dem Beschluss für eine mehr oder weniger ungefährliche Maßnahme gehalten, wenn sie nur in medizinisch sachgemäßer Weise, 
unter hygienischen Bedingungen und mit der erforderlichen Schmerzlinderung ausgeführt wird. Zwar ist es möglich, so konstatiert man, dass die Maßnahme dem Kinde in gewissem Maße Schmerzen bereitet, aber sie verursacht ihm keinen gesundheitlichen oder sonstigen bleibenden Schaden. Obwohl der Eingriff irreversibel ist, sind mit ihm keine solchen Züge verbunden, die das Kind oder den späteren Erwachsenen in negativer Weise abstempeln würden.

Die Schwere des Eingriffs in die körperliche Unversehrtheit wird bei der Beschneidung von Knaben und Mädchen in wesentlich anderer Weise beurteilt. Bei der Beschneidung von Mädchen handelt es sich dem Obersten Gerichtshof zufolge um eine Vorgehensweise, die als schwere Köperverletzung, als Genitalverstümmelung, einzustufen sei, die sich unter keinen Umständen durch religiöse oder soziale Gründe rechtfertigen lasse.

\section{Kritik an der Abwägungsargumentation im Präjudiz KKO 2008:93}

An der oben erläuterten Abwägungsargumentation kann man auf der Basis der Biomedizinkonvention und der internationalen Diskussion Kritik üben. Zunächst zum Gesamtwohl des Kindes bei der Knabenbeschneidung. Laut Artikel 6 (1) der Biomedizinkonvention darf man eine in die körperliche Unversehrtheit eines nicht einwilligungsfähigen Minderjährigen eingreifende Maßnahme nur dann vornehmen, wenn diese für ihn von unmittelbarem Nutzen (,direct benefit“) ist. ${ }^{13}$ Die Gründe zur Einschränkung der von der Konvention garantierten Rechte sind in Artikel 26 (1) erschöpfend aufgelistet (,wegen der allgemeinen Sicherheit, zur Bekämpfung von Kriminalität, zum Schutz der Volksgesundheit oder zur Sicherung der Rechte oder Freiheiten anderer Personen"). Aus ihnen lassen sich wohl keine solchen in den Begründungen des Obersten Gerichtshofes genannten religiösen, kulturellen oder sozialen Gründe ableiten, auf die sich stützend die Knabenbeschneidung im Sinne dieses Artikels begründet wäre. Die Nichterfüllung der Anforderung des unmittelbaren Nutzens ist die zentrale Begründung in meiner abweichenden, in der Minderheit gebliebenen Meinung im Bericht des Ethischen Beirats ETENE vom 15. Juni 1999, in der Beschwerdeentscheidung der Ombudsfrau RiittaLeena Paunio vom 30. November 1999 und in den Entscheidungen der Oberststaatsanwältin Päivi Hirvelä bezüglich des sanktionsartigen Absehens von Strafverfolgung vom 30. Juni 2004 gewesen (siehe dazu oben).

13 Vgl. im Allgemeinen Stultiêns et al., Minors and Informed Consent: A Comparative Approach. European Journal of Health Law 2007, S. 21 ff. 
Unabhängig davon, ob man sich bei der Einschätzung des Kindeswohles auf den Artikel 6 der Biomedizinkonvention stützt oder nicht, ist in der internationalen Diskussion Kritik daran vorgebracht worden, wie man es definiert. Die britischen Forscher Marie Fox und Michael Thomson haben bei Knabenbeschneidungen die Neuformulierung des in den Ländern des Common Law angewandten Begriffes „nach den besten Interessen“ (best interests) des Kindes gefordert. Bei der Beurteilung der Zulässigkeit des Eingriffs an Knaben aus dem Blickwinkel der besten Interessen reiche es nicht aus, das Augenmerk nur auf die Schwere des Eingriffs in die körperliche Unversehrtheit oder auf sonstige unmittelbare Auswirkungen $\mathrm{zu}$ richten, sondern man müsse die Interessen viel weiter verstehen. Bei der Beurteilung müsse man unter anderem die Auswirkungen der Maßnahme auf die Entscheidungsfreiheit des erwachsen werdenden Knaben und auf sein späteres Sexualleben mit berücksichtigen. ${ }^{14}$

Man kann auch die Frage stellen, ob die im Beschluss des Obersten Gerichtshofes vorgebrachten, das Gesamtwohl des Kindes betreffenden Umstände nicht vielmehr auf die von der religiösen Gemeinschaft und den Sorgeberechtigten definierten kollektiven Interessenaspekte des Familienlebens abzielen als auf die individuellen Interessen des Kindes in dem von Fox und Thomson aufgezeigten Sinn. In den Begründungen des Obersten Gerichtshofes ist diesbezüglich der zentrale Aspekt der, dass man der Ansicht ist, die Beschneidung würde die Entwicklung der Identität des Knaben und seine Integration in die religiöse und soziale Gemeinschaft fördern. Matti Tolvanen hat in seinem kritischen Kommentar konstatiert, es bestehe die Gefahr, dass die Beschneidung den Knaben in dem Maße an seine religiöse Gemeinschaft binde, dass es ihm sogar unmöglich sein könne, sich aus der Gemeinschaft zu lösen, wenn die Zeit gekommen sei, dass er sich ein eigenständiges Weltbild schafft. ${ }^{15}$

In der internationalen Diskussion hat man auch in Frage gestellt, ob es denn angebracht sei, die Beschneidung von Jungen und von Mädchen bezüglich der Schwere des Eingriffs in die körperliche Unversehrtheit so radikal anders zu sehen, wie man es im Allgemeinen und auch in den Begründungen des Obersten Gerichtshofes tut. So hat zum Beispiel die niederländische Forscherin Jacqueline Smith diesen in den westlichen Ländern verbreiteten Doppelstandard angegriffen und die Ansicht vertreten, dass eine Diskriminierung der zu beschneidenden (jüdischen und muslimischen) Knaben darin bestehe, dass man sie nicht in gleicher Weise vor der Zufügung unnötiger Schmerzen schüt-

14 Fox / Thomson, Reconsidering 'Best Interests'. Male Circumcision and the Rights of the Child s. 26, in: Circumcision and Human Rights (Fn. 3), S. 15 ff.

15 Tolvanen, KKO 2008:93, in: KKO:n ratkaisut kommentein [Die Entscheidungen des Obersten Gerichtshofs mit Kommentaren], Helsinki 2009, S. 142 ff. (144). 
ze wie die Mädchen und diejenigen Jungen, die keiner solchen religiösen Gemeinschaft angehören, welche die rituelle Beschneidung praktiziert. ${ }^{16}$ Der Oberste Gerichtshof hat in seinen Begründungen den Vorwurf der Diskriminierung zurückgewiesen. Deswegen solle man beide rituellen Maßnahmen in gleicher Weise bekämpfen. Auf der anderen Seite hat sich die UNO in ihren Kampagnen gegen AIDS für eine ,sichere, freiwillige, auf Wissen basierende Beschneidung von Männern" als Mittel ausgesprochen, die Ausbreitung des HI-Virus zu bekämpfen. ${ }^{17}$

Im Urteil des LG Köln vom 7. Mai 2012 (Az. 151 Ns 169/11) sieht das LG den Tatbestand der Körperverletzung als erfüllt an und bejaht auch die Rechtswidrigkeit der Knabenbeschneidung mit folgender Motivierung: allein religiöse begründete Einwilligung könne nicht als Rechtfertigungsgrund herangezogen werden, weil das Recht des Kindes auf körperliche Unversehrtheit den Grundrechten der Eltern als „verfassungsimmanente Grenze“ entgegenstehe. Eine solche Zirkumzision tangiert dazu das Recht des Kindes. ${ }^{18}$ Wie Werner Beulke und Annika Dießner ${ }^{19}$ in ihrer Analyse der jüngsten deutschen rechtswissenschaftlichen Diskussion über die Zulässigkeit der Knabenbeschneidung gezeigt haben, gibt es einen Meinungsstand zwischen der Befürwortung einer Strafbarkeit und deren Gegenposition. Die Meinungsverschiedenheiten sind erklärlich, weil kein Einverständnis über die juristische Methode (Begründungsweise) oder den Hauptinhalt der wichtigen Prinzipien oder Begriffe existiert. Ich habe oben die Begründungsweise des finnischen Obersten Gerichtshofs in der Hinsicht gelobt, dass darin eine Abwägung von kollidierenden Grund- und Menschenrechten durchgeführt wird, obgleich die Bestimmung des Inhalts und Gewichtes dem Rechtsbegriff „Kindeswohl“ sich als problematisch erwies.

\section{Die Knabenbeschneidung und das Präjudiz KKO 2008:93 als} Beispiele für die Probleme eines multikulturellen Strafrechts

Die Knabenbeschneidung und die diese betreffende Klagesache im Fall KKO 2008:93 veranschaulichen die Probleme eines multikulturellen Strafrechts und

16 Smith, Male Circumcision and the Rights of the Child, in: Essays in Human Rights from the Heart of the Netherlands, 1998 (www.nocirc.org/legal/smith.php), Conclusions.

17 Siehe Safe, Voluntary, Informed Male Circumcision and Comprehensive HIV Prevention Programming. Guidance for decision-makers on human rights, ethical and legal consideration. UNAIDS/08.19E/JC1552E, 2008 (www.unaids.org).

18 Siehe näher NJW 2012, 2128 und die Erläuterung von Beulke / Dießner 2012 (Fn. 2), S. 340 .

19 Beulke / Dießner 2012 (Fn. 2), passim. 
sonstiger rechtlicher Regulierung. Wie flexibel kann man unter Verweis auf die Religion oder die Traditionen von Kulturen bzw. Teilkulturen bei der Anwendung der strafrechtlichen Verantwortungs- und Sanktionsgründe sein und im Geiste kultureller Pluralität von der herrschenden Strafrechtsordnung abweichende Praktiken billigen oder zumindest dulden? ${ }^{20}$ Im Präjudiz KKO 2008:93 beruht die den Multikulturalismus berücksichtigende Argumentation in lobenswerter Weise auf der Abwägung von Grund- und Menschenrechten, obgleich man Details der Argumentation kritisieren kann.

Die Knabenbeschneidung ist auch in Finnland kein neues Phänomen, da sie zur Tradition der jüdischen Gemeinschaft gehört. Da in Folge der Zuwanderung von Menschen aus islamischen Ländern dieses Phänomen häufiger geworden ist und man im Kreise der öffentlichen Gesundheitsversorgung seine Haltung zu einer solchen, medizinisch nicht notwendigen Maßnahme erwägen musste, hat man ihm wachsende Aufmerksamkeit geschenkt.

Zur selben Zeit sind die Bereiche der Medizin und der Gesundheitsversorgung zunehmend verrechtlicht worden: Was auf der Grundlage der bestehenden Gesetze und Vorschriften oder des Gewohnheitsrechts keine deutlich gesellschaftlich akzeptierte (sozialadäquate) Tätigkeit in diesem Bereich ist, setzt eine diese berechtigende neue Gesetzgebung oder eine Gerichtspraxis voraus, die ein (Gewohnheits-)Recht schafft. Auf diese Entwicklung hat sich die Verstärkung des Grund- und Menschenrechtsdenkens seit den neunziger Jahren ausgewirkt. ${ }^{21}$ Wo zum Beispiel die Grund- und Menschenrechte sowie die strafrechtlichen Normen die persönliche Integrität schützen, müssen für eine Abweichung davon starke, auf der Rechtsordnung basierende Gründe gegeben sein.

Die kritikanfälligen Stellen im Präjudiz KKO 2008:93 zeigen, wie schwierig es ist, mittels einer Abwägung von Grund- und Menschenrechten durchweg überzeugende und deutlich anwendbare Rechtsnormen zu schaffen. Wegen der Vielfältigkeit des vorliegenden Problems und der Gewährleistung seiner allseitigen Regelung würde man vielmehr Gesetzgebung benötigen - also über die Knabenbeschneidung ein dem schwedischen Vorbild entsprechendes

20 Siehe im Allgemeinen über das multikulturelle Strafrecht z.B. Foblets / Dundes Renteln, Multicultural Jurisprudence, Comparative Perspectives on the Cultural Defense, Hart Publishing 2009.

21 Siehe auch $\S 80$ des finnischen Grundgesetzes (731/1999); Lahti 2007 (Fn. 5), S. 527 f. 
Gesetz, wie es auch im Bericht der Arbeitsgruppe des Sozial- und Gesundheitsministeriums vom Jahre 2003 vorgeschlagen worden ist. ${ }^{22}$

Bei der Ausarbeitung eines besonderen Gesetzes ist der vom Artikel 6 der Biomedizinkonvention möglichweise eingeräumte nationale Erwägungsspielraum zu klären. Zudem sind bei der Ausarbeitung eines besonderen Gesetzes auch die Stellung der Ärzte und des übrigen medizinischen Fachpersonals sowie die Rolle der öffentlichen Gesundheitsversorgung bei der Vornahme von Zirkumzisionen zu erwägen. Beim Fall KKO 2008:93 handelte es sich um eine Strafsache, weswegen man damals die Stellung des Arztes, der den Eingriff ausgeführt hat, nicht gesondert untersuchte, zum Beispiel unter dem Aspekt, wie die Akzeptierbarkeit des Eingriffs vom Standpunkt der Disziplinarverantwortung und Berufsausübungsaufsicht aus einzuschätzen wäre. Wegen dieser Verantwortlichkeiten wird dem Fachpersonal der Gesundheitsversorgung ein Doppelstandard auferlegt, und eine Ausschließung der Strafverantwortung bedeutet nicht unbedingt, dass damit auch eine Verletzung der beruflichen Pflichten ausgeschlossen wäre. Bei der Beurteilung dieser Aspekte ist auch die Befolgung der berufsethischen Pflichten zu berücksichtigen ${ }^{23}$, und deren Inhalt ist im Bezug zur Knabenbeschneidung ablehnend oder zumindest reserviert gewesen $^{24}$.

22 Ähnlich Tolvanen 2009 (Fn. 15), S. 143 f. Siehe auch die entsprechende Ankündigung der deutschen Bundesregierung nach dem Urteil des LG Köln vom 7.5.2012 und dazu Beulke / Dießner 2012 (Fn. 2), S. 346.

23 Siehe $\S 15$ im Gesetz über die Dienststellungen im Gesundheitswesen (559/1994) und Artikel 4 der Biomedizinkonvention.

24 So die herrschende Meinung in der finnischen Ärzteschaft; siehe Ä̈rimaa, Suomen Lääkärilehti 14/2003, S. 1631. 